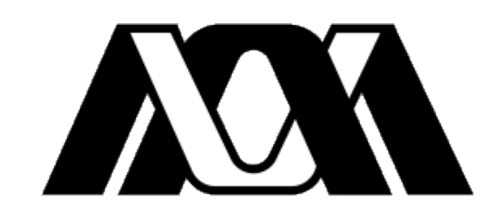

\author{
Casa abierta al tiempo \\ UNIVERSIDAD AUTÓNOMA METROPOLITANA \\ UNIDAD IZTAPALAPA
}

DIVISIÓN DE CIENCIAS BIOLÓGICAS Y DE LA SALUD

MAESTRÍA EN BIOLOGÍA DE LA REPRODUCCIÓN ANIMAL

\title{
EL EFECTO DE LA ADMINISTRACIÓN NEONATAL DE GENISTEÍNA/DAIDZEÍNA SOBRE LAS CONDUCTAS DIMÓRFICAS Y LA FERTILIDAD EN LA RATA MACHO WISTAR
}

TESIS

PARA OBTENER EL GRADO DE:

MAESTRA EN BIOLOGÍA DE LA REPRODUCCIÓN ANIMAL

PRESENTA

BIÓL. MARISSA GUILLÉN CASTRILLO

DIRECTORA

DRA. MARÍA DEL ROSARIO TARRAGÓ CASTELLANOS

ASESORES

DRA. REYNA CARMEN FIERRO PASTRANA

DR. PABLO GUSTAVO DAMIÁN MATZUMURA

Ciudad de México, enero de 2020 


\title{
COMITÉ TUTORIAL
}

\section{Directora}

Dra. María del Rosario Tarragó Castellanos Profesora-Investigadora Titular "C"

Universidad Autónoma Metropolitana-Unidad Iztapalapa

División de Ciencias Biológicas y de la Salud

Departamento Biología de la Reproducción mrtc@xanum.uam.mx

\author{
Asesores \\ Dra. Reyna Carmen Fierro Pastrana \\ Profesora-Investigadora Titular "C" \\ Universidad Autónoma Metropolitana-Unidad Iztapalapa \\ División de Ciencias Biológicas y de la Salud \\ Departamento de Ciencia de la Salud \\ reyncarmen2@hotmail.com \\ Dr. Pablo Gustavo Damián Matsumura \\ Profesor-Investigador Titular "C" \\ Universidad Autónoma Metropolitana-Unidad Iztapalapa \\ División de Ciencias Biológicas y de la Salud \\ Departamento Biología de la Reproducción \\ pgdm@xanum.uam.mx
}




\title{
MIEMBROS DEL JURADO
}

\author{
Dr. Pablo Gustavo Damián Matsumura \\ Profesor-Investigador Titular "C" \\ Universidad Autónoma Metropolitana-Unidad Iztapalapa \\ División de Ciencias Biológicas y de la Salud \\ Departamento Biología de la Reproducción \\ pgdm@xanum.uam.mx
}

\author{
Dra. Reyna Carmen Fierro Pastrana \\ Profesora-Investigadora Titular "C" \\ Universidad Autónoma Metropolitana-Unidad Iztapalapa \\ División de Ciencias Biológicas y de la Salud \\ Departamento de Ciencias de la Salud \\ reyncarmen2@hotmail.com

\begin{abstract}
M. en C. Pedro Cuapio Padilla Investigador en Hisparep

Clínica de Reproducción Asistida

Hospital Español, Ciudad de México

cuapiopp@yahoo.com.mx
\end{abstract} \\ Dr. Armando Ferreira Nuño \\ Profesora-Investigador Titular "C" \\ Universidad Autónoma Metropolitana-Unidad Iztapalapa \\ División de Ciencias Biológicas y de la Salud \\ Departamento de Ciencias de la Salud \\ fena@xanum.uam.mx
}


La Maestría en Biología de la Reproducción Animal de la Universidad Autónoma Metropolitana, pertenece al Programa Nacional de Posgrados de Calidad (PNPC) del Consejo Nacional de Ciencia y Tecnología (CONACYT). Registro de la MBRA ante CONACYT: 868900

La alumna Marissa Guillén Castrillo recibió el apoyo del CONACyT, mediante el otorgamiento de una beca económica durante todo el tiempo de duración de los estudios en el posgrado. Número de registro CVU: 795144. Extiendo un cordial agradecimiento al CONACYT y a la Universidad Autónoma Metropolitana que proporcionaron el apoyo para la realización del presente proyecto. 
Los miembros del jurado designado por la División de Ciencias Biológicas y de la Salud, Universidad Autónoma Metropolitana Iztapalapa, abajo firmantes, aprobaron la tesis titulada "El efecto de la administración neonatal de Genisteína/Daidzeína sobre las conductas dimórficas y la fertilidad en la rata macho Wistar" con fecha del 24 de enero de 2020.

\section{SECRETARIA}

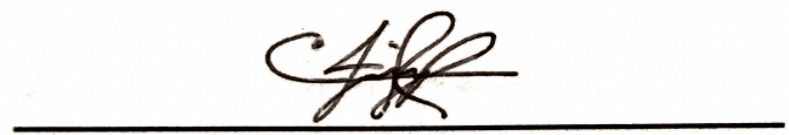

Dra. Reyna Carmen Fierro Pastrana

\section{VOCAL}

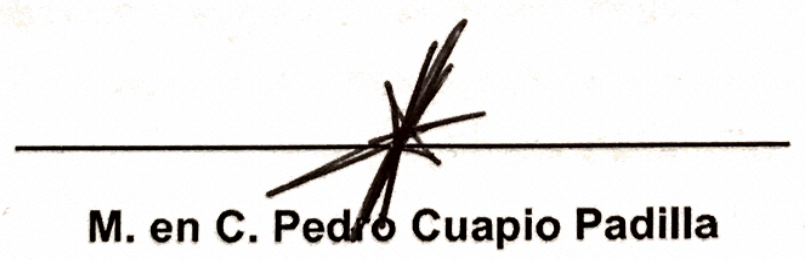

VOCAL

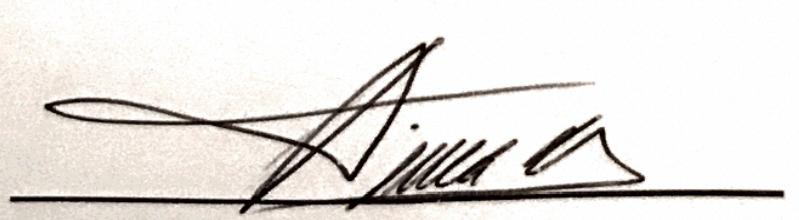

Dr. Armando Ferreira Nuño 
"E्E $\int$ pájaro rompe el cascarón. $\mathcal{E}$ l cascarón es el mundo. Quien quiera nacer, tíene que destruír un mundo. $\mathcal{E}$ l pájaro vuela hacia Dios. $\mathcal{E}$ l díos se llama $\mathcal{A}$ braxas." - Hermann Hesse, Demian

"You have to have men who are moral... and at the same time who are able to utilize their primordial instincts to kill without feeling... without passion... without judgment... without judgment! Because it's judgment that defeats us." - Colonel Walter $\mathcal{E}$. Kurtz, Apocalypse Now. Francís Ford Coppola

"I am so happy that $I$ am alive, in one piece and short. I' $m$ in a world of shit... yes. But $\mathcal{I}$ am alive. And $\mathcal{I}$ am not afraid." -Private Joker, Full Metal Jacket. Stanley Kubrick

"The days go on and on... they don't end. All my life needed was a sense of someplace to go. I don't believe that one should devote his life to morbid self-attention, I believe that one should become a person like other people." - Travis Bickle, Taxi Driver. Martín Scorsese 


\section{ÍNDICE}

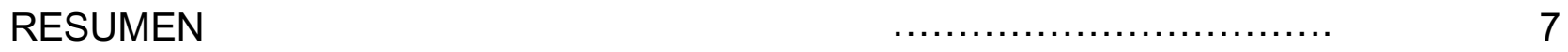

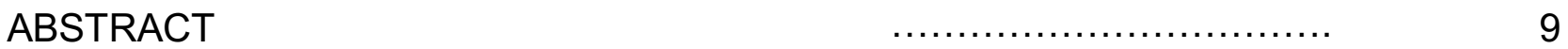

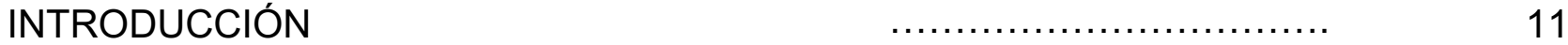

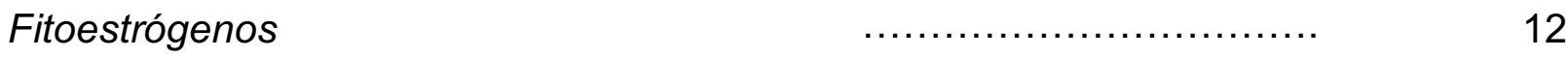

Desarrollo testicular neonatal $\quad$..............................

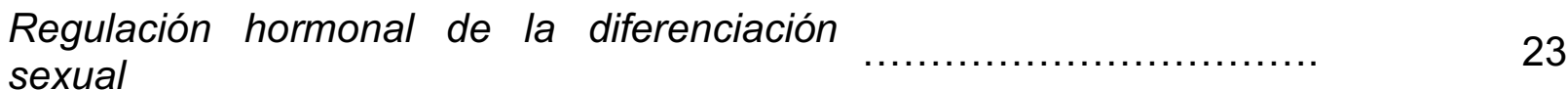

Dimorfismo sexual cerebral $\quad$...........................

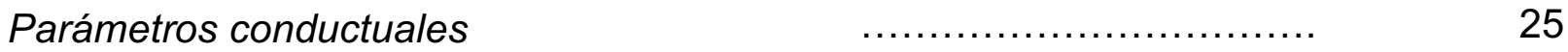

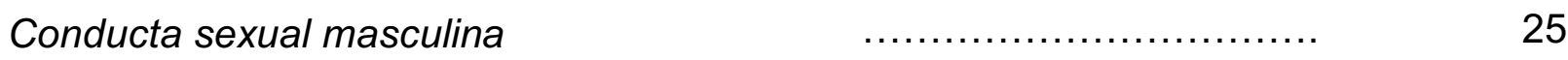

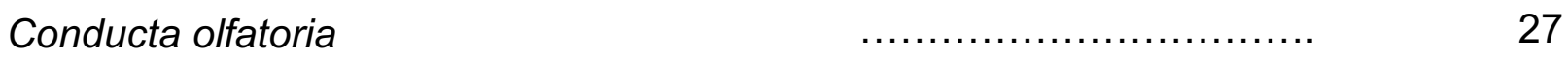

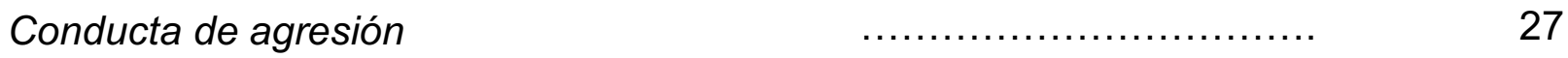

ANTECEDENTES

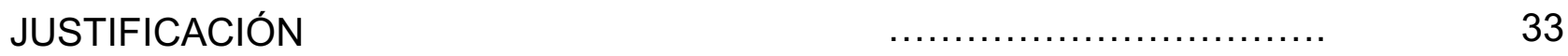

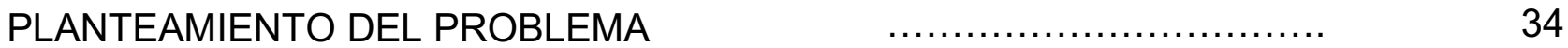

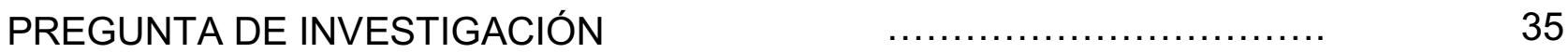

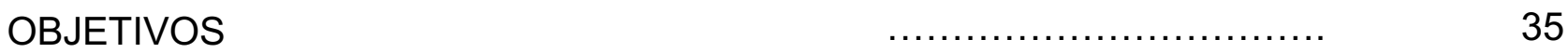

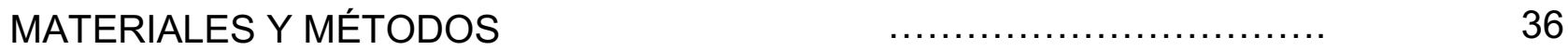

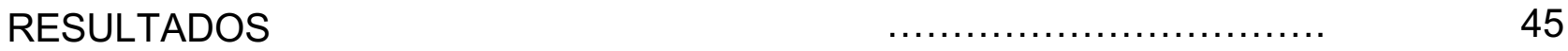

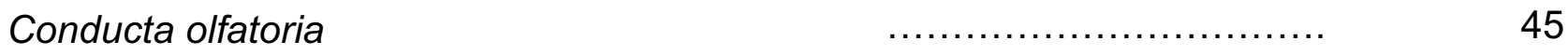

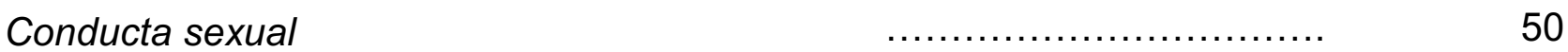

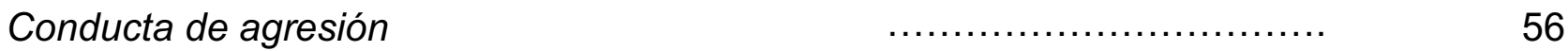

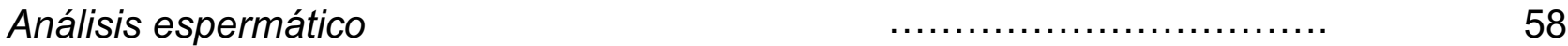

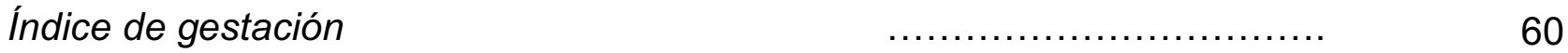

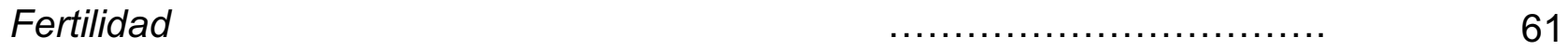

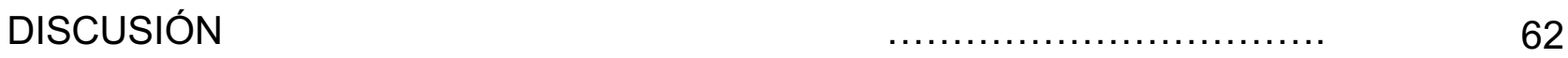

CONCLUSIONES $\quad \ldots \ldots \ldots \ldots \ldots \ldots \ldots \ldots \ldots \ldots \ldots \ldots \ldots \ldots \ldots \ldots$

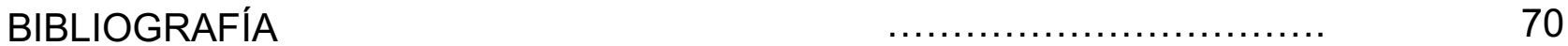




\section{RESUMEN}

Los fitoestrógenos son compuestos no esteroideos encontrados en plantas que estructural o funcionalmente son similares al estradiol, por lo que su mecanismo de acción es a través de sus receptores. Las isoflavonas Genisteína y Daidzeína son fitoestrógenos que se encuentran en cantidades significativas en las fórmulas infantiles a base de soya, las cuales se han popularizado durante los últimos 50 años debido al creciente número de bebés intolerantes a la lactosa. La ingesta de estos fitoestrógenos ha propiciado numerosos estudios con resultados controversiales, en algunos de ellos se ha demostrado los posibles efectos sobre parámetros reproductivos en las etapas críticas del desarrollo neonatal de machos, ya que pueden afectar la diferenciación sexual cerebral, del sistema endócrino, de las gónadas y, en última instancia, la fertilidad durante su adultez.

En el presente estudio se analizaron los efectos de la administración simultánea y diaria de los fitoestrógenos Genisteína y Daidzeína (G/D), en dos dosis ( $A=6.8 \mathrm{mg} / \mathrm{Kg}$ y $B=9.4 \mathrm{mg} / \mathrm{Kg}$ ), que tenían concentraciones semejantes a las encontradas en las fórmulas lácteas a base de soya (pero manteniendo la misma proporción de $64 \%$ de Genisteína y $36 \%$ de Daidzeína) en la etapa neonatal masculina, valorando sus efectos sobre parámetros conductuales y reproductivos en la etapa adulta.

Los resultados sobre conducta olfatoria señalan que ambas concentraciones de G/D inducen la pérdida de la capacidad de reconocer la orina de hembras en estro. De igual manera, se presentan efectos de ambas concentraciones de G/D sobre la conducta sexual masculina (CSM), ya que se observaron cambios tanto en el despliegue como la ejecución de la CSM, particularmente ambas concentraciones disminuyen significativamente el número total de eyaculaciones y la dosis "A" disminuyó la Tasa de Aciertos (Hit Rate). La administración de G/D induce cambios sobre la conducta de agresión, aunque de manera opuesta para las dosis estudiadas; mientras que la dosis "A" induce conductas ofensivas, con la dosis "B" produce conductas defensivas. En cuanto a los parámetros seminales, la dosis "A" disminuye la concentración y viabilidad 
de los espermatozoides, mientras que ambas dosis incrementan el número de espermatozoides inmaduros. Los resultados más contundentes se observaron en los parámetros de fertilidad, donde la dosis "A" generó una disminución dramática en el número de hembras gestantes, así como en el número de crías. Estos resultados deben ser comprobados con un mayor número de experimentos. En general, se demuestra que la administración neonatal de G/D ocasionaron cambios importantes en los parámetros conductuales y reproductivos de las ratas macho. 


\section{ABSTRACT}

Phytoestrogens are non-steroidal compounds found in plants that are structurally or functionally similar to estradiol, so their mechanism of action is through their receptors. Isoflavones genistein and daidzein are phytoestrogens that are found in significant amounts in infant formulas based on soy, which have become popular during the past 50 years due to the increasing number of lactose intolerant babies. The intake of these phytoestrogens has led to numerous studies with controversial results, in some of them the possible effects on reproductive parameters in the critical stages of the neonatal development of males have been demonstrated, since they can affect the sexual differentiation of the brain, of the endocrine system, of the gonads and, ultimately, fertility during adulthood.

In the present study, the effects of the daily administration of phytoestrogens Genistein and Daidzein (G / D) were analyzed in two doses ( $A=6.8 \mathrm{mg} / \mathrm{Kg} ; B=9.4 \mathrm{mg} / \mathrm{Kg}$ ), in similar proportions to those found in dairy formulas based on soy (but maintaining the same proportion Genistein 64\%, Daidzein 36\%) in the male neonatal stage, assessing its effects on behavioral and reproductive parameters in the adult stage.

The results on olfactory behavior indicate that both concentrations of G/D index the loss of the ability to recognize the urine of females in estrus. Similarly, there are effects of both concentrations of G/D on male sexual behavior, since changes were observed in both the display and achievement of the sexual behavior, particularly both concentrations significantly decrease the total number of ejaculations and the dose "A" the Hit rate. The administration of $G / D$ induces changes un the behavior of aggression, although in the opposite way for the dose studied; while dose "A" induces offensive behaviors, with dose "B" defensive behaviors are observed. As for the seminal parameters, the dose "A" decreases the concentration and viability of the sperm, while both concentrations increase the number of immature spermatozoa. The strongest results were observed in fertility parameters, where dose " $A$ " generated a dramatic decrease in the number of pregnant females, as well as in the number of offspring. 
These results should be verified with a greater number of experiments. In general, is it shown that neonatal administration of $G / D$ causes significant changes in the behavioral and reproductive parameters of male rats. 


\section{INTRODUCCIÓN}

Los fitoestrógenos son compuestos no esteroideos encontrados en plantas, que son estructural o funcionalmente similares a los estrógenos de los mamíferos y sus metabolitos activos. Además, asemejan a los estrógenos al unirse a sus receptores y ejercer efectos agonistas o antagonistas (Whitten et al., 1997; Whitten y Patisaul, 2001). Los fitoestrógenos pueden unirse a los receptores endógenos de estrógenos alfa $(\operatorname{RE} \alpha)$ y beta $(\operatorname{RE} \beta)$, aunque tienen mayor afinidad a los beta. Comúnmente, en humanos los fitoestrógenos se utilizan como una alternativa natural de reemplazo de los estrógenos, por sus beneficios en la salud (Nie et al., 2017).

Los fitoestrógenos se encuentran en frutas, verduras y leguminosas presentes en la dieta humana y animal (Opalka et al., 2006). Son abundantes en las leguminosas, especialmente en la soya, pero se encuentran niveles detectables en los productos integrales, como las papas, las frutas, los vegetales, las bebidas alcohólicas (Lapcıḱ et al., 1998) y en la leche de vaca (Adlercreutz y Mazur, 1997).

De forma natural se encuentran en forma glicosilada inactiva. Al ser ingeridos son hidrolizados por bacterias intestinales, para formar agliconas biológicamente activas que pueden ser absorbidas y transportadas en el torrente sanguíneo (Cederroth et al., 2012).

Por otra parte, pueden interferir en el transporte, síntesis, metabolismo y acción de unión o de eliminación natural de las hormonas, la reproducción, así como en el desarrollo y el comportamiento y debido a esto, se consideran disruptores endocrinos (EDC, por sus siglas en inglés) (Cederroth et al., 2012). En este punto, es relevante señalar que la afinidad de unión relativa del estradiol para ambos receptores de estrógenos (RE $\alpha$ y $\beta$ ) es de 100, mientras que esta afinidad para ambos RE es más alta para las isoflavonas (genisteína: $4 \mathrm{RE} \alpha$ y $87 \mathrm{RE} \beta$; daidzeína: 0.1 y 0.5 ) en comparación con otros xenoestrógenos, como el bisfenol $A$ (RE $\alpha$ y $R E \beta: 50$ y 41 
respectivamente), el nonilfenol (RE $\alpha$ : 0.05 y $\operatorname{RE} \beta$ : 0.09), el DDT (RE $\alpha$ y $R E \beta: 0.01)$ y el metoxicloro (RE $\alpha$ y $R E \beta:<0.01)$ (Kuiper et al., 1998).

Los EDC también pueden alterar la expresión de receptores de otro tipo de hormonas como la progesterona, la oxitocina y la testosterona. Además, afectan la biosíntesis de esteroides, ya que son inhibidores de las enzimas $5 \alpha$-reductasa y la aromatasa a bajas concentraciones $(<1 \mu \mathrm{M})$, pero son estrogénicos en concentraciones más altas (Almstrup et al., 2002).

\section{Clasificación y estructura de los fitoestrógenos}

Los fitoestrógenos pertenecen a los flavonoides que se dividen en los siguientes 5 grupos (Moutsatsou, 2007):

- Isoflavonas, presentes en leguminosas como los granos de soya, lentejas y chícharos. Los principales compuestos son: la genisteína, la daídzeina (Fig. 1), la biochanina A, y la formononetina.

- Lignanos, se encuentran en diversos cereales como la semilla de lino, salvado. Los principales compuestos son el enterodiol y la enterolactona.

- Coumestanos, representados principalmente en la alfalfa. Su principal compuesto es el coumestrol.

- Flavonas, se encuentra en el apio, tomillo, diente de león, flor de trébol. El principal compuesto es el Luteolin.

- Estilbenos, se encuentra en las uvas, arándanos, frambuesas y moras. El principal compuesto es el resveratrol. 
<smiles>O=c1c(-c2ccc(O)cc2)coc2cc(O)cc(O)c12</smiles>

Genistein<smiles>O=c1c(-c2ccc(O)cc2)coc2cc(O)ccc12</smiles>

Daidzein

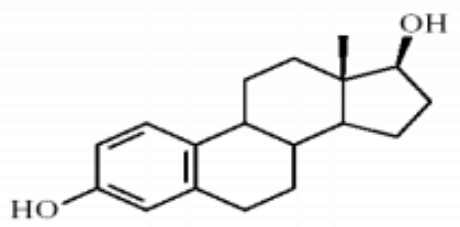

Estradiol-17 $\beta$

Figura 1. Estructura química del estradiol, genisteína y daidzeína (Riyazi et al., 2011).

A pesar de que se pueden encontrar diversas isoflavonas, las dos de mayor importancia son la Genisteína y la Daidzeína las cuales se describen a continuación. La Genisteína (4',5,7-trihidroxiisoflavona) es la isoflavona predominante en la nutrición humana, principalmente encontrada en los frijoles de soya, guisantes, lentejas o frijoles (Dixon y Ferreira, 2002; Perabo et al., 2008). La Daidzeína (4'-hidroxiisoflavona), al igual que la Genisteína, se encuentra en las semillas de soya (Liggins et al., 2000). Cabe señalar que de las isoflavonas totales de la soya, el $37 \%$ corresponde a Daidzeína y $57 \%$ de Genisteína (Basu y Maier, 2018). Estos fitoestrógenos se activan después de la eliminación de su hidrato de carbono conjugado por bacterias en el intestino, en el caso de la Daidzeína se convierte en S-equol (Chang et al., 1995).

Asimismo, estos compuestos los podemos encontrar en alimentos procesados como el caso de la fórmula láctea a base de soya, la cual se utiliza en el recién nacido cuando presenta intolerancia a la lactosa (Vandenplas et al., 2011). 


\section{Consumo de fitoestrógenos y sus efectos en la salud reproductiva}

El uso de fitoestrógenos ha cobrado relevancia en las investigaciones científicas, al ser considerados en la dieta como una excelente alternativa por las múltiples evidencias reportadas en relación a sus efectos benéficos, en la función reproductiva en organismos expuestos; aunque también se han reportado algunos riesgos por su consumo (Bennetau-Pelissero, 2016). En humanos se ha observado su uso terapéutico en la prevención del cáncer, en mujeres en la reducción de la sintomatología característica de la menopausia (Chen et al., 2015) y en la prevención de la osteoporosis (Abdi et al., 2016).

Por otro lado, se han reportado efectos negativos como amenorrea y miomas endometriales después de su uso prolongado en mujeres de 30 a 50 años (Chandrareddy et al., 2008), afectando negativamente los aspectos reproductivos. Si bien, se han reportado en general más efectos benéficos que deletéreos en la salud reproductiva humana, se requieren más estudios para determinar sus riesgos, ya que sus efectos pueden depender de la dosis, vías de administración, combinación de dos o más fitoestrógenos (Nie et al., 2017), además de factores como la edad, el tiempo de consumo, la salud gástrica (presencia de flora intestinal normal) y las características inherentes a cada persona (Patisaul y Jefferson, 2010; Nie et al., 2017).

También se ha reportado que los fitoestrógenos presentan actividad sobre el sistema nervioso central, ya que pueden inducir efectos estrogénicos o antiestrogénicos, en diferentes estructuras del eje hipotálamo-hipófisis-gónada, involucrado en la regulación de la reproducción tanto masculina y femenina (Zhao y Mu, 2011; Kurzer y Xu, 1997).

Los efectos de los fitoestrógenos son específicos para cada especie y el tipo de respuesta que pueden inducir, depende del estatus reproductivo del individuo, de la duración de la exposición, así como de la vía de administración cuando se utiliza como tratamiento (Opalka et al., 2006). 


\section{Mecanismo de acción de los fitoestrógenos}

Los fitoestrógenos pueden ejercer sus efectos a través de una variedad de mecanismos. Como se comentó al principio, estos compuestos tienen la capacidad de unirse principalmente a los receptores de estrógenos (RE $\alpha$ y $R E \beta)$ (Kuiper et al., 1997, 1998).

Los fitoestrógenos actúan ya sea iniciando la transcripción de un modo de acción clásico que involucra la interacción de los RE nucleares con los elementos de respuesta de los estrógenos (ERE) (Fig. 2), o mediante efectos no genómicos mediados por los RE asociados con la membrana citoplasmática (Cederroth et al., 2012). Los RE después de la unión con el ligando, son capaces de trasladarse desde el citoplasma al núcleo y unirse a las regiones de la transcripción del ADN o micro ARN y, por lo tanto, lograr la expresión de genes que regulan la proliferación y diferenciación celular (Dolinoy et al., 2006; Hilakivi-Clarke et al., 2010).

Mientras que los efectos no genómicos, mediados por el RE de membrana generalmente implican respuestas celulares rápidas que conducen a la liberación de óxido nítrico, flujo de calcio y/o activación de diferentes vías de señalización, como la proteína quinasa activada por AMP (AMPK), proteína quinasa activada por mitógeno (MAPK) y fosfatidil inositol 3-quinasa (PI3K), como se ha observado en varias líneas celulares (D'Eon et al., 2005; Ropero et al., 2006). 


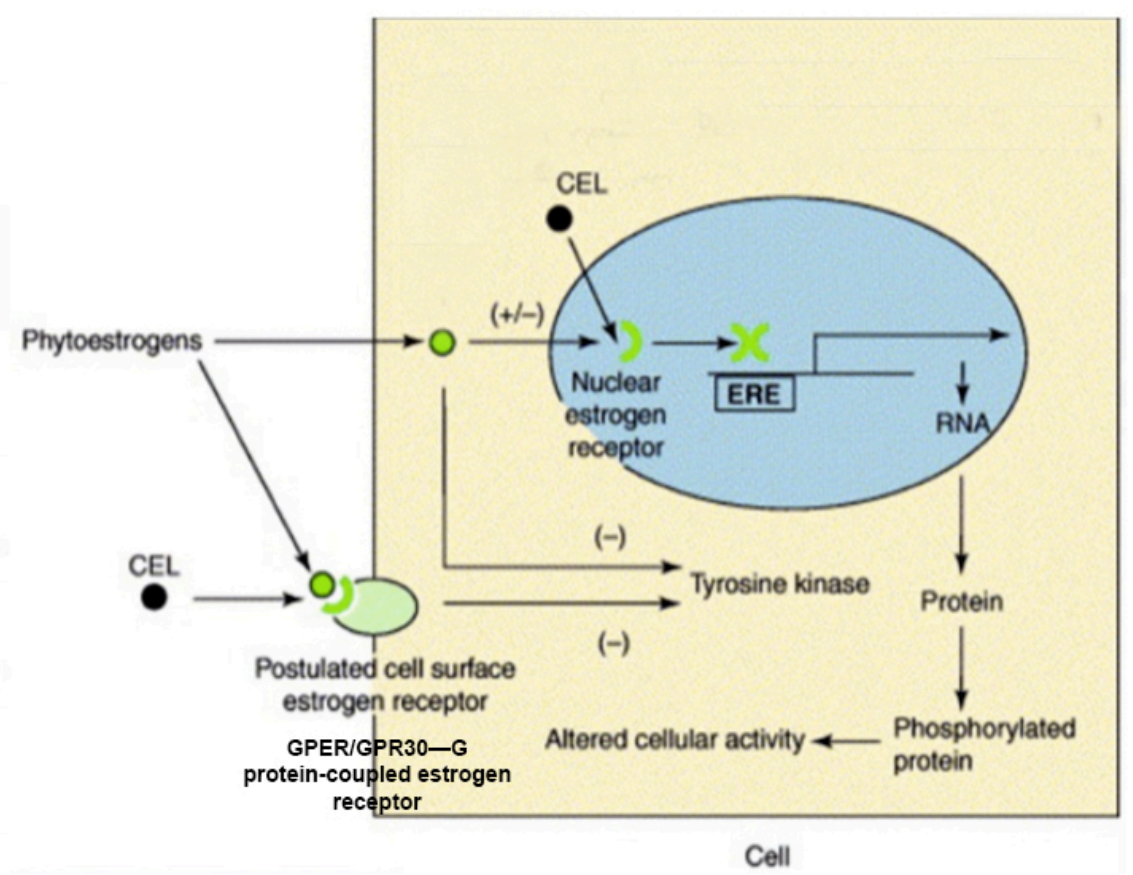

Figura 2. Mecanismo de acción de los fitoestrógenos sobre la función celular, pueden separarse en efectos mediados por RE y mediados por receptor de membrana. (Modificado de Viereck et al., 2005).

Los fitoestrógenos pueden afectar potencialmente todos los procesos regulados por estrógenos, incluida la globulina fijadora de hormonas sexuales (SHBG) (Sirotkin, 2014), ya que ésta transporta a los fitoestrógenos a las células "blanco o diana", donde pueden competir con los estrógenos endógenos por los sitios receptores y, por lo tanto, interferir en los procesos mediados por estrógenos (Martin et al., 1995; Garreau et al., 1991).

Otros de los posibles efectos de los fitoestrógenos, incluyen la interacción e inhibición de enzimas claves involucradas en la esteroidogénesis (5a-reductasa, aromatasa, 17 $\beta$-hidroxiesteroide deshidrogenasa) (Wang 2002; Opalka et al., 2006). También se ha relacionado con la inhibición de cinasas de proteínas (PKA) (tirosina proteína cinasa, proteína cinasa C), inhibición de la angiogénesis y síntesis de prostaglandinas (Kuiper et al., 1997; Munro et al., 2003; Strauss et al., 1998; Krazeisen et al., 2001). 
Los fitoestrógenos también han sido considerados moduladores selectivos de los receptores de estrógenos (phytoSERM, por sus siglas en inglés), debido a que pueden tener tanto efectos estrogénicos como antiestrogénicos (Garreau et al., 1991), con relación al ligando natural de los $\mathrm{RE}$, que es el estradiol $\left(\mathrm{E}_{2}\right)$.

\section{Desarrollo testicular neonatal en el humano}

El periodo neonatal (PND) temprano está asociado con la activación del eje hipotálamo-hipófisis-testículo (Mann y Fraser, 1996). Se ha sugerido que la función neonatal del eje hipotálamo-hipófisis-gónada puede estar involucrada en el descenso testicular, control del número de células de Sertoli, la masculinización del cerebro, el desarrollo del comportamiento social y sexual, la maduración puberal de la secreción de gonadotropinas, el establecimiento del umbral de las interacciones de retroalimentación testículo-hipófisis y en el desarrollo del sistema inmune (Mann y Fraser, 1996).

Después del nacimiento, los estrógenos maternos y placentarios ya no suprimen la producción de la hormona liberadora de gonadotropina $(\mathrm{GnRH})$ y la producción de gonadotropina hipofisaria, induciendo el segundo aumento importante de la producción de testosterona en el desarrollo masculino (Rao y Burnett, 2013). Esto da como resultado el segundo aumento importante de la producción de testosterona testicular en el neonato masculino. Durante la infancia del niño, este incremento en la testosterona se acompaña de un aumento relativamente rápido en el volumen de los túbulos seminíferos y el tamaño testicular, seguido de un crecimiento relativamente pequeño hasta los cinco años del niño (Berensztein et al., 2002). Las células germinales también experimentan cierta diferenciación durante este tiempo, aunque la mayoría de las etapas de la espermatogénesis se retrasan hasta la pubertad (Yoshida, 2006).

Asimismo, por el aumento de hormona luteinizante (LH), los niveles totales de testosterona se incrementan proporcionalmente con el desarrollo, alcanzando entre 
los tres y seis meses de edad valores máximos que se acercan al rango normal bajo presente en los hombres adultos, y luego disminuyen los valores de LH a los 6 a 8 meses de edad (Forest, 1990).

Entre los dos y cuatro meses de edad del niño, las gonadotropinas hipofisiarias estimulan un incremento en la producción de testosterona que alcanza un pico entre los tres y seis meses; posteriormente disminuye y se reactiva hasta el inicio de la pubertad. Ese breve incremento de gonadotropinas y andrógenos se conoce como "mini-pubertad" (Hutson et al., 2013). Durante la infancia, este aumento de la testosterona se acompaña de un aumento relativamente rápido en el volumen tubular y el tamaño testicular, seguido de un crecimiento relativamente pequeño hasta los 5 años de edad (Berensztein et al., 2002). Las células germinales experimentan cierta diferenciación durante este tiempo, mientras que la mayoría de las etapas de la espermatogénesis se retrasan hasta la pubertad (Schoenwolf, 2009; Yoshida, 2006)

Desarrollo testicular neonatal en la rata

Durante el período neonatal (PND) de la rata que transcurre entre los primeros siete días después del nacimiento, se desarrollan varios procesos en el testículo: se da la transición de gonocitos fetales a espermatogonias mitóticamente activas, hay una alta tasa de mitosis y maduración de células de Sertoli. Se da la regresión de Células Leydig Fetales (FLC), que son reemplazadas por Células Progenitoras de Leydig (PLC). En el PND 3, los testículos están ya constituidos por túbulos recubiertos por gonocitos y células de Sertoli mitóticamente activas (Picut et al., 2015).

Mientras que desde el punto de vista neuroendocrino, se describen los siguientes acontecimientos del PND 0 al 7: del PND 0 al 3 se registra en el neonato un alto nivel de testosterona, así como una alta concentración de la hormona folículo estimulante (FSH), que produce la transición de los gonocitos, y luego disminuye debido al aumento de la inhibina. Además, ocurre una regresión de las células de FLC y el desarrollo de PLC, que producen dihidrotestosterona (DHT), así como la mitosis de las espermatogonias en forma independiente de los andrógenos (Picut et al., 2015). 


\section{Testículos}

Los testículos son parte de los órganos genitales masculinos con funciones endocrinas (producción de hormonas masculinas) y de génesis y maduración de los gametos masculinos o espermatozoides. Están controlados por las hormonas $\mathrm{LH}$ y $\mathrm{FSH}$, que inducen la síntesis de hormonas como la testosterona y la inhibina, producidas localmente en el testículo, junto con los estrógenos (Carreau et al., 2011).

Cada testículo contiene aproximadamente 370 lóbulos seminíferos que miden aproximadamente $180 \mu \mathrm{m}$ de diámetro cada uno, que parten del cuerpo de Highmore. Estos lóbulos se encuentran entre los tabiques fibrosos que se extienden entre el testículo del mediastino y la túnica albugínea. Están encerrados por tejido conectivo, constituyendo los túbulos seminíferos, entre los cuales se encuentran las células de Leydig, vasos sanguíneos, linfáticos y nervios (Hutson, 2012).

Las células de Leydig, se encuentran en el intersticio testicular y son el sitio principal de la síntesis y secreción de testosterona, la principal hormona sexual masculina. La LH es secretada por la hipófisis estimulando a las células de Leydig para producir testosterona, que luego se acumula en el intersticio y en los túbulos seminíferos (Varghese, 2010).

Por su parte el epitelio del túbulo, está recubierto por las células de Sertoli, altas de tipo columnar, que están ubicadas en la base de los túbulos seminíferos. Su principal función es nutrir a las células germinales en desarrollo durante los diversos estadios de la espermatogénesis. Otras de sus funciones son las siguientes: la regulación de la función de la glándula hipofisiaria, (ya que las células de Sertoli secretan inhibina B que tiene un ligero efecto sobre el hipotálamo para inhibir la secreción de $\mathrm{GnRH}$ y el control de la espermatogénesis (Bennett, 2013; Varghese, 2010).

En los roedores los testículos se encuentran en el escroto, envueltos por una fuerte cubierta de tejido conectivo, la túnica albugínea. La túnica albugínea presenta un engrosamiento denominado Cuerpo de Highmore, que tiene numerosos vasos y una 
red de conductillos espermáticos denominada red de Haller, la red testicular de Haller da origen a los conos eferentes que perforan la túnica albugínea y pasan al epidídimo (Mira, 2014).

\section{Epidídimo}

El epidídimo es un órgano complejo que mantiene un ambiente intraluminal característico, es importante por efectuar la maduración espermática en las regiones próximas y de almacén de espermatozoides en regiones distales del ducto. El epidídimo de los mamíferos es uno de los ductos más largos del cuerpo con un estimado de 2, 6 y $50 \mathrm{~m}$ en la rata, humano y toro respectivamente. Diversos procesos metabólicos suceden en el tejido epididimario, tanto la actividad de absorción, como la de secreción del epitelio del epidídimo, son reguladas por andrógenos. Además de los andrógenos, otras hormonas y factores testiculares locales pueden tener influencia en la función del epidídimo (Brooks, 1983).

Se ha demostrado que el epidídimo desempeña un papel importante en la maduración de los espermatozoides, permitiendo el desarrollo post-meiótico y que los espermatozoides inmaduros progresivamente adquieran el potencial de fertilización. La maduración espermática epididimaria tiene lugar en la cabeza y el cuerpo del epidídimo, mientras que la región caudal funciona como un área de almacenamiento, donde los espermatozoides maduros adquieren una condición inactiva antes de la eyaculación (Brooks, 1983).

\section{Espermatogénesis}

El proceso de diferenciación de una espermatogonia a una espermátida se conoce como espermatogénesis. La regulación de la espermatogénesis involucra mecanismos endocrinos y paracrinos. La estimulación endocrina de la espermatogénesis incluye a la FSH como a la hormona luteinizante LH, ésta última actúa en las células de Leydig para estimular la producción de testosterona (Snoeren et al., 2014). 
La espermatogénesis involucra divisiones mitóticas y meióticas y una gran remodelación celular. La espermatogénesis se divide en tres fases: (1) proliferación y diferenciación de espermatogonias, (2) meiosis y (3) espermiogénesis, un proceso complejo posterior a la meiosis, en el que las espermátidas redondas se transforman en espermatozoides (Sharma y Agarwal, 2011).

En el túbulo seminífero las células germinales se encuentran dispuestas de forma ordenada desde la membrana basal hasta el lumen del túbulo. Las espermatogonias se encuentran en la membrana basal del túbulo seminífero, seguidas de los espermatocitos primarios, los espermatocitos secundarios y las espermátidas a medida que avanzan hacia la luz del túbulo. Las uniones estrechas soportan a las espermatogonias y a los espermatocitos tempranos dentro del compartimiento basal y todas las células germinales posteriores dentro del compartimento adluminal (Sharma y Agarwal, 2011).

\section{Morfología espermática}

Los espermatozoides son células especializadas y condensadas que carecen de procesos de crecimiento y división. La anatomía de un espermatozoide se compone de las siguientes partes (Fig. 3):

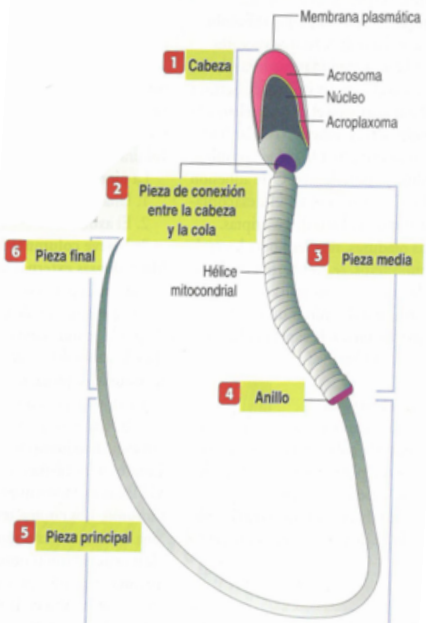

Fig. 3. Estructura y componentes de la cabeza y cola del espermatozoide. Modificado de (Stevens y Lowe, 2007). 


\section{Cabeza}

La cabeza contiene el material genético (ADN), consta de dos elementos, el núcleo y el acrosoma (Stevens y Lowe, 2007). Mide aproximadamente 4.0 a $5.5 \mu \mathrm{m}$ de largo y 2.5 a $3.5 \mu \mathrm{m}$ de ancho (Abbiramy y Shanthi 2010).

\section{Acrosoma}

El acrosoma está representado por el complejo de Golgi. Contiene varias enzimas hidrolíticas como hialuronidasa y acrosina, necesarias para la fertilización (Kruger et al., 1986). La función de la hialuronidasa es separar las células del cúmulo que envuelven al ovocito por medio de la hidrólisis del ácido hialurónico que las mantiene unidas. Asimismo, contiene acrosina, enzima hidrolítica que rompe la zona pelúcida del ovocito para que el espermatozoide pueda penetrar al interior del ovocito (Gimeno, 2014).

Pieza de conexión

La pieza de conexión o cuello se encuentra entre la cabeza y la cola (espermátida en desarrollo), incluye el centriolo proximal unido al núcleo (fosa de implantación) y el centriolo distal, que genera el axonema (Stevens y Lowe, 2007; Gimeno, 2014).

\section{Pieza media}

La pieza media de la cola del espermatozoide va desde el cuello hasta el extremo de la vaina mitocondrial dispuesta en hélice. Entre la vaina helicoidal de mitocondrias y el axonema se encuentran nueve fibras densas externas (Stevens y Lowe, 2007).

Anillo

El anillo es el sitio donde la pieza media se convierte en la principal (Stevens y Lowe, 2007). 
Pieza principal

La pieza principal está constituida por: 1) costillas de disposición concéntrica de la vaina fibrosa, ancladas en dos columnas longitudinales; 2 ) siete fibras densas externas y 3 ) el axonema central. Conforme se afila la cola del espermatozoide, las fibras densas externas, las costillas longitudinales progresivamente pierden grosor y desaparecen a una corta distancia de la punta (la pieza final) (Stevens y Lowe, 2007).

Pieza final

La pieza final incluye el axonema con 9+2 microtúbulos, rodeado exclusivamente por la membrana plasmática (Stevens y Lowe, 2007).

\section{Regulación hormonal de la diferenciación sexual}

La hipótesis de la aromatización de la diferenciación sexual cerebral, propone que la testosterona, secretada de los testículos perinatales, cruza la barrera hematoencefálica y es convertida a estradiol, en las células diana, por la enzima aromatasa; el estradiol luego actúa vía RE para masculinizar el cerebro y el comportamiento (Zuloaga et al., 2009).

En roedores la masculinización y desfeminización de la diferenciación sexual cerebral ocurre en el periodo neonatal y está mediado por el $\mathrm{E}_{2}$ (McCarthy et al., 2009). En diversos estudios, se ha demostrado que la masculinización cerebral, puede bloquearse tratando ratas macho neonatales con un inhibidor de la aromatasa o un antagonista de estrógenos (Döhler et al., 1984). Tal hallazgo podría indicar, la posible acción de los fitoestrógenos ingeridos en la etapa neonatal sobre la masculinización cerebral, ya que se sabe son inhibidores de la enzima aromatasa.

\section{Dimorfismo sexual cerebral}

Se denomina como dimorfismo sexual a las diferencias morfológicas, fisiológicas, bioquímicas y de la conducta de machos y hembras, que son mediados por la acción 
del estradiol durante períodos críticos del desarrollo (prenatal y postnatal) (Nie et al., 2017).

Los núcleos sexualmente dimórficos son el área preóptica (APO), el núcleo ventromedial (NVM), el núcleo supraquiasmático (NSQ), la amígdala (Amy) y el núcleo estría terminal (ST) (Gutiérrez et al., 2005).

El área preóptica (POA), que es el sitio principal del cerebro que controla el comportamiento sexual masculino y el comportamiento materno femenino (McCarthy et al., 2009). En ratas, el POAm se le conoce como la porción medial del área preóptica (mPOA por sus sílabas en inglés) (Allen et al., 1989).

El núcleo supraquiasmático (NSQ) difiere en forma entre hombres y mujeres; es esférico en hombres y oblongo en mujeres. Se considera que su principal dimorfismo depende del número y la forma de conexiones que presenta (Swaab et al., 1985).

Otro núcleo sexualmente dimórfico es el núcleo ventromedial (NVM). En este núcleo, la densidad sináptica es mayor en machos que en hembras (Miller y Aoki, 1991), el dimorfismo del NVM está controlado por las hormonas sexuales, y en el caso de las hembras varía a lo largo de los ciclos sexuales; además se ha relacionado en hembras con la conducta de lordosis.

Por su parte, la amígdala (Amy), núcleo sexual dimórfico es un centro de integración de información olfativa, importante para la conducta, contribuyendo a la excitación sexual de machos y hembras (Kondo et al., 1997).

El núcleo de La estría terminal (ST) es la conexión eferente principal de la amígdala. La ST se puede dividir en varias regiones (Weller y Smith, 1982). Los (núcleos de la estría terminal (NCET) es $97 \%$ más grande en volumen en machos que en hembras (Hines et al., 1992). 


\section{Parámetros conductuales}

\section{Conducta sexual masculina}

La conducta sexual está mediada por estímulos neuronales y hormonales, que varían según la especie. Hormonalmente, el $\mathrm{E}_{2}$ y la DHT favorecen la activación del apareamiento en el macho, el $\mathrm{E}_{2}$ es más importante para el apareamiento, mientras que la DHT favorece principalmente los reflejos genitales. En el sistema nervioso central, los agonistas de la dopamina facilitan el comportamiento sexual, mientras que la serotonina (5-HT), a través de su interacción con ciertos subtipos de receptores de serotonina (5-HT), facilitan la erección o la eyaculación. Las señales quimiosensoriales de los sistemas olfatorios principales y accesorios, son los estímulos más importantes para el apareamiento en roedores, aunque, la señal genitosensorial también contribuye (Hull y Domínguez, 2007).

La conducta sexual engloba tres fases (Snoeren et al; 2014): la introductoria (precopulatoria), el macho se acerca y olfatea la región anogenital de la hembra para obtener señales a través de las feromonas de la hembra, esto le confiere reconocer si la hembra se encuentra sexualmente receptiva (Hlinák, 1990). La hembras muestran diversos comportamientos para aceptar o rechazar al macho, entre estos se encuentra el comportamiento proceptivo (que incluye brincos, saltos y "orejeos") (Beach, 1976). Posteriormente, en la fase copulatoria, el macho se se acerca desde la parte posterior de la hembra y realiza diveros patrones que son: montas que se caracterizan por movimientos rápidos y poco profundos (montas) con su pelvis (Snoeren et al., 2014). Las intromisiones se caracterizan como montas con movimiento pélvico, en las que ocurre la inserción del pene (intromisión) con más fuerza durante 200-300 mseg (Beyer et al., 1981). Las hembras responden a este estímulo con un comportamiento receptivo denominado lordosis. Después de una serie de montas e intromisiones, se alcanza la eyaculación. La eyaculación consiste en dos fases, la emisión (secreción y movimiento de fluidos seminales hacia la uretra) y la expulsión (expulsión forzada de los contenidos 
uretrales) (Snoeren et al., 2014). Finalmente en la fase post-copulatoria, el macho lleva acabo el acicalamiento de la zona genital (Hull y Rodríguez-Manzo, 2017).

La interacción comienza con un comportamiento introductorio, en el que el macho se acerca y olfatea la región anogenital de la hembra para obtener señales a través de las feromonas de la hembra. La hembras muestran diversos comportamientos para aceptar o rechazar al macho, entre estos se encuentra el comportamiento proceptivo (que incluye brincos, saltos y "orejeos") (Beach, 1976); Posteriormente, el macho se acerca desde la parte posterior de la hembra, la monta y realiza movimientos rápidos y poco profundos (montas) con su pelvis (Snoeren et al., 2014).

Las intromisiones se caracterizan como montas con movimiento pélvico, en las que ocurre la inserción del pene (intromisión) con más fuerza durante 200-300 mseg (Beyer et al., 1981). Las hembras responden a este estímulo con un comportamiento receptivo denominado lordosis. Después de una serie de montas e intromisiones, se alcanza la eyaculación. La eyaculación consiste en dos fases, la emisión (secreción y movimiento de fluidos seminales hacia la uretra) y la expulsión (expulsión forzada de los contenidos uretrales) (Snoeren et al., 2014).

En las ratas, generalmente se necesitan de 10 a 20 intromisiones en un período aproximado de 2 a 10 minutos para alcanzar la eyaculación. Después de la eyaculación, los machos descansan durante \pm 5 minutos (periodo refractario) antes de iniciar el siguiente ciclo (Snoeren et al., 2014). Otros parámetros son usados para medir la conducta sexual, además del Intervalo Post-Eyaculatorio (PEI) (Chan et al., 2010; Agmo, 1997).

Asimismo, el control de la conducta sexual masculina engloba diversos mecanismos, entre ellos, neuronales en el que intervienen estructuras cerebrales (bulbo olfatorio principal y accesorio, amígdala medial, área preóptica media, núcleo preóptico medio, hipotálamo anterior, el núcleo de la base de la estría terminalis y distintas áreas en el campo tegmental central, además de extensas conexiones intrahipotalámicas) 
(Simerly et al., 1990; Simerly y Swanson, 1986; Simerly y Swanson, 1988), que dan lugar al inicio de la actividad sexual. Por otro lado, existe un mecanismo copulatorio, en el que intervienen estructuras espinales y mielencefálicas que controlan la ejecución de la conducta copulatoria (erección peneana, movimiento peneano y pélvico, ajustes posturales) (Beach y Jordan, 1956; Beach, 1967).

La detección de las feromonas de la hembra, mediante el sentido del olfato, permite al macho la identificación y discriminación de congéneres, esto es redundante para el despliegue de la conducta sexual y de agresión (Nelson y Chiavegatto, 2001).

\section{Conducta olfatoria}

El sistema vomeronasal (VNO) está compuesto por el bulbo olfativo accesorio, núcleo, el núcleo de la base de la estría terminal, la amígdala medial, el bulbo olfativo principal, la amígdala cortical posterolateral, el núcleo pre-mamilo ventral, el área preóptica, el núcleo ventromedial (Cherian et al., 2014). En los roedores, muchos comportamientos sociales son impulsados por el sentido del olfato, como la identificación de conespecíficos, identificación y discriminación de congéneres (Cherian et al., 2014).

Los roedores exhiben comportamientos sociales diferentes, como la agresión territorial y el apareamiento, a través de la transmisión e interpretación de señales olfativas conocidas como información social (Rennie, et al., 2013). Asimismo, se encuentra el olfateo anogenital (Wisniewski et al., 2005), ya que las feromonas del área anogenital, son detectadas por el órgano vomeronasal como señales utilizadas para el reconocimiento social en roedores (Keverne, 2002).

\section{Conducta de agresión}

La conducta de agresión en roedores se caracteriza por alejar a los intrusos o a los rivales de su territorio, de su pareja, de la cría, del alimento. 
En las ratas, el comportamiento de ataque puede ser provocado por la estimulación eléctrica del área hipotalámica intermedia y el polo ventrolateral del núcleo hipotalámico ventromedial, llamado colectivamente "área de ataque". Las conexiones aferentes y eferentes al "área de ataque" (Kruk, 1991), que incluyen la amígdala, la corteza prefrontal, el tabique, el núcleo talámico mediodorsal, el tegmento ventral y la sustancia gris periacueductal, también están involucradas en el comportamiento agresivo (Siegel et al., 1999).

Los andrógenos son importantes mediadores de la agresión de varias maneras: (1) durante el desarrollo, los andrógenos guían la organización del cerebro hacia un patrón similar al masculino, al inducir o prevenir la muerte de las células neuronales; (2) más adelante, la testosterona después de la pubertad estimula a los circuitos neuronales que se organizaron perinatalmente, probablemente haciendo que los estímulos que inducen la agresión, sean más notables.

La conducta de agresión comprende diferentes etapas: preataques conductuales, donde se encuentra el olfateo de investigación (30 segundos) por parte del residente al intruso, seguido rápidamente por la piloerección que comúnmente está acompañado por el chirrido de los dientes (Nelson y Chiavegatto, 2001; Blanchard y Blanchard, 1977).

El ataque activo involucra la persecución, ataque (mordida o embestida hacia el intruso), boxeo (postura vertical acompañada por las patas delanteras apretadas), postura dominante (el residente se para o agacha sobre el intruso), traqueteo de la cola, sacudida o vibración), retroceder (alejarse del intruso). Los ataques defensivos incluyen, postura subordinada (rata en posición supina, inmóvil), congelamiento. 


\section{ANTECEDENTES}

Durante aproximadamente un siglo, las fórmulas para bebés se han consumido en los Estados Unidos y actualmente forman parte importante del mercado de fórmulas para lactantes (Westmark, 2017). En el caso de los infantes que presentan intolerancia a la lactosa, la leche de soya ha sido una gran solución. Como se ha señalado, los fitoestrógenos: Genisteína y Daidzeína son los más abundantes en las semillas de soya y, por ende, en los alimentos a base de ésta. Durante la lactancia, los bebés que son intolerantes a la lactosa y son alimentados con suplementos de leche de soya, pueden alcanzar concentraciones circulantes de isoflavonas en un rango de $552 \mu \mathrm{g} / \mathrm{L}$ a $1775 \mu \mathrm{g} / \mathrm{L}$ (Setchell et al., 1997). Tomando en cuenta que los valores endógenos de estradiol son de $40-80 \mathrm{pg} / \mathrm{mL}$, los niveles de isoflavonas son de 13,000 to 22,000 veces más altas que los niveles endógenos de estrógenos (Zung et al., 2001). Las altas concentraciones plasmáticas de isoflavonas observadas en lactantes alimentados con fórmula a base soya, indican que la absorción de isoflavonas de soya del tracto intestinal es eficiente y que estos compuestos tienen alta biodisponibilidad (Setchell, 1998). Hasta donde se sabe, no ha habido informes previos de las concentraciones plasmáticas de isoflavonas en los lactantes alimentados con fórmulas a base de soya u otros regímenes dietéticos. Esta información es esencial para evaluar si los fitoestrógenos circulan en concentraciones suficientes para tener un efecto fisiológico. De acuerdo con Chen y Rogan (2004) y McCarver (et al., 2011), no se han realizado estudios farmacocinéticos, definidos como medición de las concentraciones de isoflavona en muestras de sangre o plasma en serie, en lactantes o niños, a excepción de los que se conocen son los dados por (Setchell, 1998) y (Cao et al., 2009), sin embargo, no informan los efectos estrogénicos en infantes.

Se han realizado diversos estudios para determinar los riesgos y beneficios de la ingesta de la leche de soya durante los primeros días de vida, los cuales en ocasiones presentan resultados contradictorios o poco claros. 
Algunos de los estudios realizados en infantes, no revelan efectos negativos por el consumo de fitoestrógenos durante el desarrollo gonadal. Tal es el caso de Andres y cols. (2012), quienes realizaron un estudio prospectivo y longitudinal en niños entre 1 y 2 meses de edad, a los que determinaron el volumen y las características estructurales de órganos reproductivos (los volúmenes y las características de útero, ovarios, próstata y testículo) al cumplir los 5 años de edad. Se incluyeron un total de 101 infantes (50 y 51 niñas) de los cuales 35 infantes fueron amamantados, 32 alimentados con fórmula de leche de vaca y 34 con leche de soya, durante 12 meses. Los resultados concluyeron que, en ningún caso, niñas o niños presentaron diferencias significativas en el volumen y las características estructurales de los órganos reproductivos.

De manera similar, Bernbaum (et al., 2007), que estudiaron una población de 37 niños, en Filadelfia (Estados Unidos), donde se les administró fórmula láctea de soya desde el nacimiento hasta los seis meses, los resultados de los análisis físicos indicaron que no se encontraron anomalías escrotales y testiculares.

Contradictoriamente, se ha demostrado que los fitoestrógenos, pueden inducir cambios en conductas sexualmente dimórficas en humanos expuestos durante el desarrollo temprano. En un estudio realizado en Avon, Reino Unido, con un total de 7, 076 infantes (3, 664 niños y 3, 412 niñas) hasta los 42 meses de edad; las madres informaron los hábitos de amamantamiento, así como la alimentación infantil consumida a los 1, 6, 15 y 24 meses después del parto, y la edad en la que se les administraron otras leches o fórmulas. Con esta información se formaron cuatro grupos: leche materna, fórmula temprana ( $\leq 4$ meses de edad), soya temprana ( $\leq 4$ meses de edad) y soya tardía (después de los 4 meses a los 15 meses de edad) (Adgent et al., 2011). A los 42 meses de edad se realizaron pruebas de juego de roles de género, utilizando el Inventario de Actividades Prescolares (PSAI), que es un instrumento utilizado para evaluar los comportamientos de dimorfismo sexual en niños en estudios previos de disruptores endocrinos ambientales, como ftalatos, bifenilos policlorados, dioxinas y fitoestrógenos (Swan et al., 2010; Nakajima et al., 2006). La 
prueba consta de tres categorías: (i) juguetes, (ii) actividades y (iii) características de personalidad del niño (Golombok y Rust, 1993). Los resultados obtenidos indicaron que la exposición temprana a la soya se relacionó con un comportamiento de juego menos típico de las niñas; sin embargo, en los niños no se encontraron cambios en el comportamiento (Adgent et al., 2011).

Por otro lado, los estudios en modelos animales han sido una gran herramienta para evidenciar los efectos de la administración neonatal de Genisteína o Daidzeína en la etapa neonatal. Strauss (et al., 1998) en un estudio realizado con ratones macho HanNMRI que se caracterizan por tener un crecimiento rápido (River, s.f.), a los que se les administró el día 3 postnatal (DPN 3), Genisteína (0.1 mg/día o $1 \mathrm{mg} /$ día), encontraron anormalidades en la morfología del complejo uretro-prostático con la dosis de 1 $\mathrm{mg} / \mathrm{día}$. En cambio, el grupo tratado con la dosis baja de genisteína $(0.1 \mathrm{mg} / \mathrm{día}) 5 \mathrm{de}$ los 11 animales mostraron hiperplasia en los conductos colectores prostáticos.

Sin embargo, Nagao (et al., 2001) en un estudio realizado con ratas macho SpragueDawley en el DPN 5, con diversas dosis de Genisteína (12.5, 25, 50, o $100 \mathrm{mg} / \mathrm{Kg}$ ), encontraron que los machos no presentaron cambios en el conteo de espermatozoides, en la fertilidad y en la concentración sérica de testosterona.

Se ha evaluado el efecto de los fitoestrógenos en la conducta sexual de ratas macho adulto, ya sea mediante su administración en la etapa gestacional (administrada a la madre durante el primer día gestacional (u otro) hasta el nacimiento de las crías) o neonatal a través de diferentes dosis de Genisteína u otro fitoestrógeno.

En un estudio realizado por Whitten et al., (1995), en el cual se administró Coumestrol, que es el fitoestrógeno más potente) por tener una afinidad de unión relativa del estradiol en el ERa y ER $\beta$ de 20 y 140, respectivamente, se administraron $100 \mathrm{mg} / \mathrm{Kg}$ a ratas Sprague Dawley, durante los primeros 10 días postnatales y hasta el día 21 de lactancia, los resultados de conducta sexual en adultos indicaron un incremento en las 
latencias de monta, intromisión y eyaculación en comparación con los machos del grupo control.

Asimismo, Rodriguez-Gomez (et al., 2014) administraron dos dosis de Genisteína (5 y $100 \mu \mathrm{g}$ ), del día 11 de gestación al 8 postparto a ratones CD1, encontrando en los resultados de las pruebas de conducta sexual en etapa adulta, con ambas dosis, una disminución en las latencias de monta, intromisión, y los machos no se presentaron eyaculaciones en comparación con el grupo control.

De manera similar, Wisniewski (et al., 2003), administraron Genisteína $(0.5 \mathrm{mg} / \mathrm{Kg}$ y $300 \mathrm{mg} / \mathrm{Kg}$ ) del día uno de gestación al nacimiento en ratas Long Evans; en comparación con el grupo control los resultados de conducta sexual en etapa adulta en los machos tratados con genisteína indicaron un aumento en las latencias de monta, intromisión, y no eyacularon.

En relación con los parámetros de fertilidad, Eustache (et al., 2009), luego de administrar genisteína (1 y $10 \mathrm{mg} / \mathrm{Kg}$ ) del día uno gestacional al 21 postnatal, reportaron una reducción en el número de camada, así como una disminución del conteo espermático en comparación con los machos del grupo control. Asimismo Cederroth (et al., 2010), administraron en ratones CD1 adultos, seis semanas antes del apareo dos dietas de Genisteína con Daidzeína (baja: 355 ppm y alta: 389 ppm), los resultados indicaron una reducción en el número de camada, así como una disminución del conteo espermático a comparación del testigo.

De acuerdo con Delclos (et al., 2001), en ratas macho la administración de una dosis de $180 \mathrm{mg} / \mathrm{Kg} /$ día de Genisteína del día siete gestacional al 50 postnatal, produjo en la edad adulta una espermatogénesis anormal (los túbulos seminíferos mostraron retención de espermátidas alargadas en las etapas X-XII y una reducción de espermátidas y degeneración de espermatocitos). En cambio, Nagao (et al., 2001), 
luego de administrar varias dosis de genisteína $(12.5,25,50$ y $100 \mathrm{mg} / \mathrm{Kg})$ al quinto día postnatal, no encontraron efectos deletéreos en la espermatogénesis.

Debido a que los efectos descritos por la administración neonatal de fitoestrógenos es muy variable y en ocasiones contradictoria, en el presente estudio se pretende analizar el efecto de la administración simultánea de Genisteína y Daidzeína, principales fitoestrógenos presentes en la soya en diferentes concentraciones, pero manteniendo la misma proporción en ambos, similar a la que se encuentra en la leche de soya administrada a neonatos y evaluar los efectos en diversos parámetros reproductivos de la rata macho Wistar.

\section{JUSTIFICACIÓN}

Los fitoestrógenos se encuentran en varios productos alimenticios, incluyendo las fórmulas infantiles a base de soya (Fonseca et al., 2014). Se ha demostrado el efecto benéfico de los fitoestrógenos en adultos, que incluye la disminución en la sintomatología de la menopausia y en la incidencia de los cánceres dependientes de estrógenos. Sin embargo, dado que las etapas de desarrollo, pre y neonatal se consideran las más sensibles a los disruptores endocrinos, siendo las gónadas, el sistema endócrino y el cerebro los más afectados en los procesos de diferenciación (McCarver et al., 2011); existen controversias sobre los posibles efectos "benéficos" de los fitoestrógenos en el desarrollo infantil, especialmente cuando se utilizan en dosis elevadas y por tiempos prolongados.

Se ha reportado que la exposición temprana de sustancias químicas con actividad de tipo estrogénico, puede causar anormalidades en el tracto reproductor masculino, comprometiendo la calidad y producción de esperma en animales experimentales, y posiblemente en poblaciones de vida silvestre y humanos (Fielden et al., 2003; Napier et al., 2014). 
La mayoría de los estudios reportados se han centrado en la exposición de un solo fitoestrógeno en el periodo de gestación, lactancia y en el periodo posterior al destete (Napier et al., 2014).

Lo anterior, aunado a los resultados contradictorios que se han reportado, sugiere la necesidad de realizar estudios en los cuales se analice el efecto de la administración conjunta de Genisteína y Daidzeína para analizar, bajo el mismo esquema, el efecto de la administración neonatal valorando diversos aspectos conductuales y reproductivos en la etapa adulta y correlacionarlos entre ellos. Los datos experimentales obtenidos de animales se pueden consideran relevantes para la evaluación del riesgo en la salud reproductiva humana.

\section{PLANTEAMIENTO DEL PROBLEMA}

El consumo humano de alimentos que contienen fitoestrógenos ha aumentado en las últimas décadas debido, principalmente, al surgimiento de nuevos regímenes alimenticios a base de soya, donde su ingesta se ha extendido a los recién nacidos, a pesar de que todavía no hay suficientes estudios de los efectos a largo plazo que estos puedan causar.

Si bien se ha reportado que las fórmulas lácteas a base de soya tienen baja toxicidad en el desarrollo infantil, existen reportes que señalan que los fitoestrógenos pueden tener efectos deletéreos en la espermatogénesis en la edad adulta y, por ende, en su capacidad reproductiva.

El estudiar en humanos el efecto de la ingesta de fitoestrógenos en etapa neonatal se ha limitado a estudios retrospectivos, los cuales tiene como desventajas que hay poca adherencia de los pacientes al estudio, el bajo control de parámetros que no otorgan certeza de los métodos de empleo y administración, así como largo periodo entre su ingesta y la madurez sexual donde se pueden presentar problemas asociados a la fertilidad masculina. Esto limita la veracidad y confiabilidad de los resultados, por lo 
que los modelos murinos han sido la opción para evaluar el efecto de estos compuestos por el control que se tiene sobre estos.

Asimismo, la mayoría de los estudios realizados en modelos animales se han enfocado a analizar el efecto de un solo fitoestrógeno, perdiendo de vista que las fórmulas lácteas a base de soya contienen una variedad de estos compuestos que pueden ejercer efectos de tipo estrogénico con actividades agonistas o antagonistas entre ellos, siendo los principales Genisteína y Daidzeína.

La propuesta del presente proyecto es utilizar un modelo murino que permita analizar la relación directa entre la causa y el efecto de la administración simultánea de dos fitoestrógenos, genisteína y daidzeína, en la misma proporción que se presentan en las fórmulas lácteas a base de soya, pero en dos diferentes dosis (baja y alta), sobre la fisiología y conducta reproductiva masculina.

\section{PREGUNTA DE INVESTIGACIÓN}

¿Cuáles son los efectos de la exposición crónica neonatal y simultánea de Genisteína con Daidzeína en dos dosis sobre los aspectos conductuales y reproductivos de la rata Wistar macho adulta?

\section{OBJETIVOS}

\section{Objetivo General}

Determinar el efecto de la administración crónica neonatal y simultánea de Genisteína y Daidzeína en dos dosis en la conducta y en parámetros reproductivos de la rata Wistar macho adulta. 


\section{Objetivos Particulares}

Evaluar en la rata macho adulta el efecto de la administración crónica neonatal y simultánea de dos dosis de Genisteína con Daidzeína (A: $6.8 \mathrm{mg} / \mathrm{Kg}$ y B: $9.4 \mathrm{mg} / \mathrm{Kg}$ ), que tienen la misma proporción de estos fitoestrógenos (64\% de genisteína y $36 \%$ de daidzeína) sobre:

1) La conducta olfatoria.

2) La conducta sexual.

3) La conducta de agresión.

4) Los parámetros seminales.

5) La fertilidad.

\section{MATERIALES Y MÉTODOS}

\section{Animales}

Se utilizaron 15 ratas machos neonatos de la cepa Wistar del bioterio de la UAMIztapalapa, los cuales fueron mantenidos de acuerdo con lo estipulado en los lineamientos aprobados por el Comité Institucional de Cuidado y Uso de Animales de Bioterio de la UAM y el "Reglamento de la Ley General de Salud en Materia de Investigación en Salud" de la Secretaría de Salud Mexicana (NOM-062-ZOO-1999). Los animales se mantuvieron en un cuarto de bioterio con temperatura controlada entre los 18 y $26{ }^{\circ} \mathrm{C}$, en jaulas de acrílico $(42.5 \times 52.5 \times 19.3 \mathrm{~cm})$, con fotoperiodo invertido de 12-h luz y 12-obscuridad (la luz se apagó a las 7:00 am), con agua y alimento para ratas ad libitum, Abene BDL-7100 especial libre de fitoestrógenos.

Las crías en el día cero de nacimiento fueron sexadas y mantenidas en grupos de 10 crías por hembra (5 machos y 5 hembras) hasta el día del destete. Las crías fueron distribuidas aleatoriamente para que todos los machos recibieran la misma estimulación (lamido en él área genital), ya que este estímulo favorece que los machos en etapa adulta desplieguen montas e intromisiones (Richmond y Sachs, 1984). 


\section{Tratamiento}

El análisis del contenido de isoflavonas en las fórmulas de soya para infantes varían según la marca analizada. Este análisis revela un consumo diario que puede variar en un rango de 2.1 a $9.4 \mathrm{mg} / \mathrm{Kg} / \mathrm{día}$, manteniendo toda una relación de $64 \%$ Genisteína y 36\% Daidzeína (Setchell et al., 1997; Setchell et al., 1998; Chen y Rogan, 2004).

Dado que la mayoría de las fórmulas comerciales se encuentra en la media de los valores mencionados y el valor alto, en el presente trabajo se decidió utilizar las siguientes dosis, las cuales tuvieron siempre la siguiente relación $64 \%$ de Genisteína y $36 \%$ de Daidzeína.

Con las crías se formaron 3 grupos de neonatos, los cuales recibieron el siguiente tratamiento:

Grupo 1 Testigo: $10 \mu \mathrm{l} /$ día de Aceite de Olivo.

Grupo 2 Dosis baja de isoflavonas: $6.8 \mathrm{mg} / \mathrm{Kg} /$ día disueltos en $10 \mu \mathrm{l}$ de Aceite de Olivo.

Grupo 3 Dosis alta de isoflavonas: $9.4 \mathrm{mg} / \mathrm{Kg} / \mathrm{día}$ disueltos en $10 \mu \mathrm{l}$ de Aceite de Olivo.

Los fitoestrógenos fueron administrados por vía subcutánea del día 1 al día 10 postnatal (PND), tanto a machos como a hembras para evitar que la madre percibiera diferente olor entre las crías. Una vez destetadas las crías se mantuvieron en grupos de cinco machos por tratamiento y al alcanzar los 250 gramos de peso se iniciaron las pruebas conductuales.

\section{Prueba de conducta olfatoria}

Con el fin de evaluar el efecto de la administración conjunta de genisteína con daidzeína sobre la conducta olfatoria asociada a la conducta sexual, que les permite discriminar a sus congéneres e identificar a sus conespecíficos por el estímulo que 
producen en el órgano vomeronasal las feromonas de los roedores (Cherian et al., 2014), se realizó el siguiente experimento:

Se utilizó un redondel de acrílico ( $40 \mathrm{~cm}$ de alto $\times 30 \mathrm{~cm}$ de diámetro) con aserrín limpio (que se cambió después de cada prueba) (Fig. 4), en el cual se colocaron cuatro contenedores metálicos de $4 \times 5 \mathrm{~cm}$ con perforaciones con muestras estímulo que contenían los siguientes olores: 1) aserrín impregnado con orín de rata macho, 2) aserrín impregnado con orín de rata hembra, 3) alimento de rata empleado y 4) una infusión de manzana con canela. Los contenedores de aserrín se limpiaron y volvieron a llenar con muestras nuevas de aserrín después de cada prueba.

La duración de la prueba fue de 20 minutos. Los machos se introdujeron en el centro del redondel y se cuantificó el tiempo que permanecieron olfateando directamente cada contenedor que se cuantificó como tiempo de permanencia.

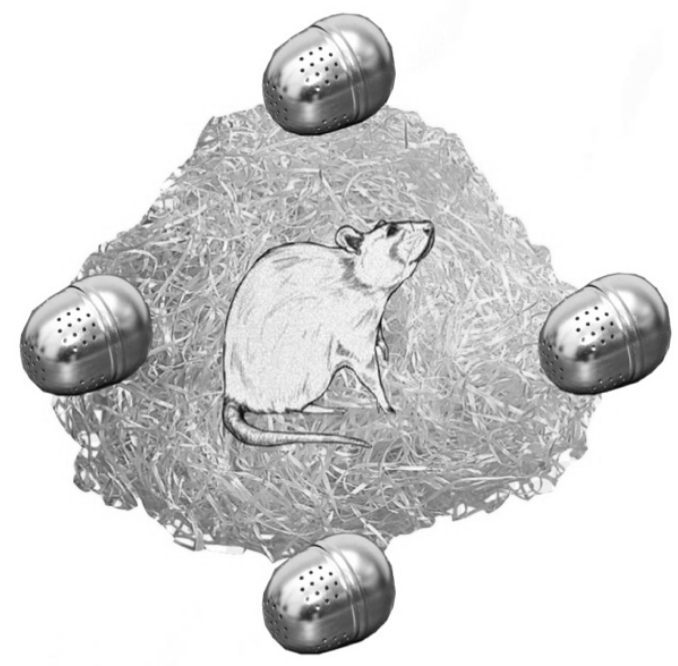

Figura 4. Representación de la arena para llevar acabo las pruebas de conducta olfatoria. 


\section{Pruebas de conducta sexual}

Para las pruebas de conducta sexual se utilizaron 25 hembras ovariectomizadas (OV), las cuales, fueron estimuladas para que presentaran receptividad sexual mediante la inyección s.c. de $10 \mu \mathrm{g}$ BEstradiol 3-Benzoato (Sigma), 48 y 24 horas previas a la prueba, y $0.5 \mathrm{mg}$ de progesterona (Sigma) por rata, cuatro horas antes de iniciar las pruebas de conducta. Previo realizar las pruebas, se verificó que las hembras estuvieran receptivas, apretando los flancos traseros con la finalidad de evaluar la respuesta de lordosis, ésta consiste el levantamiendo de la espalda y los cuartos traseros para permitir la intromisión del pene del macho (Lebas et al., 1986).

Se realizaron cuatro pruebas de conducta sexual de 30 min cada una (una por semana). Las tres primeras se consideraron de entrenamiento. Las pruebas se iniciaron 4 horas después de apagarse la luz. Cinco minutos antes de la prueba cada macho se colocó en un redondel de acrílico transparente de $40 \mathrm{~cm}$ de alto $\times 30 \mathrm{~cm}$ de diámetro, con cama de aserrín. Al concluir este periodo, se introdujo en el redondel de cada macho a una hembra receptiva, las cuales fueron cambiadas de redondel cada 5 minutos durante los 30 que duró la prueba.

Se analizaron los siguientes parámetros:

$\checkmark$ Latencia de monta LM: tiempo que tarda el macho en realizar la primera monta a partir de que se introduce a la hembra.

$\checkmark$ Latencia de intromisión LI: tiempo que tarda el macho en realizar la primera intromisión a partir de que se introduce a la hembra; si lo primero que realiza el macho es una intromisión se consideran iguales las latencias de monta e intromisión.

$\checkmark$ Latencia de eyaculación LE: tiempo que transcurre desde la primera intromisión hasta que ocurre la eyaculación.

$\checkmark$ Número de montas en 30 minutos.

$\checkmark$ Número de intromisiones en 30 minutos.

$\checkmark$ Número total de eyaculaciones: número de eyaculaciones en $30 \mathrm{~min}$. 
$\checkmark$ Hit rate (HR o Tasa de Aciertos): número de intromisiones / número de montas + número de intromisiones. Los valores para indicar una buena eficiencia copulatoria del macho van de 0.5 a 1 (Rodríguez-Manzo y Canseco-Alba, 2015).

\section{Prueba de conducta de agresión}

Las pruebas de conducta de agresión se realizaron con la finalidad de evaluar la desfeminización del cerebro, ya que en los roedores durante la etapa postnatal se da la masculinización y desfeminización (Patisaul y Jefferson, 2010) de este y se sabe que compuestos como los fitoestrógenos pueden intervenir en este proceso.

Para realizar las pruebas de agresión, en un redondel de acrílico de $40 \mathrm{~cm}$ de alto $\times$ $30 \mathrm{~cm}$ de diámetro con aserrín, se introdujo un macho sexualmente experto (que eyacula de tres a cuatro veces en 30 min) (Olivier et al., 2006; Hull y Domínguez, 2007; Ferreira Nuño y cols. 2010) (residente) durante 5 minutos con la finalidad de que reconociera el lugar. Posterior a los 5 minutos se introdujo a un macho experimental (intruso). Cada prueba tuvo una duración de 20 minutos y durante este tiempo se registró el número de veces que presentaron los machos intrusos conductas tantos ofensivas como defensivas basados en los siguientes criterios:

Conducta ofensiva: ataque (mordida o embestida hacia el intruso), boxeo (postura vertical acompañada por las patas delanteras apretadas), postura dominante (el residente se para o agacha sobre el intruso), traqueteo de la cola (sacudida o vibración) (Wisniewski et al., 2005).

Conducta defensiva: retroceder (alejarse del intruso), postura subordinada (rata en posición supina, inmóvil), congelar (detener todo movimiento) (Wisniewski et al., 2005). 


\section{Pruebas de fertilidad}

Para realizar las pruebas de fertilidad se establecieron unidades reproductoras constituidas por tres hembras vírgenes (200-250 gramos) y un macho de la raza Wistar. Las unidades reproductoras permanecieron durante 15 días con la finalidad de que las hembras presentaran en promedio 3 ciclos estrales. Al finalizar este periodo, se retiraron los machos y se verificó el estado de gravidez de las hembras. Se calculó el número de hembras gestantes y se determinó el índice de gestación (IG = número de hembras gestantes/total de hembras $X$ 100). Posterior al parto se cuantificaron y sexaron las crías.

\section{Obtención de muestras}

Una vez concluidas las pruebas anteriores los machos fueron sacrificados por medio de decapitación (NOM-062-ZOO-1999), previo al sacrificio se registró el peso corporal. Obtención de espermatozoides

Para el análisis espermático se utilizó el epidídimo izquierdo específicamente la región de la cauda o cola. Se realizó un picado de la misma en $500 \mu \mathrm{l}$ de solución Ringer a $34^{\circ} \mathrm{C}$ en un tubo Eppendorf y se mantuvo en agitación suave por unos minutos para favorecer la separación de los espermatozoides (World Health Organization, 2010).

El picado de los espermatozoides se filtró utilizando una malla de lycra con un diámetro de trama de $20 \mu \mathrm{m}$, se realizó un lavado con $500 \mu \mathrm{l}$ de Ringer para filtrar el remanente de material biológico y así separar el fluido con espermatozoides del tejido epididimario (León-Galván et al., 1999; Arenas-Ríos et al., 2005). Los espermatozoides se separaron por centrifugación ( $500 \mathrm{~g}$ x 5 minutos), separando en las cuales se separó el sobrenadante y se resuspendió el botón en el cual se encontraban los espermatozoides en con $1000 \mu \mathrm{l}$ de Ringer. A esta última suspensión se le consideró como la muestra de espermatozoides lavados. 


\section{Evaluación espermática}

La muestra de espermatozoides lavados, obtenidos de la región caudal del epidídimo fue evaluada de acuerdo con los criterios establecidos en el manual de la Organización Mundial de la Salud (World Health Organization, 2010).

\section{Concentración espermática}

Dilución: $1: 100,10 \mu \mathrm{l}$ de espermatozoides y $990 \mu \mathrm{l}$ de agua destilada. Se agitó la muestra en un tubo Eppendorf. Se agregaron $10 \mu \mathrm{l}$ en cada lado de la cámara de Neubauer y se dejó reposar durante 1 minuto para que las células sedimenten y se contaron al microscopio óptico con un aumento de 400x (World Health Organization, 2010). Solo se contaron los que se encontraban en el cuadro superior izquierdo como lo muestran las flechas (Fig. 5).

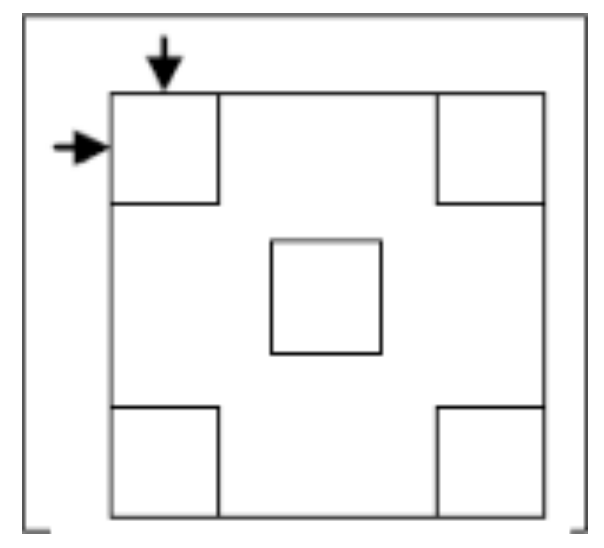

Figura 5. Sitios de la reglilla de la cámara de Neubauer, que indican los lugares donde deben ser contados los espermatozoides.

Para determinar la concentración de espermatozoides en millones por $\mathrm{ml}$, se cuantificaron cinco cuadros por reglilla (dos reglillas, 10 cuadros en total), se obtuvo el promedio y este se dividió entre el factor de 0.4 (correspondiente a la dilución 1:100) y el resultado se expresó en millones de espermatozoides por $\mathrm{ml}\left(\mathrm{x} 10^{6} / \mathrm{ml}\right)$ (World Health Organization, 2010). 


\section{Viabilidad espermática y morfología espermática}

Se tomó una alícuota de $10 \mu \mathrm{l}$ de semen y se añadieron $10 \mu \mathrm{l}$ de Eosina- Nigrosina en un portaobjetos, se realizaron frotis y se observó al microscopio óptico a 400x contando 100 espermatozoides con ayuda de un contador diferenciando entre vivos (no teñidos) y muertos (teñidos) (World Health Organization, 2010).

En el caso de la morfología se realizó a un aumento de 1000x, se distinguieron las siguientes categorías espermáticas: normales, defectos de cabeza, defectos de cuello y pieza media, defectos del flagelo.

\section{Daño al ADN de espermatozoides}

Se tomó una alícuota de $10 \mu \mathrm{l}$ de espermatozoides para realizar un frotis sobre una laminilla de vidrio, posteriormente los portaobjetos se fijaron con solución de Carnoys ( $3 \mathrm{ml}$ de cloroformo, $6 \mathrm{ml}$ de etanol absoluto, $1 \mathrm{ml}$ de ácido acético glacial y $1 \mathrm{~g}$ de cloruro férrico) colocados en una cuba de coloración por dos horas, una vez transcurridas las dos horas las láminas se dejaron secar por unos minutos para agregar la solución de naranja de acridina $(0.02 \%$ de naranja de acridina en fosfato de citrato) durante cinco minutos de acuerdo con el procedimiento de Tejada et al., (1984). Las muestras se analizaron bajo el microscopio de fluorescencia de luz reflejada, contando 100 espermatozoides de acuerdo con el color de la fluorescencia: verde, rojo, naranja o amarillo. Los espermatozoides con fluorescencia roja-naranja indicaron ADN desnaturalizado, mientras que los verdes indicarán ADN intacto (Ortega López et al., 2010).

\section{Compactación de ADN en espermatozoides}

Para cada muestra de espermatozoides, se evaluó la condensación de la cromatina de los núcleos espermáticos, se usó la tinción de azul de anilina (Sellami et al., 2013). Se extenderán $10 \mu \mathrm{L}$ de la muestra de espermatozoides en un portaobjetos de vidrio, dejándose secar al aire. Los frotis se fijaron con una solución de glutaraldehído al 3\% 
en tampón de fosfato $0.2 \mathrm{M}(\mathrm{pH}=7.2)$ durante 30 minutos. Los portaobjetos se tiñeron luego con solución acuosa de azul de anilina al 5\% mezclada con ácido acético al $4 \%$ $(\mathrm{pH}=3,5)$ durante 5 minutos.

Para cada frotis teñido, se evaluaron 100 espermatozoides con microscopio óptico (1000x). Los espermatozoides que presenten núcleos sin teñir, se consideraron espermatozoides con cromatina madura, mientras que aquellos con coloración azul se consideraron células con la cromatina inmadura (Sellami et al., 2013).

\section{Análisis estadístico}

Con los datos de cada uno de los parámetros evaluados en cada prueba, se calculó el promedio y la desviación estándar (D.E.), de los datos obtenidos por cada grupo tratado, siendo comparados contra el grupo testigo. La comparación para los tres grupos independientes se realizó mediante una prueba de ANOVA no paramétrica de Kruskal-Wallis seguida por una prueba post hoc de Tukey mediante el programa VassarStats. Se señaló el valor de $p$ en cada grupo y el nivel de significancia se fijó cuando $(p \leq 0.05)$. Letras diferentes y asteríscos se usaron para indicar diferencias significativas $\left(p<0.05^{*}\right.$ o $\left.p<0.01^{* *}\right)$ entre los grupos. 


\section{RESULTADOS}

\section{Conducta olfatoria}

\section{Conducta olfatoria: Testigo}

Los animales del grupo testigo al explorar los cuatro contenedores, mostraron una clara preferencia por el contenedor que contenía el aserrín con orín de la hembra en estro $(30.80 \pm 3.08)$, que fue significativamente mayor a los demás contenedores $(p<0.01)$. Algunos de los machos del grupo testigo incluso intentaron agarrar el contenedor y la mayoría del tiempo que duró la prueba permanecieron cerca de este contenedor, mostrando una clara preferencia por este olor (Fig. 6).

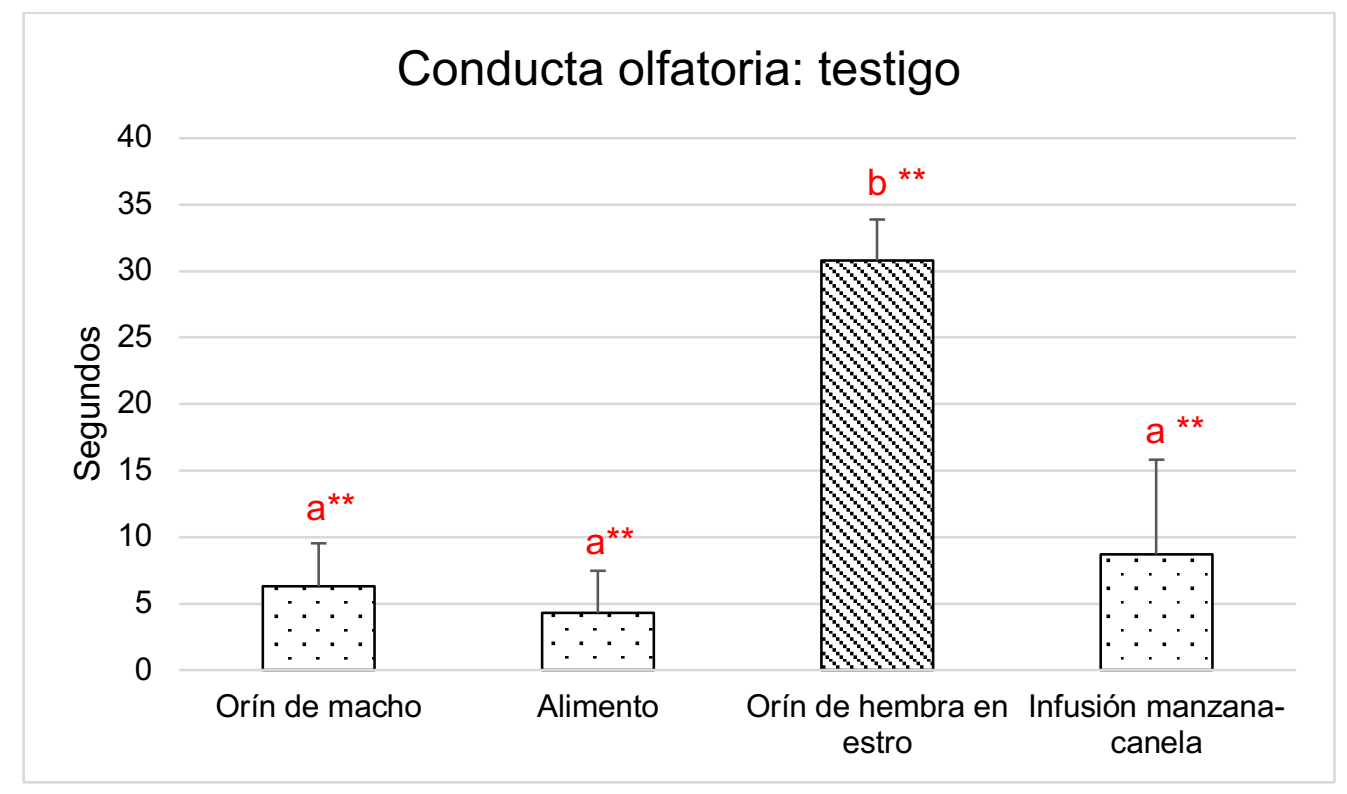

Figura 6. Efecto de la administración de genisteína/daidzeína sobre la conducta olfatoria en el grupo testigo. Se observa una clara preferencia por los machos de este grupo al estímulo del orín de la hembra en estro. " $a *$ " diferente de " $\mathrm{b}^{* * "}(p<0.01)$, luego de aplicar el ANOVA de Kruskall-Wallis seguida de la prueba post hoc de Tukey. Se expresa el promedio $\pm D E, n=10$ por grupo. 


\section{Conducta olfatoria: Dosis baja}

Los machos del grupo a los que se administró la dosis baja, mostraron una preferencia al olor de la hembra en estro, siendo menor al del grupo testigo (14.40 \pm 4.42$)$, y estos no permanecieron cerca de éste. Si bien, los machos de la dosis baja presentaron una preferencia ante el olor de la hembra en estro, la discriminación de olores y la preferencia por este no fue tan clara como en el caso de los machos del grupo testigo (Fig. 7).

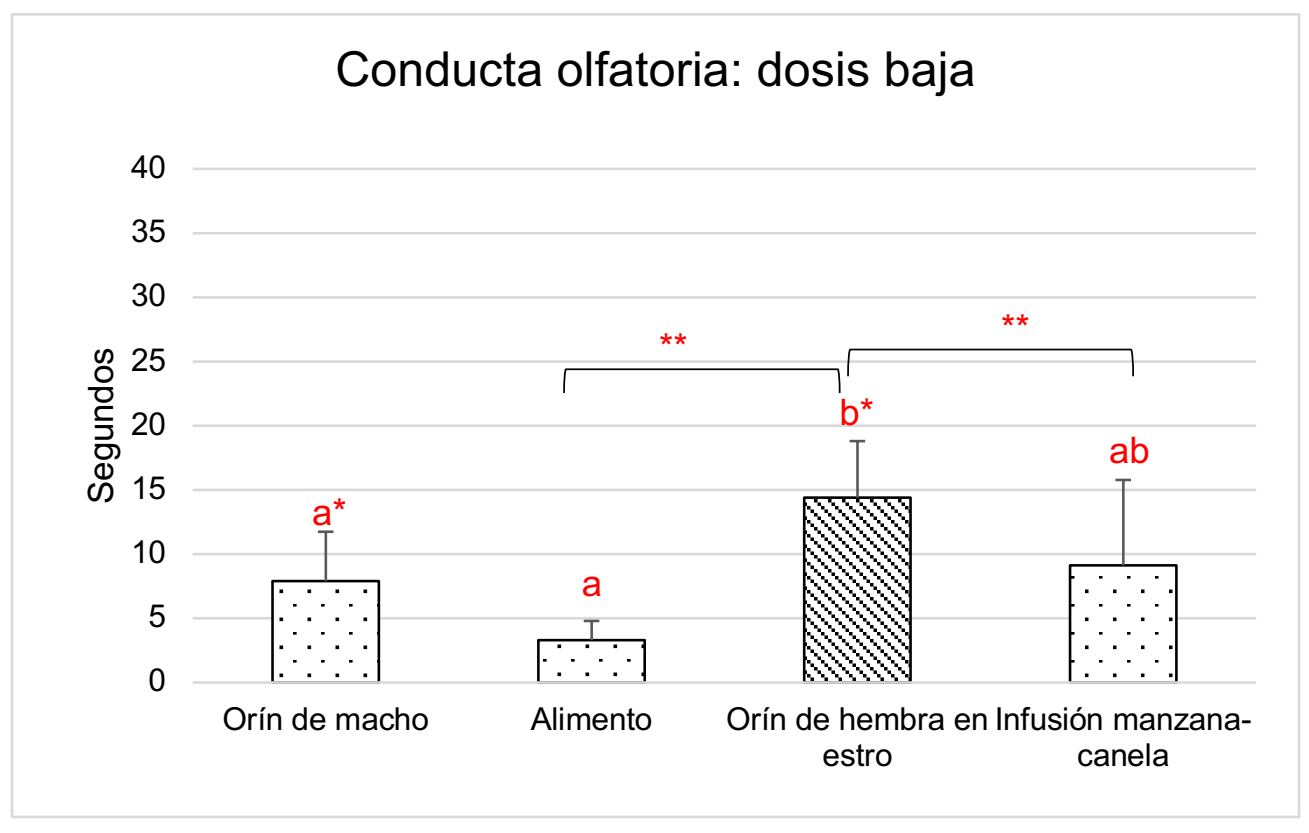

Figura 7. Efecto de la administración de genisteína/daidzeína sobre la conducta olfatoria. Se observa un aumento cercano al doble en la latencia de monta en los animales que recibieron la dosis baja en comparación con los del testigo y de la dosis alta. "a*" diferente de " $\mathrm{b}^{\star *}(p<0.05)$, " $\mathrm{a}^{\star *}$ " diferente de " $\mathrm{b}^{\star *}$ $(p<0.01)$, " $b^{* * "}$ diferente de "ab"** $(p<0.01)$, luego de aplicar la ANOVA de Kruskall Wallis seguida de la prueba post hoc de Tukey. Se expresa el promedio $\pm \mathrm{DE}, \mathrm{n}=10$ por grupo. 


\section{Conducta olfatoria: Dosis alta}

Por último, los machos del grupo a los que se administró la dosis alta, presentaron baja preferencia hacia el olor de la hembra en estro $(9.1 \pm 4.93)$, en comparación con el estímulo del orín de macho $(23.1 \pm 10.87)$, siendo significativamente mayor $(p<0.05)$.

En el caso de estos machos, se observa que no pudieron discriminar claramente los olores, por lo que no presentaron una preferencia olfatoria.

Además de la menor preferencia olfatoria por la orina de hembras en estro de los animales tratados con la dosis alta, llama la atención que al introducir a los animales en el redondel con los cuatro contenedores e iniciar la exploración, los animales del grupo testigo tardaron la mitad del tiempo que los tratados en iniciar a identificar los olores lo cual indica una alteración en la percepción olfatoria (Fig. 8).

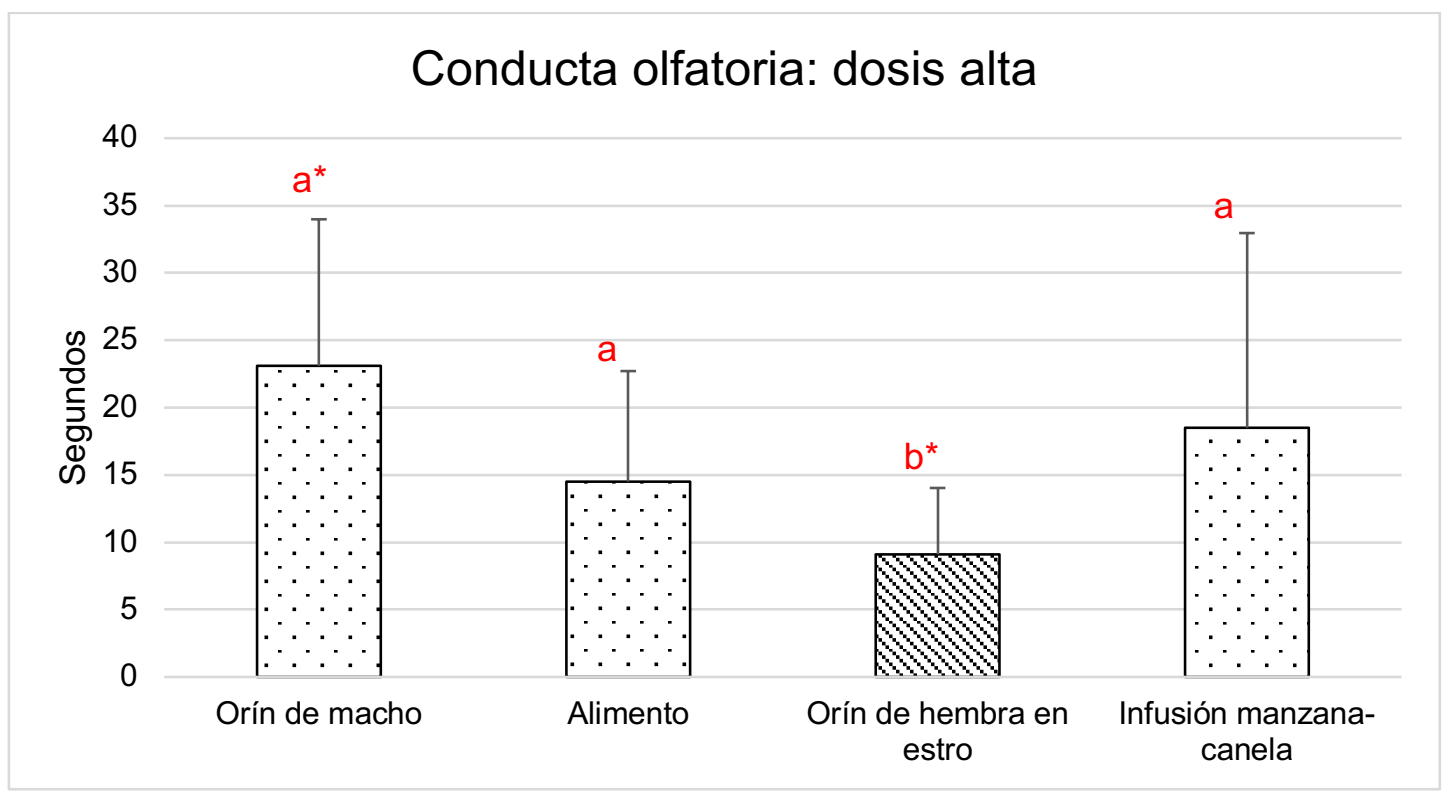

Figura 8. Efecto de la administración de genisteína/daidzeína sobre la conducta olfatoria. Se observa un aumento cercano al doble en la latencia de monta en los animales que recibieron la dosis baja en comparación con los del testigo y de la dosis alta. "a*" diferente de "b*" $(p<0.05)$, luego de aplicar la ANOVA de Kruskall Wallis seguida de la prueba post hoc de Tukey. Se expresa el promedio $\pm D E, n=10$ por grupo. 


\section{Conducta olfatoria entre grupos}

Al analizar la preferencia olfatoria en cada grupo, observamos que el tratamiento con la dosis alta fue el que presentó cambios significativos con relación al grupo testigo y el tratado con la dosis baja. A continuación se comparan las preferencias olfatorias para cada estímulo entre los tres grupos.

Orín de macho

En cuanto al contenedor que contenía el estímulo de orín de macho, se observó una clara preferencia de los machos tratados con la dosis alta, siendo significativamente mayor ( $p<0.01$ ) en comparación con el grupo testigo y la dosis baja (Fig. 9A).

Alimento

De acuerdo con la figura 9B, que corresponde al contenedor del alimento, los machos del grupo testigo y la dosis baja presentaron una preferencia menor por este estímulo, siendo los machos de la dosis alta los que presentaron una preferencia significativamente mayor $(p<0.01)$ en comparación a los otros dos grupos.

Orín de hembra en estro

En relación al contenedor del estímulo de orín de hembra en estro, se observa que los machos del grupo testigo presentaron una preferencia significativamente mayor $(p<0.01)$ en comparación con los grupos tratados, sin embargo, los machos del grupo tratado con la dosis baja presentaron una preferencia menor que el control pero mayor a la que presentaron los animales tratados con la dosis alta. Mientras que los machos de la dosis alta presentaron una preferencia significativamente menor en comparación con la dosis baja $(p<0.05)$, siendo más notoria la diferencia con el grupo testigo $(p<0.01)$ (Fig. 9C). 


\section{Infusión manzana-canela}

Finalmente, para el contenedor con la infusión de manzana-canela, se observó que el grupo testigo y la dosis baja presentaron una menor preferencia, siendo los machos de la dosis alta los que presentaron una preferencia significativamente mayor $(p<0.05)$ con respecto a la dosis baja (Fig. 9D).
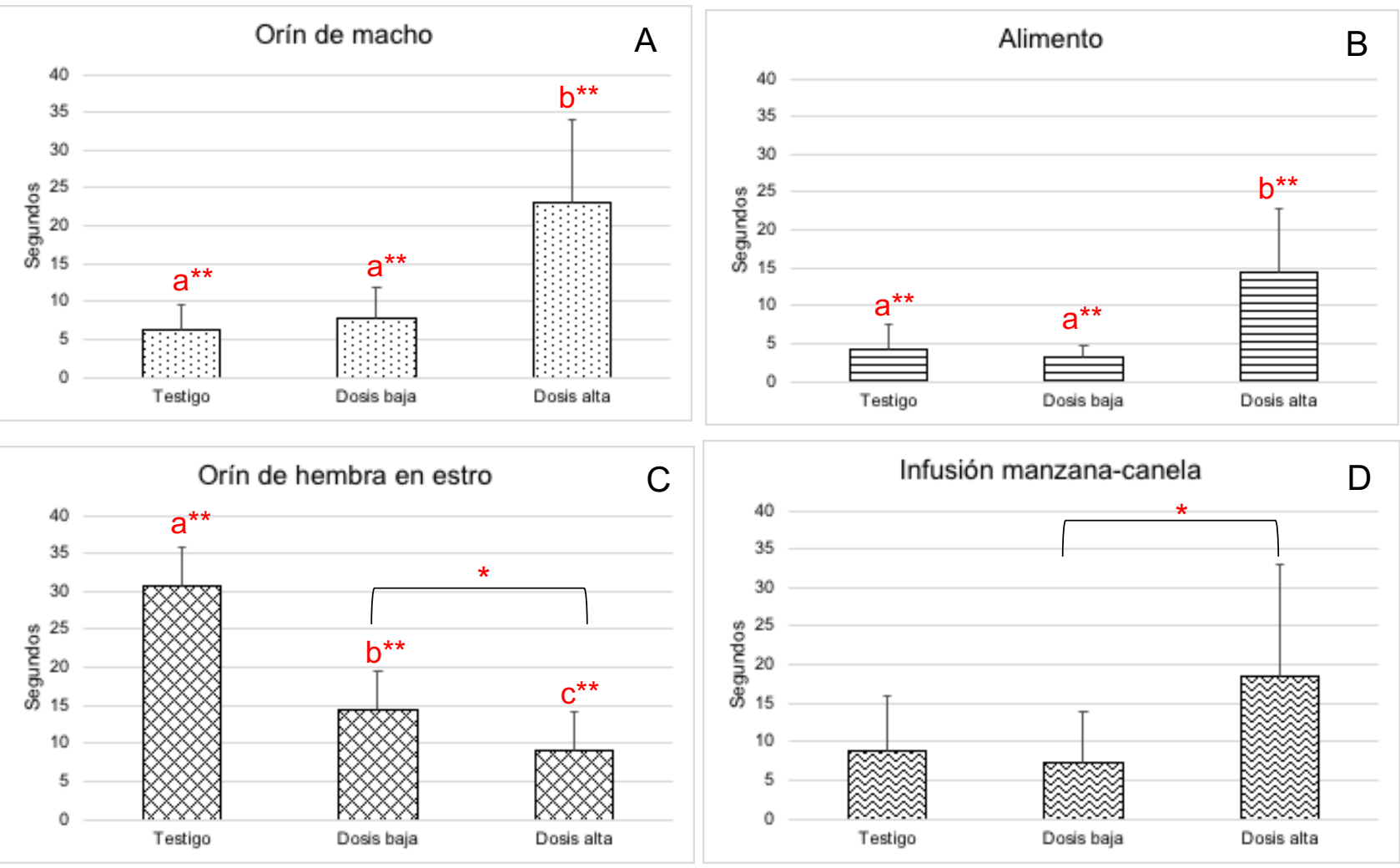

Figura 9. Preferencia olfatoria: promedio $\pm \mathrm{DE}$ del tiempo de permanencia frente a los contenedores que tienen diferentes muestras estímulos. "a*" diferente de " $\mathrm{b}^{*}(p<0.05)$, "a** diferente de " $\mathrm{b}^{* * "}(p<0.01)$, "b" diferente de " ${ }^{*}$ " $(p<0.05)$, " $\mathrm{b}^{* *}$ " diferente de " $\mathrm{c}^{* * "}(p<0.01),{ }^{*}(\mathrm{p}<0.05)$, luego de aplicar el ANOVA de Kruskall-Wallis seguida de la prueba post hoc de Tukey. Promedio $\pm \mathrm{DE}, \mathrm{n}=10$ por grupo. 


\section{Conducta sexual}

Se presentan los datos de la primera serie eyaculatoria, ya que no todos los animales tratados con los fitoestrógenos desplegaron conducta sexual en las siguientes series, por lo que no se presenta el periodo refractario. Para el total de eyaculaciones se muestran los datos recopilados de las cuatro series evaluadas.

\section{Latencia de monta}

Para la latencia de monta, se puede observar que los machos del grupo testigo tuvieron una latencia de monta de $11.74 \pm 5.67 \mathrm{~s}$, la cual fue similar a la dosis alta $11.57 \pm 6.70$ $\mathrm{s}$, mientras que los machos de la dosis baja tuvieron una latencia de monta de 20.57 $\pm 4.72 \mathrm{~s}$, que fue significativamente mayor a la de los grupos testigo y dosis alta $(p<0.05)$ (Fig. 10).

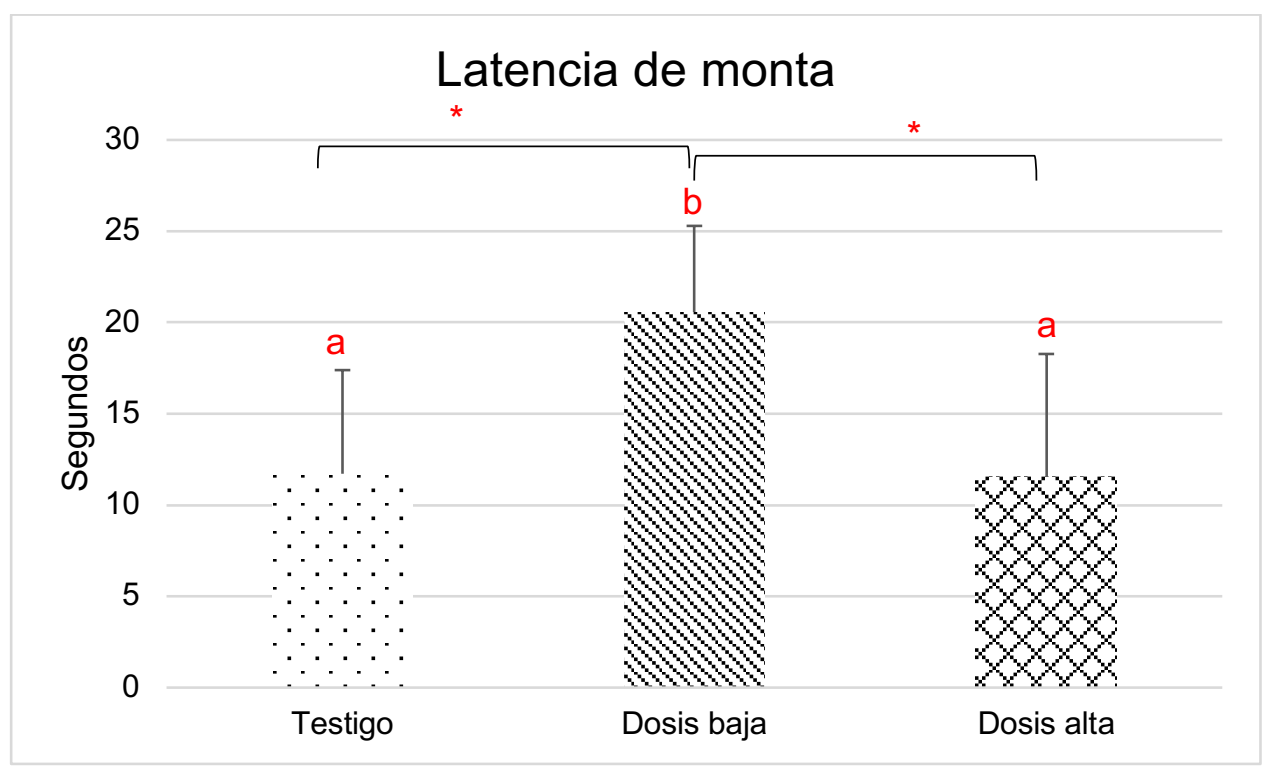

Figura 10. Efecto de la administración de Genisteína/Daidzeína sobre la latencia de monta. Se observa un aumento cercano al doble en la latencia de monta en los animales que recibieron la dosis baja en comparación con los del testigo y de la dosis alta. " ${ }^{*}$ " diferente de " $\mathrm{b}^{*}$ " $(p<0.05)$, luego de aplicar la ANOVA de Kruskall-Wallis seguida de la prueba post hoc de Tukey. Se expresa el promedio \pm DE, $n=7$ por grupo. 


\section{Latencia de intromisión}

En cuanto a la latencia de intromisión, el grupo testigo tuvo una latencia de intromisión promedio de $19.16 \pm 11.78 \mathrm{~s}$ la cual fue significativamente menor $(p<0.05)$ que la dosis baja $35.16 \pm 11.47 \mathrm{~s}$, mientras que la dosis alta tuvo una latencia de intromision de $11.16 \pm 7.83 \mathrm{~s}$ que fue significativamente menor con respecto al grupo testigo $(p<0.05)$ y al grupo de dosis baja $(p<0.01)$ (Fig. 11).

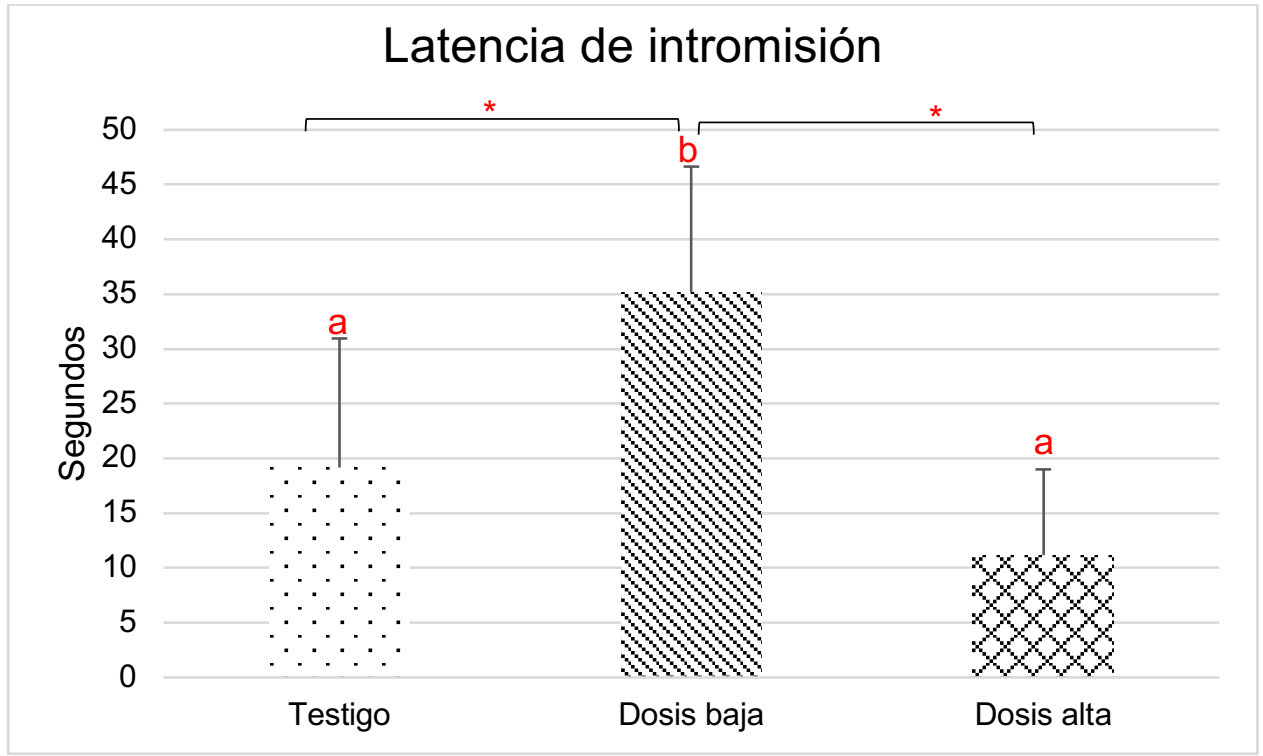

Figura 11. Efecto de la administración de Genisteína/Daidzeína sobre la latencia de intromisiones. Los tres grupos muestran latencias diferentes, siendo mayor en la dosis baja y menor en la dosis alta, con relación al anterior y el testigo. Se observa que los machos de la dosis baja tardaron más tiempo en realizar la primer intromisión. "a*" diferente de " $b$ " $(p<0.05)$, luego de aplicar la ANOVA de KruskallWallis seguida de la prueba post hoc de Tukey. Se expresa el promedio $\pm \mathrm{DE}, \mathrm{n}=7$ por grupo.

\section{Latencia de eyaculación}

Con relación a la latencia de eyaculación observamos que los machos del grupo testigo tardaron 333. $85 \pm 152.94 \mathrm{~s}(3.18-10 \mathrm{~min})$, este tiempo fue significativamente menor $(p<0.05)$ al tiempo que tardaron los animales tratados con la dosis baja $799.14 \pm 310.6$ 
$\mathrm{s}(10.78-23.95 \mathrm{~min})$ y la dosis alta $(p<0.01) 946 \pm 191.73 \mathrm{~s}(14.08-21.80 \mathrm{~min})$ (Fig. 12).

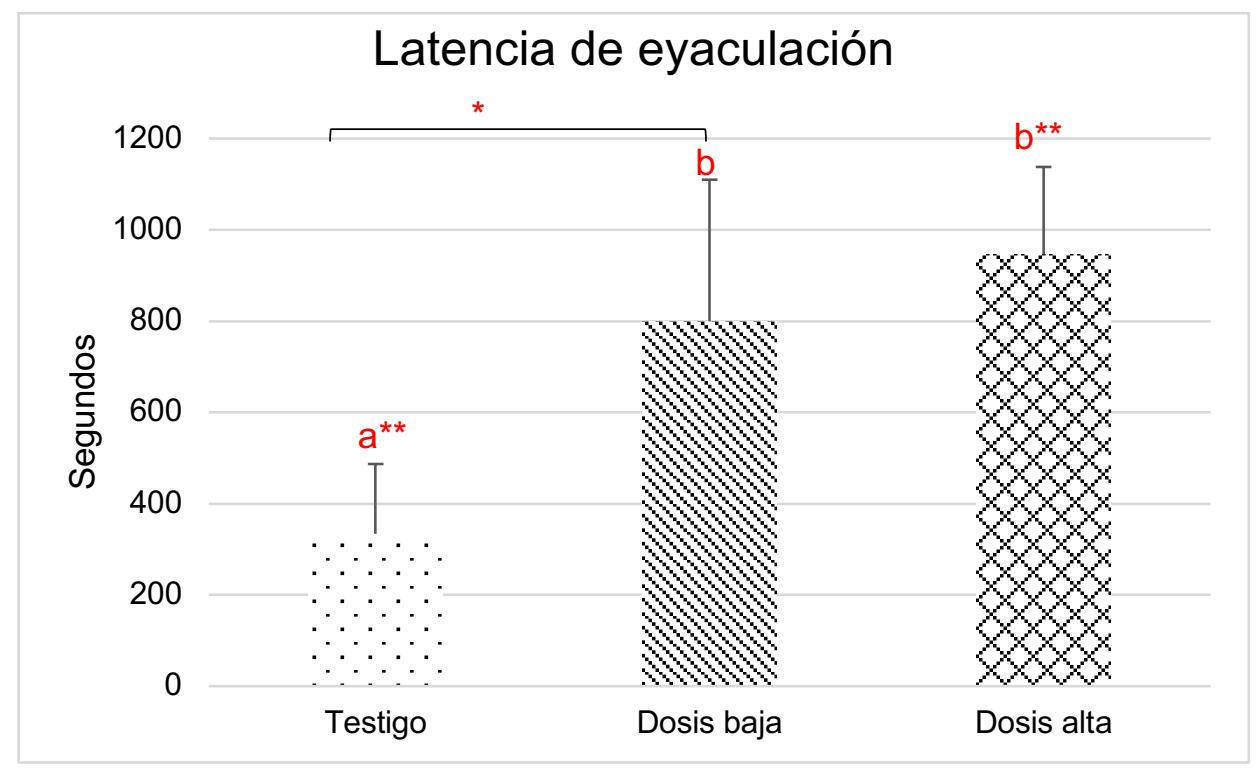

Figura 12. Efecto de la administración de Genisteína/Daidzeína sobre la latencia de eyaculación. Se observa que los machos tratados tardaron más tiempo en realizar la primera eyaculación. "a*" diferente de " $\mathrm{b}^{* "}(p<0.05)$, "a*" diferente de " $\mathrm{b}^{* * "}(p<0.01)$ luego de aplicar la ANOVA de Kruskall-Wallis seguida de la prueba post hoc de Tukey. Se expresa el promedio $\pm \mathrm{DE}, \mathrm{n}=7$ por grupo.

\section{Número de montas}

En el grupo de animales del grupo testigo tuvo en promedio $14.16 \pm 9.08$ montas siendo similar el promedio de montas de los animales de la dosis alta $14.5 \pm 8.87$, mientras que el numero de montas obtenido por los machos de la dosis baja fue de $24.83 \pm 14.07$ montas, el cual fue significativamente diferente al obtenido por el grupo testigo $(p<0.05)($ Fig. 13). 


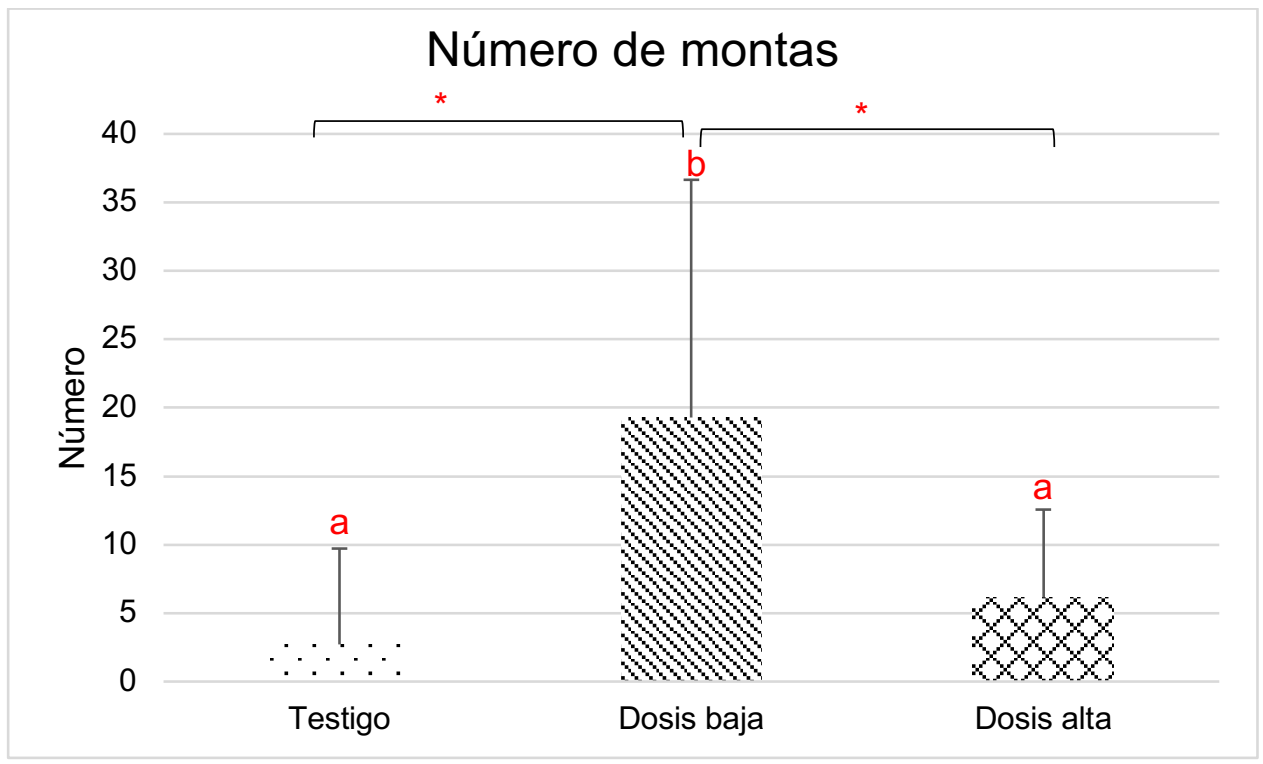

Figura 13. Efecto de la administración de Genisteína/Daidzeína sobre el número de montas. Se observa que los machos de la dosis baja presentaron un mayor número de montas. "a*" diferente de "b*" $(p<0.05)$, luego de aplicar la ANOVA de Kruskall-Wallis seguida de la prueba post hoc de Tukey. Se expresa el promedio $\pm D E, n=7$ por grupo. Promedio $\pm D E, n=7$ por grupo.

\section{Número de intromisiones}

Para el número de intromisiones no se presentaron diferencias significativas entre los grupos; sin embargo, se observa una tendencia a incrementar el número de intromisiones en forma dependiente de la dosis. El grupo testigo presentó un menor número de intromisiones $(10.28 \pm 5.73)$ en comparación con las obtenidas por los grupos de la dosis baja $(15.42 \pm 5.44)$ y alta $(17 \pm 3.46)$ (Fig.14). 


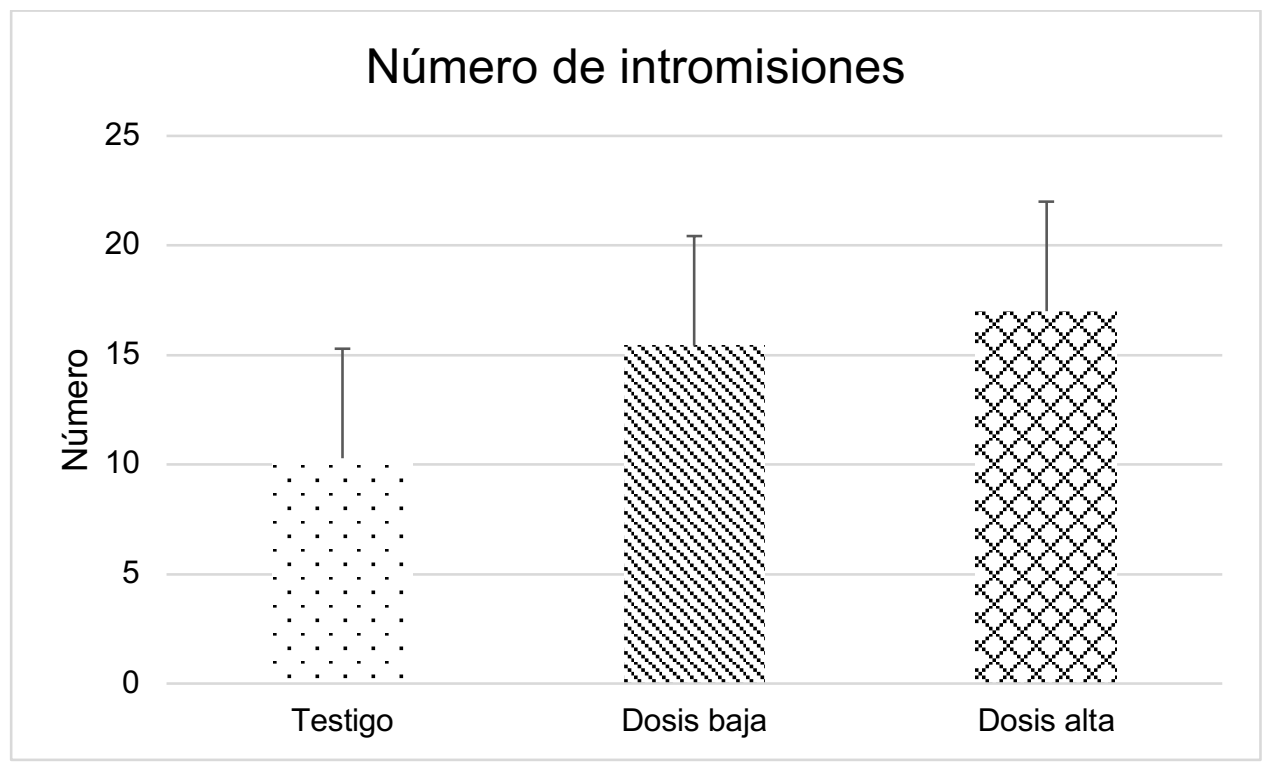

Figura 14. Efecto de la administración de Genisteína/Daidzeína sobre el número de intromisiones. El análisis estadístico no reveló diferencias significativas entre los grupos $(p>0.05)$, mediante la prueba de ANOVA no paramétrica de Kruskal-Wallis y una prueba post hoc de Tukey. Se expresa el promedio $\pm \mathrm{DE}, \mathrm{n}=7$.

\section{Total de eyaculaciones}

Los animales del grupo testigo realizaron de $3-5$ (3.57 \pm 0.78$)$ eyaculaciones en promedio durante los 30 minutos que duró la prueba, siendo significativamente mayor al obtenido por el grupo de la dosis baja $(p<0.01)$ que presentaron de $1-2(1.14 \pm$ $0.69)$ eyaculaciones y al de la dosis alta $(p<0.01)$ que también tuvieron de $1-2$ eyaculaciones (1.57 \pm 0.53$)$ (Fig. 15). 


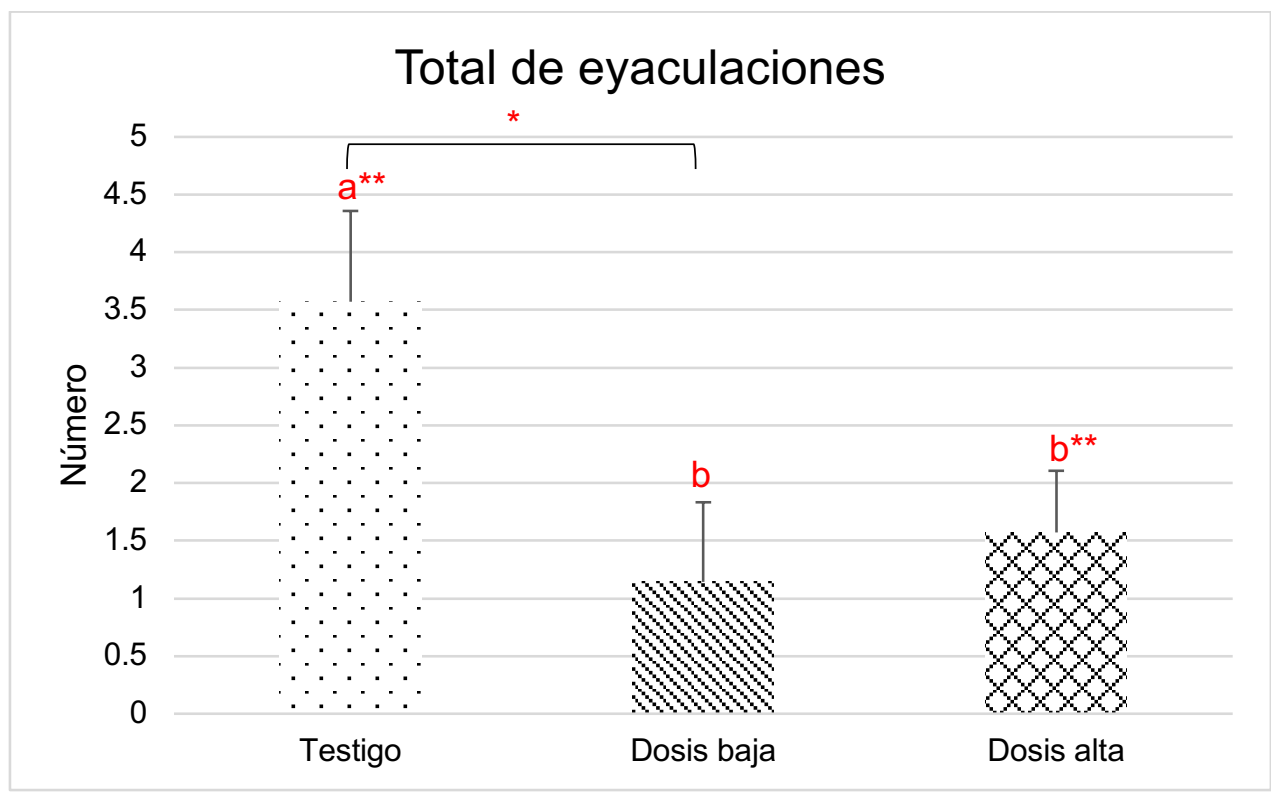

Figura 15. Efecto de la administración de Genisteína/Daidzeína sobre el total de eyaculaciones. "a*” diferente de " $\mathrm{b}^{* \prime}(p<0.05)$, "a**" diferente de " $\mathrm{b}^{\star * " ~}(p<0.01)$ luego de aplicar la ANOVA de Kruskall-Wallis seguida de la prueba post hoc de Tukey. Se expresa el promedio $\pm \mathrm{DE}, \mathrm{n}=7$ por grupo.

\section{Hit rate}

En cuanto al hit rate o eficiencia copulatoria, se observa que tanto el grupo tratado con testigo como el de la dosis alta tuvieron buena eficiencia copulatoria, siendo de $0.8 \pm$ 0.10 para el testigo y $0.77 \pm 0.10$ para la dosis alta. Los machos de la dosis baja presentaron una menor eficiencia copulatoria, $(0.48 \pm 0.17)$, la cual fue significativamente menor $(p<0.01)$ en relación a la obtenida por los otros dos grupos (Fig. 16). 


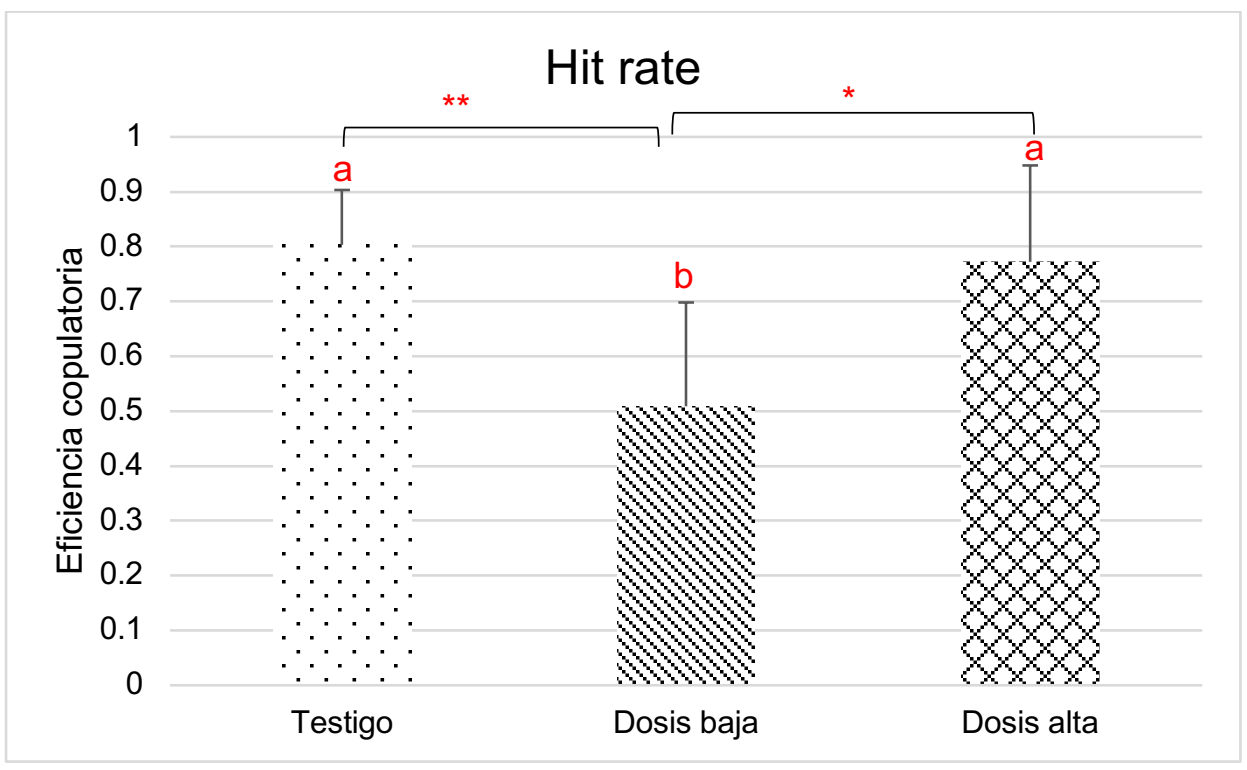

Figura 16. Efecto de la administración de Genisteína/Daidzeína sobre el Hit rate, siendo el grupo testigo y la dosis alta con la mejor eficiencia copulatoria. " $a^{* * "}$ diferente de " $b^{* * "}(p<0.01)$, "a*" diferente de "b*" $(p<0.05)$ luego de aplicar la ANOVA de Kruskall-Wallis seguida de la prueba post hoc de Tukey. Se expresa el promedio $\pm \mathrm{DE}, \mathrm{n}=7$ por grupo.

\section{Conducta de agresión}

\section{Conducta ofensiva}

En relación a la conducta ofensiva los machos del grupo testigo presentaron de 5 a 10 ataques $(7.8 \pm 1.92)$ durante la prueba, y estos valores fueron significativamente diferentes $(p<0.05)$ a los ataques presentados por los machos de las dosis bajas (12.2 \pm 2.86 , rango $9-16)$ y alta $(12.2 \pm 2.86$, rango $9-16)$. Se considera que este último grupo presentó una conducta de tipo "social", al intentar en varias ocasiones olfatear al macho residente, la cual fue una conducta opuesta a la de tipo "agresiva" que presentaron los animales de la dosis baja (Fig. 17). 


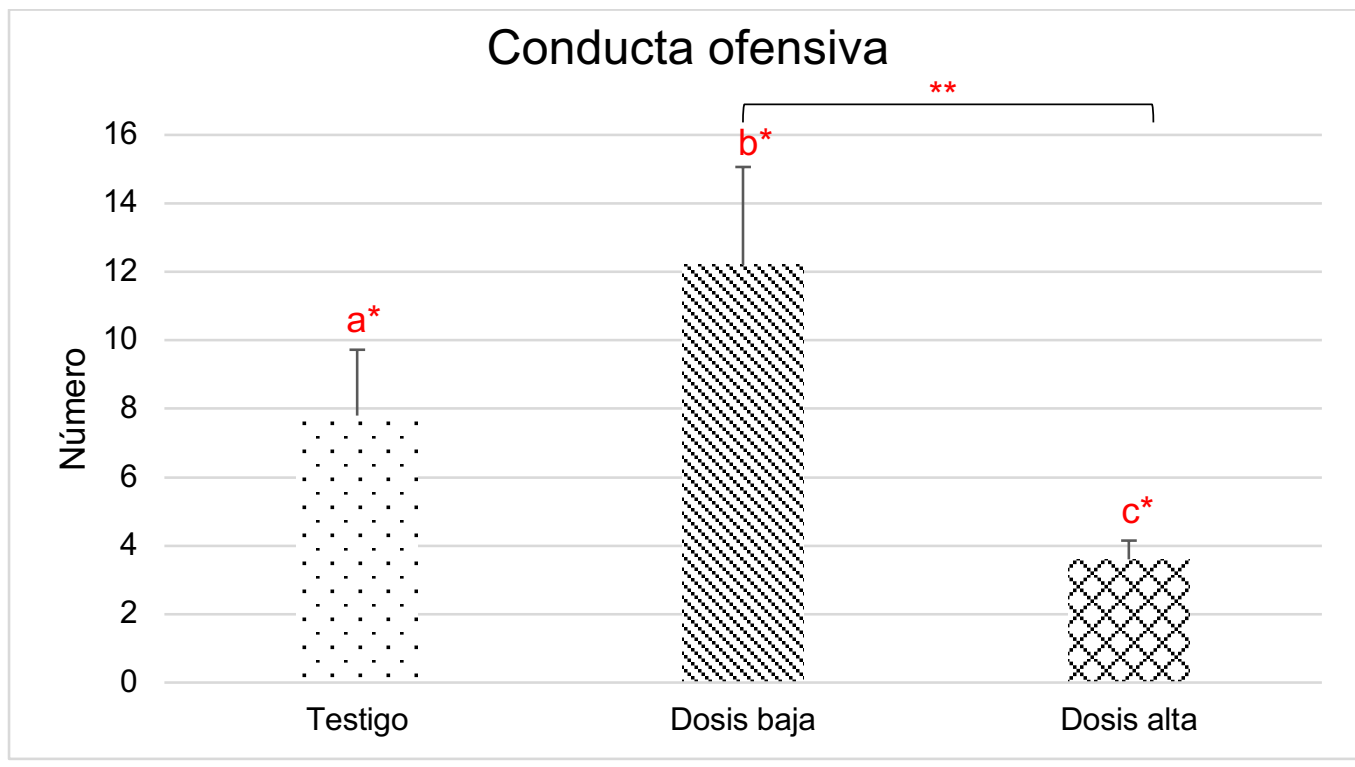

Figura 17. Efecto de la administración de Genisteína/Daidzeína sobre la conducta ofensiva. Los machos de la dosis baja presentaron un número mayor de ataques ofensivos en comparación con los machos de la dosis alta y los tratados con testigo. "a*" diferente de " $\mathrm{b}^{*}$ " $(p<0.05)$, "a*" diferente de " $\mathrm{c}^{*}$ " $(p<0.05)$, " $\mathrm{b}^{\star *}$ " diferente de "c**" luego de aplicar la ANOVA de Kruskall-Wallis seguida de la prueba post hoc de Tukey. Se expresa el promedio $\pm \mathrm{DE}, \mathrm{n}=5$ por grupo.

\section{Conducta defensiva}

Los resultados obtenidos de la conducta defensiva se muestran en la figura 18. La conducta defensiva en el caso de los machos del grupo testigo fue nula, mientras que fue escasa en los machos tratados con la dosis baja, en comparación con los machos de la dosis alta $(p<0.01)$, los cuales presentaron mayor número de respuestas defensivas $2-3(2.4 \pm 0.54)$ y permanecieron en conducta de congelamiento por tiempo prolongado. 


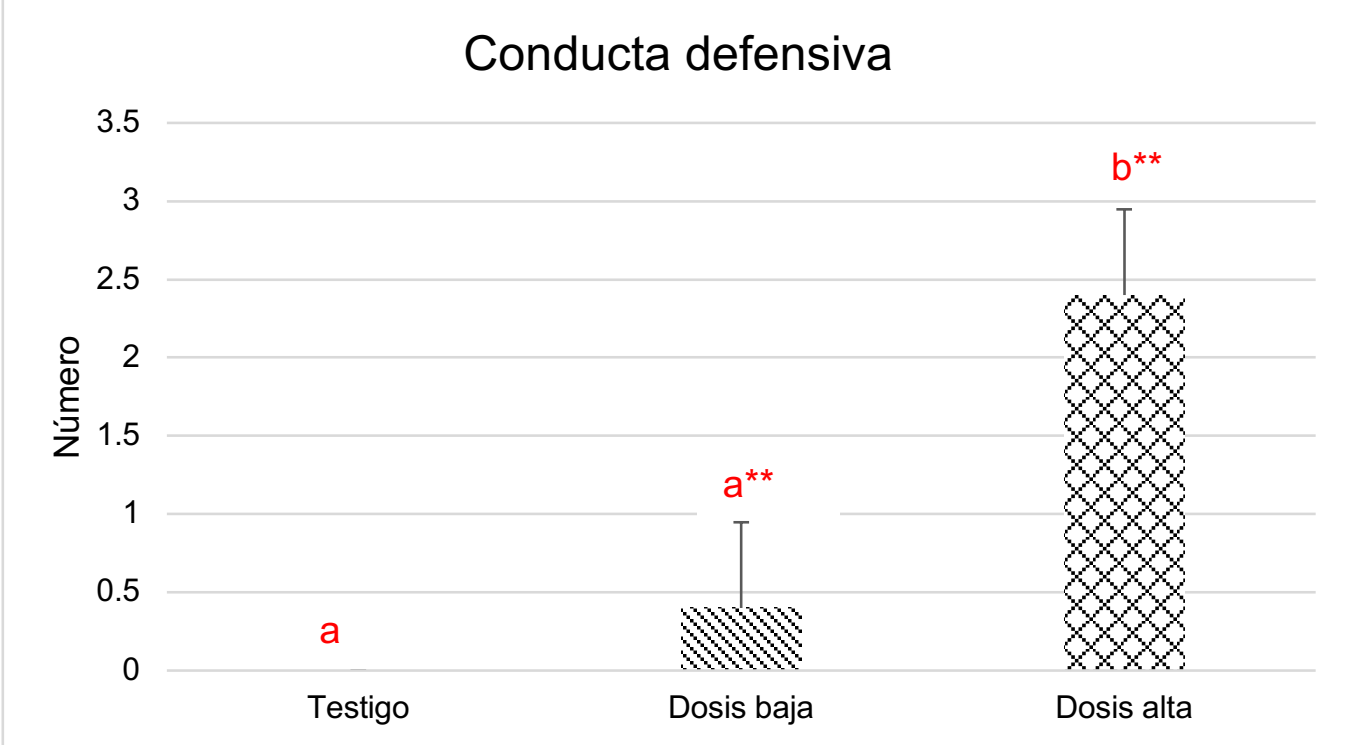

Figura 18. Efecto de la administración de Genisteína/Daidzeína sobre la conducta defensiva. Se observa que los machos de la dosis alta presentaron un mayor número de defensas. "a*" diferente de "b*" $(p<0.05)$, luego de aplicar la ANOVA de Kruskall-Wallis seguida de la prueba post hoc de Tukey. Se expresa el promedio $\pm \mathrm{DE}, \mathrm{n}=5$ por grupo.

\section{Análisis espermático}

Los resultados del efecto de la administración de genisteína/daidzeína sobre los parámetros obtenidos del análisis espermático se presentan en la Tabla 1. Los resultados muestran una disminución significativa $(p<0.05)$ de la concentración espermática en el grupo tratado con la dosis baja y los grupos testigo y dosis alta, este mismo efecto se muestra en la viabilidad y en los parámetros de inmadurez de los espermatozoides.

En relación con la morfología no se encontraron diferencias estadísticamente significativas $(p>0.05)$ entre los grupos tratados y el testigo, siendo un porcentaje muy bajo de anormalidades para los tres grupos, de igual manera que en el parámetro del daño al ADN. 
Tabla 1. Efecto de la administración de Genisteína/Daidzeína en los parámetros de calidad espermática.

\begin{tabular}{|c|c|c|c|}
\hline \multirow[b]{2}{*}{ Parámetro } & \multirow[b]{2}{*}{ Testigo } & \multicolumn{2}{|c|}{ Dosis } \\
\hline & & Baja & Alta \\
\hline $\begin{array}{l}\text { Concentración espermática } \\
\left(\times 10^{6} / \mathrm{mL}\right)\end{array}$ & $121.8 \pm 87.9$ & $101.16 \pm 72.0$ & $121.8 \pm 49.1$ \\
\hline \multicolumn{4}{|l|}{ Viabilidad (\%) } \\
\hline $\begin{array}{l}\text { Vivos } \\
\text { Muertos }\end{array}$ & $\begin{array}{l}97 \pm 3.0^{\mathrm{a}^{*}} \\
3 \pm 3.0^{\mathrm{a}^{*}}\end{array}$ & $\begin{array}{l}87 \pm 7.0^{\mathrm{a}} \\
13 \pm 7.0^{\mathrm{a}}\end{array}$ & \begin{tabular}{|l}
$94.6 \pm 4.1^{b^{*}}$ \\
$5.3 \pm 4.1^{b^{*}}$
\end{tabular} \\
\hline \multicolumn{4}{|l|}{ Morfología (\%) } \\
\hline Normales & $99.4 \pm 0.8$ & $99.1 \pm 1.5$ & $99.5 \pm 0.8$ \\
\hline Anormales & $0.6 \pm 0.8$ & $0.8 \pm 1.5$ & $0.5 \pm 0.8$ \\
\hline \multicolumn{4}{|l|}{ Compactación de ADN (\%) } \\
\hline Maduros & $96.6 \pm 6.0$ & $76.1 \pm 13.3$ & $83.0 \pm 7.6$ \\
\hline Inmaduros & $3.4 \pm 6.0^{b^{* *}}$ & $23.8 \pm 13.3^{a}$ & $17 \pm 7.0^{\mathrm{b}^{* *}}$ \\
\hline Daño a ADN (\%) & & & \\
\hline Sin daño & 100 & $95.6 \pm 10.4$ & $91.2 \pm 21.4$ \\
\hline Con daño & 0 & $4.3 \pm 10.4$ & $8.7 \pm 21.4$ \\
\hline
\end{tabular}

Los datos se expresan como la media $\pm D E(n=6)$.

"a" diferente de "b*" $(p<0.05)$, "a*" diferente de "b**" $(p<0.01)$, luego de aplicar la ANOVA de KruskallWallis seguida de la prueba post hoc de Tukey. 


\section{Índice de gestación}

Los resultados obtenidos para el índice de gestación muestran que todas las hembras de las unidades reproductivas de los machos tratados con el testigo y la dosis alta quedaron gestantes. Los machos que recibieron la dosis baja únicamente gestaron al $25 \%$ de las hembras (Fig. 19).

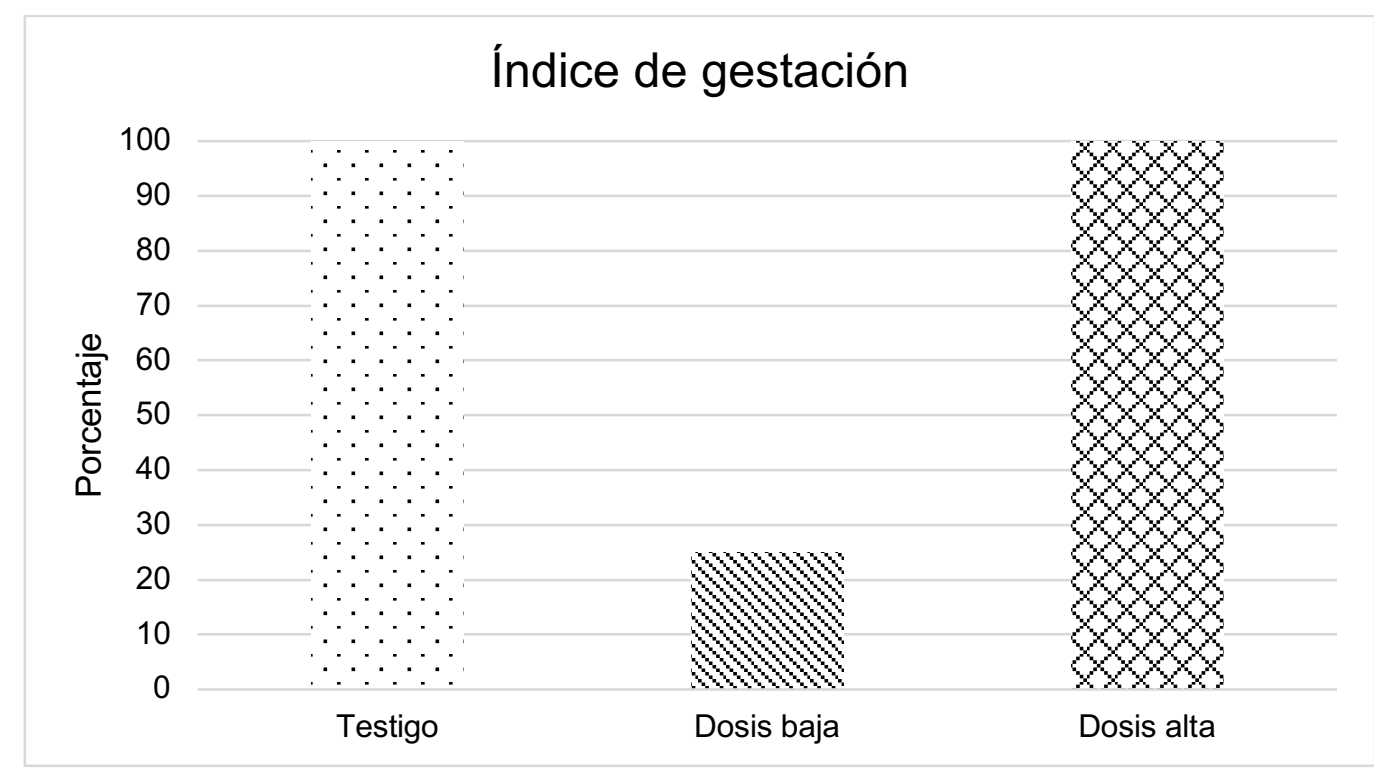

Figura 19. Efecto de la administración de Genisteína/Daidzeína sobre el índice de gestación. Se observa una reducción en el número de hembras gestantes para los machos que fueron tratados con la dosis baja, $n=8$ por grupo. 


\section{Fertilidad}

En cuanto a la fertilidad únicamente se compara por el número de hembras gestantes y no por el total, ya que no todas las hembras de la dosis baja quedaron gestantes. Las hembras cruzadas con los machos tratados con testigo tuvieron en promedio 12.2 \pm 2.10 crías, las hembras cruzadas con los machos de las dosis baja $(p<0.01)$ y alta $(p<0.05)$ tuvieron un menor número de crías, con relación al testigo. En la dosis baja el promedio de crías fue de $0.42 \pm 1.13$ y para la dosis alta de $7.62 \pm 1.99$ este último mayor a la dosis baja pero menor al testigo (Fig. 20).

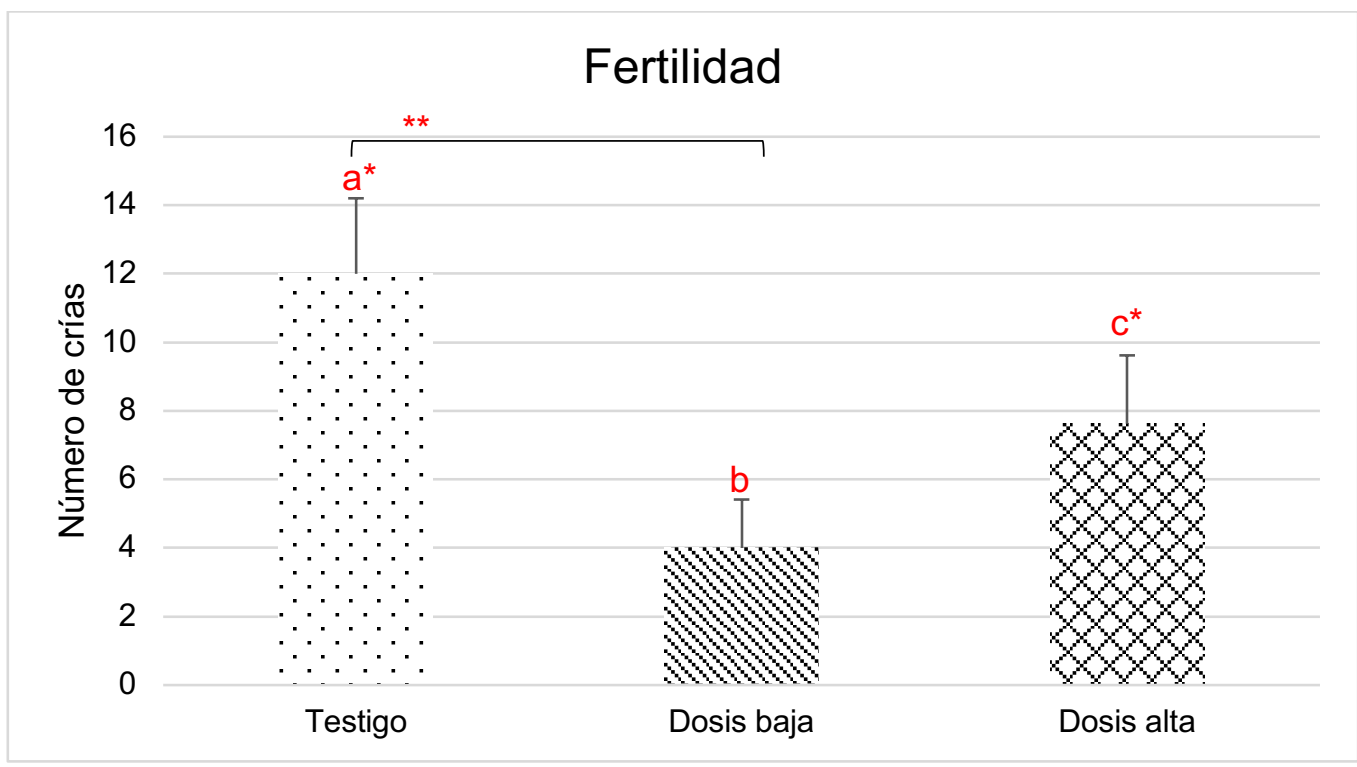

Figura 20. Efecto de la administración de Genisteína/Daidzeína sobre la fertilidad. Se muestra el número de crías por tratamiento, siendo la dosis baja la que presentó el menor número. "a*" diferente de "b*" $(p<0.05)$, "a**" diferente de "b**" $(p<0.01)$, luego de aplicar la ANOVA de Kruskall-Wallis seguida de la prueba post hoc de Tukey. Se expresa el promedio $\pm \mathrm{DE}$. 


\section{DISCUSIÓN}

Los resultados obtenidos en el presente trabajo confirman que los efectos inducidos por fitoestrógenos van a depender tanto de la dosis administrada como el parámetro que se esté evaluando. Estudios reportados en la literatura, en los cuales se han administrado en diferentes esquemas y dosis Genisteína y/o Daidzeína muestran una gran variedad de resultados que van desde alteraciones y anomalías en el desarrollo (Delclos et al., 2001; Atanassova et al., 2000; Henry y Witt, 2006; Cederroth et al., 2010), hasta trabajos en los cuales se reporta que no tuvieron ningún efecto (Takagi et al., 2004; Nagao et al., 2001). Mientras que en el presente estudio se demostraron anomalías en los parámetros estudiados como los parámetros conductuales, espermáticos y de fertilidad.

La etapa neonatal en la rata macho es crítica para los procesos de diferenciación y desarrollo tanto del cerebro como del aparato reproductor. El octavo día postnatal es un periodo crítico en roedores para la diferenciación sexual de los circuitos neurales, ya que los estrógenos exógenos previenen la masculinización de la conducta sexual y la desfeminización. Se sugiere que esto se puede presentar al competir con el estradiol sintetizado endógenamente $\mathrm{o}$ al inhibir la producción de andrógenos testiculares (Whitten et al., 1994). Estos procesos de diferenciación en etapa neonatal pueden manifestarse en el adulto por alteraciones en las conductas sociales y sexuales, así como en parámetros reproductivos (Wisniewski et al., 2005).

Una de las primeras conductas que se evaluaron en el presente trabajo fue la conducta olfatoria. Los machos del grupo testigo presentaron una clara preferencia por el contenedor que tenia orín de hembra en estro. Una característica de los machos de este grupo fue que cuando identificaron el olor del orín de la hembra, permanecieron ahí e incluso se querían llevar dicho contenedor. Sin embargo, en el caso de los machos del grupo tratado con la dosis alta, a pesar de no mostrar una aparente preferencia olfatoria, se observó que el tiempo que pasaron en el contenedor que contenía el estímulo de orín de macho fue significativamente mayor al de los demás. 
Asimismo, cuando se realizaron las pruebas de conducta sexual estos machos respondieron de mejor forma que el grupo de la dosis baja, por lo que podría sugerirse que estos machos no presentan una preferencia sexual clara.

Desde 1977, Birch propuso al olfato como uno de los mecanismos más importantes de comunicación, ya que provee a los individuos la información necesaria sobre la presencia de alimento, de un individuo del sexo opuesto para reproducirse o del mismo sexo para agredirlo. Las principales señales son de tipo químico. En los mamíferos se han desarrollado sistemas específicos que permiten discriminar las diferentes señales (Díaz y cols. 1998) los cuales se consideran especie-específicas y pueden promover respuestas conductuales e incluso endocrinas.

Jones y Nowell (1974) propusieron que la orina es una fuente importante de señales la cual individuos conespecíficos pueden transmitir señales sexuales, que pueden activar una serie de respuestas conductuales tanto en macho como en la hembra. El órgano responsable de captar estas señales es el vomeronasal, el cual se relaciona con los procesos de diferenciación y organización neural de las vías que regulan las conductas sexuales dimórficas; en estos procesos de diferenciación se encuentran involucrados los esteroides sexuales (Segovia y Guillamón, 1993).

El análisis histológico del órgano vomeronasal en machos bajo el mismo esquema y dosis de administración del presente trabajo reveló que tanto la dosis baja como la alta inducen cambios en la morfología lo cual explica el que no se presente una preferencia olfatoria (manuscrito en proceso).

En un trabajo previo realizado en nuestro laboratorio en el cual se administró neonatalmente Genisteína, Daidzeína y la combinación de ambas y se realizó el análisis morfométrico del testículo, se observó que la genisteína inducia un efecto estrogénico en la mayoría de los parámetros analizados, Daidzeína por sí sola en la misma concentración de Genisteína no indujo cambios significativos. Sin embargo, el efecto sinérgico de los dos fitoestrógenos indujo el mayor número de cambios en todos los parámetros y en general contrarios a los de Genisteína sola (Ramírez, 2006). 
Cuando se relaciona la conducta olfatoria con la conducta sexual, se observa que los machos tratados con la dosis baja tuvieron una mayor latencia de monta ya que tardaron más tiempo en identificar a la hembra receptiva, aparentemente los machos tratados con la dosis alta tuvieron menor latencia de monta lo que sugiere que a pesar de tener mayor dificultad que los de la dosis baja en discriminar entre los olores, pudieron identificar más rápidamente a la hembra receptiva aunque es importante mencionar que a lo largo de las pruebas realizadas se pudo observar que los machos de la dosis alta necesitaban olfatear el área genital de la hembra cada vez que iban a realizar una monta o intromisión lo cual se observaba en los otros machos cuando se les cambiaba la hembra o de manera esporádica.

A pesar de que los machos de la dosis alta muestran una dificultad en identificar los olores, tuvieron mayor facilidad incluso que el grupo testigo para realizar la primera intromisión. Los machos tratados con la dosis baja tardaron más tiempo que los otros dos grupos en poder realizar una intromisión y requirieron mayor número de montas para alcanzar un umbral excitatorio y poder eyacular. Esto se refleja en los valores de Hit rate en los cuales se observa que la tasa de acierto o eficiencia copulatoria fue mejor en los animales tratados con el testigo o dosis alta. Sin embargo, se observa que el total de eyaculaciones realizados por los animales de ambos grupos experimentales son menores a los del grupo tratado con el testigo.

Rodriguez-Gomez (et al., 2014) reportaron que la administración de dos dosis de genisteína (5 y $100 \mu \mathrm{g}$ ), del día 11 de gestación al 8 postparto a ratones CD1, induce una disminución en las latencias de monta, intromisión en comparación con el testigo, sin presentarse eyaculaciones.

Por otro lado, Wisniewski y cols. (2003) reportan que la administración de genisteína (5 o $300 \mathrm{mg} / \mathrm{Kg}$ ) durante todo el periodo gestacional presentó una disminución en las latencias de monta e intromisión con respecto al testigo, asimismo un menor número de montas e intromisiones, donde los machos tratados tampoco presentaron eyaculaciones durante el estudio. 
De manera contraria, estudios realizados con $20 \mu \mathrm{g}$ de Genisteína administrada durante el periodo neonatal, reportaron que los animales tratados presentaron múltiples eyaculaciones (10) en comparación con el testigo (Csaba y Karabélyos, 2002); mientras que Morales-Otal y cols. (2016), reportaron un efecto donde la administración de $50 \mu \mathrm{g}$ de Genisteína neonatal facilita la conducta sexual.

Los resultados anteriores abarcan dos etapas del desarrollo (etapa gestacional y neonatal) y únicamente se realizó la administración de Genisteína. En ambos estudios en los cuales se administró genisteína sola durante la etapa neonatal la induce un efecto facilitador de la conducta sexual, sin embargo, lo que se observa cuando se administra Genisteína junto con Daidzeína es que este efecto se pierde. Esto podría deberse a que la menor potencia estrogénica de la Daidzeína con relación a la genisteína, podría estar modificando la respuesta estrogénica inducida sólo por Genisteína la cual también se pudiera ver modificada por el efecto de la Daidzeína.

En cuanto a los estudios realizados con alimento de soya, Cardoso y Báo (2009) administraron durante el periodo perinatal a la lactancia a conejos tres diferentes dietas: dieta testigo (libre de soya y alfalfa), dieta libre de soya y alfalfa suplementada con $10 \mathrm{mg} / \mathrm{Kg} / \mathrm{día}$ de isoflavonas y $20 \mathrm{mg} / \mathrm{Kg} /$ día de isoflavonas, dieta con $18 \%$ de carne de soya. En cuanto a la conducta sexual, no reportaron diferencias con respecto al testigo.

Otras de las conductas evaluadas en el presente estudio fue la conducta de agresión, en la cual se observó que los machos administrados con la dosis baja, presentaron una conducta ofensiva incluso mayor que la que presentan los machos tratados con testigo en contraposición los machos tratados con la dosis alta, quienes presentaron conducta defensiva que no fue observada en los machos inyectados con testigo y fue muy escasa en los de la dosis alta, llegando incluso a permanecer congelados por tiempo prolongado.

Wisniewski y colaboradores (2005), administraron Genisteína durante la etapa perinatal (5 y $300 \mathrm{mg} / \mathrm{Kg}$ ) y analizaron la conducta de agresión, observando que los 
animales administrados con la dosis de $5 \mathrm{mg} / \mathrm{Kg}$ participaron más en las conductas defensivas, a comparación de la dosis de $300 \mathrm{mg} / \mathrm{Kg}$, que exhibieron un mayor número de ataques ofensivos, este trabajo sugiere que a mayor dosis de Genisteína mayor conducta defensiva y viceversa a menor dosis de Genisteína mayor conducta defensiva. En el presente estudio, se observaron resultados contrarios a los propuestos por Wisniewski (2005), esto puede deberse como en el caso de la conducta sexual que se están administrando dos fitoestrógenos con potencias estrogénicas diferentes y con capacidad de uno de ellos también puede actuar como antiandrógeno lo cual modificaría los procesos de diferenciación sexual cerebral normales. Esto lleva a sugerir la hipótesis que los machos que recibieron la dosis alta de Genisteía con Daidzeína, no se desfeminizaron en algunas áreas del cerebro. En roedores la masculinización y desfeminización del cerebro se da durante el periodo postnatal. De este modo, la masculinización y desfeminización del cerebro se afecta por la administración de Genisteína, que es capaz de inhibir a las enzimas aromatasa y $5 \alpha$ esteroide reductasa, necesarias para el metabolismo de los andrógenos y estrógenos, así como su unión con sus receptores (Fritz et al., 2003; Weber et al., 1999).

Es importante mencionar que al parecer las áreas que regulan la conducta sexual así como la conducta de agresión, si bien ambas son dependientes de hormonas esteroides para su diferenciación, los resultados observados sugieren que la presencia o distribución de los receptores de estrógenos y andrógenos es diferente en las áreas que determinan cada una de estas conductas, por lo que la cantidad administrada de cada uno de los fitoestrógenos influye en los procesos de masculinización/desfeminización.

A pesar de que se observaron cambios en las conductas sexuales y de agresión en los animales tratados, no se esperaba que los animales tratados con la dosis alta, que a pesar del bajo número de eyaculaciones que presentaron por prueba, obtuvieran un $100 \%$ similar al del grupo tratado con el testigo y mayor que la dosis baja, sin embargo, al evaluar el número de crías se observó que en ambos tratamientos independientemente del índice gestacional, la fertilidad es muy baja. 
En un estudio realizado por Nagao (et al., 2001) con diferentes dosis de Genisteína $(12.5,25,50$ y $100 \mathrm{mg})$ administrados a ratas durante los primeros cinco días postnatales, no encontraron efectos adversos en la fertilidad. Mientras que en un estudio realizado del día uno gestacional al 21 postnatal, con administración de Genisteína (1 mg/Kg y $10 \mathrm{mg} / \mathrm{Kg}$ ), se encontró una disminución en el número de camada de ambas dosis (siete crías) a comparación del testigo (13 crías) (Whitten et al., 2002).

En contraste, Cederroth (et al., 2010), que administraron a ratones CD1 adultos, tres semanas antes del apareamiento, una dieta baja y alta de Genisteína con Daidzeína (335 ppm y 389 ppm, respectivamente), encontraron una reducción en la fertilidad del $21 \%$ en la dieta alta.

Los resultados obtenidos de fertilidad se pueden relacionar parcialmente con los datos obtenidos en el análisis espermático, en el cual se encontró una disminución el número de espermatozoides vivos y maduros en mayor porcentaje en la dosis baja que en la alta y un incremento en el porcentaje (aunque no por mucho) de espermatozoides que presentaron daño en el DNA mayor en la dosis alta que en la baja. Estas alteraciones pueden explicar parcialmente la baja fertilidad observada en los animales tratados. Asimismo, se sabe que la madurez de la cromatina del espermatozoide es esencial para la capacidad de fertilización de este, ya que, durante la espermiogénesis, el núcleo es completamente reorganizado y pasa por una característica compactación. Esta condensación de la cromatina incluye un reemplazo de histonas por proteínas de transición y después por proteínas básicas denominadas protaminas. Estas protaminas empaquetan fuertemente el ADN nuclear en cromatina altamente condensada; de hecho, el núcleo espermático tiene una importante estabilidad mecánica y química (Hou et al., 1995). Anormalidades en la condensación de la cromatina pueden causar daños en el ADN como desnaturalización y fragmentación asociado con infertilidad masculina (Agarwal, 2003), como se refleja en el presente estudio, evidenciado por el bajo índice gestacional y el número de crías en las hembras de la dosis baja, con respecto al testigo y la dosis alta. 
De acuerdo con estudios reportados por Cardoso y Báo (2009) y por Fielden y colaboradores (2003), que evaluaron los efectos en la concentración espermática mediante de la administración tanto de soya y de Genisteína $(0.1,0.5$ y $10 \mathrm{mg} / \mathrm{Kg} / \mathrm{d})$ en etapa gestacional a lactancia no encontraron cambios en el número de espermatozoides de los grupos tratados con respecto al testigo. En el presente estudio al evaluar este parámetro no se observaron diferencias entre los grupos tratados y el testigo. 


\section{CONCLUSIONES}

En el presente estudio se comprobó que el efecto de los fitoestrógenos durante la etapa neonatal, dependen de la dosis y del parámetro analizado.

Los efectos de los fitoestrógenos fueron contrarios en los parámetros conductuales como conducta olfatoria, sexual y de agresión.

Por último, se encontraron efectos similares en los tratamientos administrados, tanto en la fertilidad y el índice de gestación, reflejados en la disminución del número de crías. 


\section{BIBLIOGRAFÍA}

Abbiramy V.S., y Shanthi, V. 2010. Spermatozoa Segmentation and Morphological Parameter Analysis Based Detection of Teratozoospermia. International Journal of Computer Applications. 3(7), 19-23.

Abdi, F., Alimoradi, Z., Haqi, P., y Mahdizad, F. 2016. Effects of phytoestrogens on bone mineral density during the menopause transition: a systematic review of randomized, controled trials. Climacteric: The Journal of the International Menopause Society. 19(6): 535-545.

Adgent, M. A., Daniels, J. L., Edwards, L. J., Siega-Riz, A. M., y Rogan, W. J. 2011. Early-Life Soy Exposure and Gender-Role Play Behavior in Children. Environmental Health Perspectives, 119(12), 1811-1816.

Adlercreutz, H., y Mazur, W. 1997. Phyto-oestrogens and Western Diseases. Annals of Medicine. 29(2): 95-120.

Agarwal, A. 2003. Role of sperm chromatin abnormalities and DNA damage in male infertility. Human Reproduction Update, 9(4), 331-345.

Agmo, A. 1997. Male rat sexual behavior. Brain Research. Brain Research Protocols, 1(2), 203-209.

Allen, L.S., Hines, M., Shryne, J.E., y Gorski, R.A. 1989. Two sexually dimorphic cell groups in the human brain. J.Neurosci. 9: 497-506.

Almstrup, K., Fernández, M., Petersen, J. Olea., N. Skakkebaek, N., y Leffers, H. 2002.

Dual effects of phytoestrogens result in u-shaped dose-response curves. Environmental health perspectives. 110:743-748. 
Andersson, A., Toppari, J., Haavisto, A., Petersen, J., Simell, T., y Simell, O. 1998. Longitudinal reproductive hormone profiles in infants: peak of inhibin $B$ levels in infant boys exceeds levels in adult men. J Clin Endocr Metab. 83(2):675-681.

Andres, A., Cleves, M., Bellando, J., Pivik, R., Casey, P., y Badger, T. 2012. Body fat and bone mineral content of infants fed breast milk, cow's milk formula, or soy formula during the first year of life. J Pediatr. $129: 1134-40$

Arenas-Ríos, E., León-Galván M. A., Mercado, M. A., y Rosado., A. 2005. Superoxide dismutase, catalase, and glutathione peroxidase during epididymal maturation and prolonged storage of spermatozoa in the Mexican big-eared bat (Corynorhinus mexicanus). Canadian Journal of Zoology. 83: 1556-1565.

Atanassova, N., Mckinnell, C., Turner, K. J., Walker, M., Fisher, J. S., Morley, M., Millar, M. R., Groome, N. P., y Sharpe, R. M. 2000. Comparative effects of neonatal exposure of male rats to potent and weak (environmental) estrogens on espermatogenesis at puberty and the relationship to adult testis size and fertility: evidence for stimulatory effects of low estrogen levels. Endocrinology. 141(10): 3898-3907.

Bakker, J., Van Ophemert, J., y Slob, A.K. 1993. Hormonal regulation of adult partner preference behavior in neonatally ATD-treated male rats. Behavioral Neuroscience. 107: 480-487.

Beach, F. A., y Jordan, L. 1956. Sexual Exhaustion and Recovery in the Male Rat. Quarterly Journal of Experimental Psychology, 8(3), 121-133.

Beach, F. A. 1967. Cerebral and hormonal control of reflexive mechanisms involved in copulatory behavior. Physiological Reviews, 47(2), 289-316.

Beach, F. A. 1976. Sexual attractivity, proceptivity, and receptivity in female mammals. Hormones and Behavior, 7(1), 105-138. 
Bennett, N. E. 2013. Functional anatomy of the hypothalamic-pituitary-gonadal axis and the male reproductive tract. En J. P. Mulhall, L. D. Applegarth, R. D. Oates, y P. N. Schlegel (Eds.), Fertility Preservation in Male Cancer Patients (pp. 1-10).

Bennetau-Pelissero, C. 2016. Risks and benefits of phytoestrogens: where are we now? Current Opinion in Clinical Nutrition and Metabolic Care. 19(6): 477-483.

Berensztein, E. B., Sciara, M. I., Rivarola, M. A., y Belgorosky, A. 2002. Apoptosis and Proliferation of Human Testicular Somatic and Germ Cells during Prepuberty: High Rate of Testicular Growth in Newborns Mediated by Decreased Apoptosis. The Journal of Clinical Endocrinology y Metabolism. 87(11): 5113-5118.

Bernbaum, J. C., Umbach, D. M., Ragan, N. B., Ballard, J. L., Archer, J. I., SchmidtDavis, H., y Rogan, W. J. 2007. Pilot Studies of Estrogen-Related Physical Findings in Infants. Environmental Health Perspectives, 116(3), 416-420.

Beyer, C. Contreras, J. Moralí, G., y Larsson, K. 1981. Effects of castration and sex steroid treatment on the motor copulatory pattern of the rat. Physiology y behavior. 27(4): 727-730.

Birch, M. C. 1977. Mammalian Odours and Pheromones. The Institute of Biology's Studies in Biology No. 73. D. Michael Stoddart. The Quarterly Review of Biology, 52(4), 455-456

Blanchard, R. J., y Caroline Blanchard, D. 1977. Aggressive behavior in the rat. Behavioral Biology, 21(2), 197-224.

Brooks, D. E. 1983. Epididymal functions and their hormonal regulation. Australian journal of biological sciences, 36(3), 205-222.

Cao, Y., Calafat, A. M., Doerge, D. R., Umbach, D. M., Bernbaum, J. C., Twaddle, N. C., y Rogan, W. J. 2009. Isoflavones in urine, saliva, and blood of infants: Data from a 
pilot study on the estrogenic activity of soy formula. Journal of Exposure Science \& Environmental Epidemiology, 19(2), 223-234.

Cardoso, J., y Báo, S. 2009. Morphology of Reproductive Organs, Semen Quality and Sexual Behaviour of the Male Rabbit Exposed to a Soy-containing Diet and Soyderived Isoflavones during Gestation and Lactation: Effects of Perinatal Exposure to Isoflavones. Reproduction in Domestic Animals, 44(6), 937-942.

Carrasco, M. Á., y González, M. J. 2006. Aspectos conceptuales de la agresión: Definición y modelos explicativos [Theoretical issues on aggression: concept and models]. Acción Psicológica, 4(2), 7-38.

Carreau, S. Bois, C. Zanatta L, Silva, F. Bouraima-Lelong, H. y Delalande, C. Estrogen signaling in testicular cells. 2011. Life Science. 89: 584-7.

Cederroth, Christopher R., Zimmermann, C., Beny, J.-L., Schaad, O., Combepine, C., y Descombes, P. 2010. Potential detrimental effects of a phytoestrogen-rich diet on male fertility in mice. Molecular and Cellular Endocrinology, 321(2), 152-160.

Cederroth, C. Zimmermann, C. y Nef, S. 2012. Soy, phytoestrogens and their impact on reproductive health. Molecular and Cellular Endocrinology. 355:192- 200.

Chan, J. S. W., Waldinger, M. D., Olivier, B., y Oosting, Ronald. S. 2010. Drug-Induced Sexual Dysfunction in Rats. En J. N. Crawley, C. R. Gerfen, M. A. Rogawski, D. R. Sibley, P. Skolnick, y S. Wray (Eds.), Current Protocols in Neuroscience ( $p$. ns0934s53).

Chandrareddy, A., Muneyyirci-Delale, O., McFarlane, S. I., y Murad, O. M. 2008. Adverse effects of phytoestrogens on reproductive health: A report of three cases. Complementary Therapies in Clinical Practice, 14(2), 132-135.

Chang, Y., Nair, M. y Nitiss, J. 1995. Metabolites of daidzein and genistein and their biological activities. Journal of natural products. 58(12), 1901-1905. 
Chen, A., y Rogan, W. J. 2004. Isoflavones in soy infant formula: a review of evidence for endocrine and other activity in infants. Annu Rev Nutr. 24:33-54.

Chen, M., Lin, C., y Liu, C. 2015. Efficacy of phytoestrogens for menopausal symptoms: a meta-analysis and systematic review. Climacteric. 18(2): 260-269.

Cherian, S., Wai Lam, Y., McDaniels, I., Struziak, M., y Delay, R. J. 2014. Estradiol rapidly modulates odor responses in mouse vomeronasal sensory neurons. Neuroscience, 269, 43-58.

Csaba, G., y Karabélyos, Cs. 2002. Effect of single neonatal treatment with the soy bean phytosteroid, genistein on the sexual behavior of adult rats. Acta Physiologica Hungarica, 89(4), 463-470.

Delclos, K. B., Bucci, T. J., Lomax, L. G., Latendresse, J. R., Warbritton, A., Weis, C. C., y Newbold, R. R. 2001. Effects of dietary genistein exposure during development on male and female CD (Sprague-Dawley) rats. Reproductive Toxicology (Elmsford, N.Y.), 15(6), 647-663.

Díaz V., Morales A., Quiroga C., Monti-Bloch L., Jennings-White C., y Berliner D. 1998. Feromonas en el humano: redescubriendo el sexto sentido. En Velázquez. Moctezuma J. (ed). Biología de la Reproducción UAM México pp 441-457.

D’Eon, T. M., Souza, S. C., Aronovitz, M., Obin, M. S., Fried, S. K., y Greenberg, A. S. 2005. Estrogen Regulation of Adiposity and Fuel Partitioning: EVIDENCE OF GENOMIC AND NON-GENOMIC REGULATION OF LIPOGENIC AND OXIDATIVE PATHWAYS. Journal of Biological Chemistry, 280(43), 35983-35991

Dixon, R. y Ferreira, D. 2002. Genistein. Phytochemistry. 60(3): 205-211. 
Döhler, K. D., Coquelin, A., Davis, F., Hines, M., Shryne, J. E., y Gorski, R. A. 1984. Pre- and postnatal influence of testosterone propionate and diethylstilbestrol on differentiation of the sexually dimorphic nucleus of the preoptic area in male and female rats. Brain Research, 302(2), 291-295.

Dolinoy, D. C., Weidman, J. R., Waterland, R. A., y Jirtle, R. L. 2006. Maternal Genistein Alters Coat Color and Protects $A$ vy Mouse Offspring from Obesity by Modifying the Fetal Epigenome. Environmental Health Perspectives, 114(4), 567-572.

Eustache, F., Mondon, F., Canivenc-Lavier, M. C., Lesaffre, C., Fulla, Y., Berges, R., y Auger, J. 2009. Chronic Dietary Exposure to a Low-Dose Mixture of Genistein and Vinclozolin Modifies the Reproductive Axis, Testis Transcriptome, and Fertility. Environmental Health Perspectives, 117(8), 1272-1279.

Ferreira Nuño, A., Fernández Soto, C., Olayo Lortia, J., Ramirez Carreto, R., Paredes, R. G., Velázquez Moctezuma, J., y Morales Otal, A. (2010). Copulatory pattern of male rats in a multiple partner choice arena. J Sex Med (12), 3845-3856.

Ferris, C. F., y Grisso, T. (Eds.). 1996. Understanding aggressive behavior in children. New York, N.Y: New York Academy of Sciences.

Fielden, M., Samy, S. Chou, K., y Zacharewski, T. 2003. Effect of human dietary exposure levels of genistein during gestation and lactation on long-term reproductive development and sperm quality in mice. Food and chemical toxicology. 41(4): 447454.

Fonseca, N., Villar, M., Donangelo, C., y Perrone, D. 2014. Isoflavones and soyasaponins in soy infant formulas in Brazil: Profile and estimated consumption. Food Chemistry. 143: 492-498. 
Fritz, W. A., Cotroneo, M. S., Wang, J., Eltoum, I.-E., \& Lamartiniere, C. A. (2003). Dietary diethylstilbestrol but not genistein adversely affects rat testicular development. The Journal of Nutrition, 133(7), 2287-2293.

Garreau, B., Vallette, G., Adlercreutz, H., Wähälä, K., Mäkelä, T., Benassayag, C., y Nunez, E. A. 1991. Phytoestrogens: New ligands for rat and human a-fetoprotein. Biochimica et Biophysica Acta (BBA) - Molecular Cell Research, 1094(3), 339-345.

Gimeno, I. 2014. Morfología espermática y parámetros seminales básicos en varones normo y oligoastenoteratozoospérmicos. 53.

Glover, A. 2006. Acute exposure of adult male rats to dietary phytoestrogens reduces fecundity and alters epididymal steroid hormone receptor expression. Journal of Endocrinology, 189(3), 565-573.

Golombok, S., y Rust, J. 1993. The Measurement of Gender Role Behaviour in PreSchool Children: A Research Note. Journal of Child Psychology and Psychiatry, 34(5), 805-811.

Gutiérrez, H. H., Onofre, M. V., Rosado-García, A., y Torres, A. M. R. 2005. Diferenciación sexual en el sistema nervioso central Sexual differentiation in the central nervous system. 22.

Henry, L. A., y Witt, D. M. 2006. Effects of Neonatal Resveratrol Exposure on Adult Male and Female Reproductive Physiology and Behavior. Developmental Neuroscience, 28(3), 186-195.

Hess, R. A. 1990. Quantitative and qualitative characteristics of the stages and transitions in the cycle of the rat seminiferous epithelium: light microscopic observations of perfusion fixed and plastic-embedded testes. Biol Reprod. 43 (3):525-42. 
Hilakivi-Clarke, L., Andrade, J. E., y Helferich, W. 2010. Is Soy Consumption Good or Bad for the Breast? The Journal of Nutrition, 140(12), 2326S-2334S.

Hlinák, Z. 1990. Precopulatory behaviour of male rats: Developmental aspects and dependence on female's solicitation. Activitas Nervosa Superior, 32(4), 264-282.

Hines, M., Allen, L. S., y Gorski, R. A. 1992. Sex differences in subregions of the medial nucleus of the amygdala and the bed nucleus of the stria terminalis of the rat. Brain Research, 579(2), 321-326.

Hofman, M. A., y Swaab, D. F. 1986. The sexually dimorphic nucleus of the preoptic area in the human brain: a comparative morphometric study. J. Anat. 164: 55-72.

Hou, J. W., Chen, D., y Jeyendran, R. S. 1995. Sperm nuclear maturity in spinal cordinjured men: Evaluation by acidic aniline blue stain. Archives of Physical Medicine and Rehabilitation, 76(5), 444-445.

Hsieh, C. J., Hsu, Y. L., Huang, Y. F., y Tsai, E. M. 2018. Molecular Mechanisms of Anticancer Effects of Phytoestrogens in Breast Cancer. Current Protein y Peptide Science.19(3): 323-332.

Hull, E. y Dominguez, J. 2007. Sexual behavior in male rodents. Hormones and Behavior. 52(1): 45-55.

Hull, E. M., y Rodríguez-Manzo, G. (2017). Male Sexual Behavior. En Hormones, Brain and Behavior (pp. 1-57). Elsevier. https://doi.org/10.1016/B978-0-12-803592-4.000018

Hutson, J. M. 2012. Embryology of the Human Genital Tract. En J. M. Hutson, G. L. Warne, y S. R. Grover (Eds.), Disorders of Sex Development (pp. 11-21). Berlin, Heidelberg: Springer Berlin Heidelberg. 
Hutson, J. M., Li, R., Southwell, B. R., Petersen, B. L., Thorup, J., y Cortes, D. 2013. Germ cell development in the postnatal testis: the key to prevent malignancy in cryptorchidism? Frontiers in Endocrinology, 3: 11.

Jefferson, N., y Williams, C. J. 2011. Circulating levels of genistein in the neonate, apart from dose and route, predict future adverse female reproductive outcomes. Reproductive Toxicology. 31(3): 272-279.

Jefferson, W. N., Patisaul, H. B., y Williams, C. J. 2012. Reproductive consequences of developmental phytoestrogen exposure. Reproduction. 143(3): 247-260.

Jones, R. B., y Nowell, N. W. 1974. The urinary aversive pheromone of mice: Species, strain and grouping effects. Animal Behaviour, 22(1), 187-191.

Jones, B. A., Shimell, J. J., y Watson, N. V. 2011. Pre- and postnatal bisphenol A treatment results in persistent deficits in the sexual behavior of male rats, but not female rats, in adulthood. Hormones and Behavior, 59(2), 246-251

Keverne, E. B. 2002. Mammalian Pheromones: From Genes to Behaviour. Current Biology, 12(23), R807-R809.

Kondo, Y., Sachs, B. D., y Sakuma, Y. 1997. Importance of the medial amygdala in rat penile erection evoked by remote stimuli from estrous females. Behavioural Brain Research, 88(2), 153-160.

Kouki, T. Okamoto, M. Wada, S. Kishitake, M. y Yamanouchi, K. 2005. Suppressive effect of neonatal treatment with a phytoestrogen, coumestrol, on lordosis and estrous cycle in female rats. Brain Res Bull. 64:449-454.

Krazeisen, A., Breitling, R., Möller, G., y Adamski, J. 2001. Phytoestrogens inhibit human 17ß-hydroxysteroid dehydrogenase type 5. Molecular and Cellular Endocrinology, 171(1-2), 151-162 
Kruger, T. F., Menkveld, R., Stander, F. S. H., Lombard, C. J., Van der Merwe, J. P., van Zyl, J. A., y Smith, K. 1986. Sperm morphologic features as a prognostic factor in in vitro fertilization. Fertility and Sterility. 46(6): 1118-1123.

Kumi-Diaka, J., Rodriguez, R., y Goudaze, G. 1998. Influence of genistein (4', 5, 7trihydroxyisoflavone) on the growth and proliferation of testicular cell lines. Biology of the Cell. 90(4): 349-354.

Kuiper, G. G. J. M., Carlsson, B., Grandien, K., Enmark, E., Häggblad, J., Nilsson, S., y Gustafsson, J.-Å. 1997. Comparison of the Ligand Binding Specificity and Transcript Tissue Distribution of Estrogen Receptors $\alpha$ and $\beta$. Endocrinology, 138(3), 863-870.

Kuiper, G.G., Lemmen, J.G., Carlsson, B., Corton, J.C., Safe, S.H., van der Saag, P.T., van der Burg, B., y Gustafsson, J.A. 1998. Interaction of estrogenic chemicals and phytoestrogens with estrogen receptor beta. Endocrinology.139, 4252-4263.

Kurzer, M. S., y Xu, X. 19979. Dietary phytoestrogens. Annu Rev Nutr. 17:353-81.

Kruk, M. R. 1991. Ethology and pharmacology of hypothalamic aggression in the rat. Neuroscience \& Biobehavioral Reviews, 15(4), 527-538

Lapcıḱ, O., Hill, M., Hampl, R., Wähälä, K., y Adlercreutz, H. 1998. Identification of isoflavonoids in beer. Steroids. 63(1): 14-20.

Lebas, F., Coudert, P., Rouvier., R, y de Rochambeau H. 1986. The rabbit husbandry, health and production. FAO Animal Production and Health Series No. 21.

León-Galván, M. A., Fonseca, T., López-Wilchis, R., y Rosado. A. 1999. Prolonged storage of spermatozoa in the genital tract of female Mexican big-eared bats (Corynorhinus mexicanus): the role of lipid peroxidation. Canadian Journal of Zoology. 77: 7-12. 
Liggins, J., Bluck, L., Runswick, S., Atkinson, C., Coward, W., y Bingham, S. 2000. Daidzein and genistein contents of vegetables. British Journal of Nutrition. 84(5): 717725.

Mann, D. R. y Fraser, H. M. 1996. The neonatal period: a critical interval in male primate development. Journal of Endocrinology. 149(2): 191-197.

Martin, M. E., Haourigui, M., Pelissero, C., Benassayag, C., y Nunez, E. A. 1995. Interactions between phytoestrogens and human sex steroid binding protein. Life Sciences, 58(5), 429-436.

McCarthy, M. M., de Vries, G. J., y Forger, N. G. 2009. Sexual Differentiation of the Brain: Mode, Mechanisms, and Meaning. En Hormones, Brain and Behavior (pp. 17071746).

McCarver, G., Bhatia, J., Chambers, C., Clarke, R., Etzel, R., Foster, W., y Turner, K. 2011. NTP-CERHR expert panel report on the developmental toxicity of soy infant formula. Birth Defects Research Part B: Developmental and Reproductive Toxicology. 92(5): 421-468.

McEwen, B. S., Lieberburg, I., Chaptal, C., y Krey, L. C. 1977. Aromatization: Important for sexual differentiation of the neonatal rat brain. Hormones and Behavior, 9(3), 249263.

Miller, L.D.P., y Aoki, A. 1991. Stereological analysis of the hypothalamic ventromedial nucleus. II. Hormone-induced changes in the synaptogenic pattern. Devl. Brain Res. 61: 189-196.

Mira, J. 2014. Estudio de la anatomía del epidídimo, del gubernáculo del proceso vaginal en las criptorquidias y hernias inguinales del niño (Tesis doctoral). Universidad Miguel Hernández. Elche, España. 
Morales-Otal, A., Ferreira-Nuño, A., Olayo-Lortia, J., Barrios-González, J., y TarragóCastellanos, R. 2016. Effects of neonatal treatment with two phytoestrogens on male rat sexual behavior and partner preference. Behav Pharmacol. (7): 570-578.

Mostrom, M., y Evans, T. 2011. Chapter 52 - Phytoestrogens A2 - Gupta, Ramesh C. En Reproductive and Developmental Toxicology (pp. 707-722). San Diego: Academic Press.

Moutsatsou, P. 2007. The spectrum of phytoestrogens in nature: our knowledge is expanding. Hormones-athens. 6(3): 173-193.

Munro, I. C., Harwood, M., Hlywka, J. J., Stephen, A. M., Doull, J., Flamm, W. G., y Adlercreutz, H. 2003. Soy Isoflavones: A Safety Review. Nutrition Reviews, 61(1), 133.

Nagao, T., Yoshimura, S., Saito, Y., Nakagomi, M., Usumi, K., y Ono, H. 2001. Reproductive effects in male and female rats of neonatal exposure to genistein. Reproductive Toxicology, 15(4), 399-411.

Nakajima, S., Saijo, Y., Kato, S., Sasaki, S., Uno, A., Kanagami, N., y Kishi, R. 2006. Effects of Prenatal Exposure to Polychlorinated Biphenyls and Dioxins on Mental and Motor Development in Japanese Children at 6 Months of Age. Environmental Health Perspectives, 114(5), 773-778.

Napier, I. D., Simon, L., Perry, D., Cooke, P. S., Stocco, D. M., Sepehr, E., y Akingbemi, B. T. 2014. Testicular Development in Male Rats Is Sensitive to a Soy-Based Diet in the Neonatal Period1. Biology of Reproduction, 90(2).

Nef, S., y Parada, L. F. 2000. Hormones in male sexual development. Genes y Development. 14(24): 3075-3086. 
Nelson, R. J., y Chiavegatto, S. 2001. Molecular basis of aggression. Trends in Neurosciences, 24(12), 713-719.

Nie, Q., Xing, M., Hu, J., Hu, X., Nie, S., y Xie, M. 2017. Metabolism and health effects of phyto-estrogens. Critical Reviews in Food Science and Nutrition. 57(11): 2432-2454.

Norma Oficial Mexicana NOM-062- ZOO-1999. Diario Oficial de la Federación, 22 de agosto de 2001. Consultado el día 11 de noviembre de 2017. Disponible en: http://www.fmvz.unam.mx/fmvz/principal/archivos/062ZOO.PDF

Olivier, B., Chan, J. S., Pattij, T., de Jong, T. R., Oosting, R. S., Veening, J. G., y Waldinger, M. D. 2006. Psychopharmacology of male rat sexual behavior: modeling human sexual dysfunctions? Int J Impot Res (Suppl 1), S14- 23.

Opalka, M., Kaminska, B., Piskula, M., Puchajda-Skowronska, H., y Dusza, L. 2006. Effects of Phytoestrogens on Testosterone Secretion by Leydig Cells from Bilgoraj Ganders (Anser anser). Birtish Poultry Science. 47(2): 237-245.

Ortega López, L., Vila, E. O., Domínguez, P. L., Segovia, A. G., Gómez, I. O., Calonge, R. N., y Peregrín, P. C. 2010. Comparación entre el test de fragmentación de ADN espermático mediante la técnica de SCD y el índice de vitalidad medida con el test de naranja de acridina. Revista Internacional de Andrología. 8(3): 114-121.

Osterlund, M., Gustafsson, J., Keller, E., y Hurd, Y. 2000. Estrogen receptor beta (ER beta) messenger ribonucleic acid (mRNA) expression within the human forebrain: distinct distribution pattern to ER alpha mRNA. J Clin Endocr Metab. 85(10): 38403846 .

Patisaul, H. B. y Jefferson, W. 2010. The pros and cons of phytoestrogens. Frontiers in Neuroendocrinology. 31(4): 400-419. 
Perabo, F., Von Löw, E., Ellinger, J., Von Rücker, A., Müller, S., y Bastian, P. 2008. Soy isoflavone genistein in prevention and treatment of prostate cancer. Prostate cancer and prostatic diseases. 11(1): 6 .

Picut, C. A., Remick, A. K., de Rijk, E. P. C. T., Simons, M. L., Stump, D. G., y Parker, G. A. 2015. Postnatal Development of the Testis in the Rat: Morphologic Study and Correlation of Morphology to Neuroendocrine Parameters. Toxicologic Pathology, 43(3), 326-342.

Rao, P. K., y Burnett, A. L. 2013. Development of the Male Reproductive System. En P. K. Kavoussi, R. A. Costabile, y A. Salonia (Eds.), Clinical Urologic Endocrinology (pp. 11-24). London: Springer London.

Rennie, S. M., Moita, M. M., y Mainen, Z. F. 2013. Social cognition in the rodent: Nothing to be sniffed at. Trends in Cognitive Sciences, 17(7), 306-307.

Richmond, G., y Sachs, B. D. 1984. Maternal discrimination of pup sex in rats. Developmental Psychobiology, 17(1), 87-89. https://doi.org/10.1002/dev.420170108

Riyazi, S. R., Nezhad, Y. E., Fathi, H., y Davoudi, J. 2011. Chemical properties, health benefits and threats of soy isoflavones. 14 .

Rissman, E. F., Early, A. H., Taylor, J. A., Korach, K. S., y Lubahn, D. B. 1997. Estrogen Receptors Are Essential for Female Sexual Receptivity. Endocrinology, 138(1), 507510.

River, C. s.f. NMRI Mice. Consultado el día 26 de diciembre en 2019. Disponible en: http://mtweb.cs.ucl.ac.uk/mus/mus/binnaz/OUTBREDS/Useful-info-TOREAD/NMRI\%20version\%20Gb\%200607.pdf 
Rodriguez-Gomez, A., Filice, F., Gotti, S., y Panzica, G. 2014. Perinatal exposure to genistein affects the normal development of anxiety and aggressive behaviors and nitric oxide system in CD1 male mice. Physiology \& Behavior, 133, 107-114.

Rodríguez-Manzo, G. y Canseco-Alba, A. 2015. Anandamide Reduces the Ejaculatory Threshold of Sexually Sluggish Male Rats: Possible Relevance for Human Lifelong Delayed Ejaculation Disorder. J Sex Med, 12:1128-1135.

Ropero, A. B., Alonso-Magdalena, P., Ripoll, C., Fuentes, E., Nadal, A., 2006. Rapid endocrine disruption: environmental estrogen actions triggered outside the nucleus. $J$. Steroid Biochem. Mol. Biol. 102, 163-169.

Schoenwolf, G. C. 2009. Larsen's human embryology. Philadelphia: Churchill Livingstone/Elsevier.

Segovia, S., y Guillamón, A. 1993. Sexual dimorphism in the vomeronasal pathway and sex differences in reproductive behaviors. Brain Research Reviews, 18(1), 51-74.

Sellami, A., Chakroun, N., Ben Zarrouk, S., Sellami, H., Kebaili, S., Rebai, T., y Keskes, L. 2013. Assessment of Chromatin Maturity in Human Spermatozoa: Useful Aniline Blue Assay for Routine Diagnosis of Male Infertility. Advances in Urology. 1-8.

Setchell, K. D., Zimmer-Nechemias, L., Cai, J., y James, H. 1997. Exposure of infants to phyto-oestrogens from soy-based infant formula. Lancet. 350: 23-27.

Setchell, K. D., Zimmer-Nechemias, L., Cai, J., y James, H. 1998. Isoflavone content of infant formulas and the metabolic fate of these phytoestrogens in early life. The American Journal of Clinical Nutrition. 68: 1453-1461.

Sharma, R., y Agarwal, A. 2011. Spermatogenesis: An Overview. En A. Zini y A. Agarwal (Eds.), Sperm Chromatin (pp. 19-44). New York, NY: Springer New York. 
Sherrill, J. D., Sparks, M., Dennis, J., Mansour, M., Kemppainen, B., Bartol, F., y Akingbemi, B. 2010. Developmental Exposures of Male Rats to Soy Isoflavones Impact Leydig Cell Differentiation1. Biology of Reproduction. 83(3): 488-501.

Shibayama, T., Fukata, H., Sakurai, K., Adachi, T., Komiyama, M., Iguchi, T., y Mori, C. 2001. Neonatal exposure to genistein reduces expression of estrogen receptor alpha and androgen receptor in testes of adult mice. Endocrine journal. 48(6): 655- 663.

Siegel, A., Roeling, T. A., Gregg, T. R., y Kruk, M. R. 1999. Neuropharmacology of brain-stimulation-evoked aggression. Neuroscience and Biobehavioral Reviews, 23(3), 359-389.

Simerly, R. B., y Swanson, L. W. 1986. The organization of neural inputs to the medial preoptic nucleus of the rat. The Journal of Comparative Neurology, 246(3), 312-342.

Simerly, R. B., y Swanson, L. W. 1988. Projections of the medial preoptic nucleus: APhaseolus vulgaris leucoagglutinin anterograde tract-tracing study in the rat. The Journal of Comparative Neurology, 270(2), 209-242.

Simerly, R. B., Swanson, L. W., Chang, C., y Muramatsu, M. 1990. Distribution of androgen and estrogen receptor mRNA-containing cells in the rat brain: An in situ hybridization study. The Journal of Comparative Neurology, 294(1), 76-95.

Sirotkin, A.V., 2014. Regulators of Ovarian Functions. Nova Science Publishers, Inc, New York, USA p. 194.

Snoeren, E. M. S., Veening, J. G., Olivier, B., y Oosting, R. S. 2014. Serotonin 1A receptors and sexual behavior in male rats: A review. Pharmacology Biochemistry and Behavior, 121, 102-114.

Stevens, A. y Lowe, J. S. 2007. Histología humana. Madrid: Elsevier. 
Strauss, L., Mäkelä, S., Joshi, S., Huhtaniemi, I., y Santti, R. 1998. Genistein exerts estrogen-like effects in male mouse reproductive tract. Molecular and cellular endocrinology. 144(1-2): 83-93.

Swaab, D.F. Fliers, E. y Partiman, T. 1985. The suprachiasmatic nucleus of the human brain in relation to sex, age and dementia. Brain Research. 342: 37-44.

Swan, S. H., Liu, F., Hines, M., Kruse, R. L., Wang, C., Redmon, J. B., y Weiss, B. 2010. Prenatal phthalate exposure and reduced masculine play in boys.

Takagi, H., Shibutani, M., Lee, K.-Y., Lee, H. C., Nishihara, M., Uneyama, C., y Hirose, M. 2004. Lack of modifying effects of genistein on disruption of the reproductive system by perinatal dietary exposure to ethinylestradiol in rats. Reproductive Toxicology, 18(5), 687-700.

Tejada, R. I., Mitchell, J. C., Norman, A., Marik, J. J., y Friedman, S. 1984. A test for the practical evaluation of male fertility by acridine orange (AO) fluorescence ${ }^{* *}$ Supported by grant LT-RT-6000 from the Tyler Research Foundation and in part by the US Department of Energy, Contract no. AT03-76EV-70118. Fertility and Sterility, 42(1), 87-91.

Tong, S., Hutson, J., y Watts, L., 1996. Does Testosterone Diffuse Down the Wolffian Duct During Sexual Differentiation? The Journal of Urology. 155(6): 2057- 2059.

Ramírez, V. 2006. Efecto de la administración neonatal de los fitoestrógenos genisteína y daidzeina solas y/o en combinación sobre la morfología testicular de la rata Wistar.

Vandenplas, Y., De Greef, E., Devreker, T., y Hauser, B. 2011. Soy infant formula: is it that bad?: Soy infant formula. Acta Paediatrica. 100(2) :162-166. 
Varghese, A. 2010. Chapter -01 Anatomy and Physiology of Male Gametogenesis. En A. Rao Kamini, A. Agarwal, y M. Srinivas, Andrology Laboratory Manual (pp. 1-9). Jaypee Brothers Medical Publishers (P) Ltd.

Viereck, V., Emons, G., y Wuttke, W. 2005. Black cohosh: Just another phytoestrogen? Trends in Endocrinology and Metabolism, 16(5), 214-221.

Wang, LQ., 2002. Mammalian phytoestrogens: enterodiol and enterolactone. J. Chromatogr. B Analyt. Technol. Biomed. Life Sci. 777, 289-309.

Weber, K. S., Jacobson, N. A., Setchell, K. D., y Lephart, E. D. 1999. Brain Aromatase and 5alpha-Reductase, Regulatory Behaviors and Testosterone Levels in Adult Rats on Phytoestrogen Diets. Proceedings of the Society for Experimental Biology and Medicine, 221(2), 131-135.

Weller, K. L., y Smith, D. A. 1982. Afferent connections to the bed nucleus of the stria terminalis. Brain Research, 232(2), 255-270.

West, M. C. L., Anderson, L., Mcclure, N., y Lewis, S. E. M. 2005. Dietary oestrogens and male fertility potential. Human Fertility, 8(3), 197-207.

Westmark, C. J. 2017. Soy-Based Therapeutic Baby Formulas: Testable Hypotheses Regarding the Pros and Cons. Frontiers in Nutrition. 3:23.

Whitten, P. L., Russell, E., y Naftolin, F. 1994. Influence of phytoestrogen diets on estradiol action in the rat uterus. Steroids, 59(7), 443-449.

Whitten, P. L., Russell, C. Lew. E., e Isaetolimi, F. 1995. Potential Adverse Effects of Phytoestrogens. The Journal of Nutrition, 1233 Suppl: 771S-776S 
Whitten, P., Lewis, C., Russell, E., y Naftolin, F. 1995. Phytoestrogen influences on the development of behavior and gonadotropin function. Proc Soc Exp Biol Med. 208(1):82-86

Whitten, P. Kudo, S. y Okubo, K. 1997. Isoflavonoids. In: D'Mello JPF, editor. Handbook of Plant and Fungal Toxicants. Boca Raton: CRC Press, 117-137.

Whitten, P. y Patisaul, H. 2001. Cross-Species and Interassay Comparisons of Phytoestrogen Action. Evironmental Health Perspectives. 109(1): 5-20.

Whitten, P. L, Patisaul, H. B., y Young, L. J. 2002. Neurobehavioral actions of coumestrol and related isoflavonoids in rodents. Neurotoxicology and Teratology, 24(1), 47-54.

Wisniewski, A. B., Klein, S. L., Lakshmanan, Y., y Gearhart, J. P. 2003. Exposure to Genistein During Gestation and Lactation Demasculinizes the Reproductive System in Rats. The Journal of Urology, 169(4), 1582-1586.

Wisniewski, A., Cernetich, A., Gearhart, J., y Klein, S. 2005. Perinatal exposure to genistein alters reproductive development and aggressive behavior in male mice. Physiology \& Behavior, 84(2), 327-334.

World Health Organization (Ed.). 2010. WHO laboratory manual for the examination and processing of human semen (5th ed). Geneva: World Health Organization.

Yoshida, S. 2006. The first round of mouse spermatogenesis is a distinctive program that lacks the self-renewing spermatogonia stage. Development. 133(8), 1495-1505.

Zhao, E. 2011. Phytoestrogen Biological Actions on Mammalian Reproductive System and Cancer Growth. Scientia Pharmaceutica, 79(1), 1-20. 
Zuloaga, D. G., Jordan, C. L., y Breedlove, S. M. (s. f.). Sexual Differentiation of the Brain. 6.

Zung, A., Reifen, R., Kerem, Z., y Zadik, Z. 2001. Phytoestrogens: The Pediatric Perspective: Journal of Pediatric Gastroenterology and Nutrition, 33(2), 112-118. 


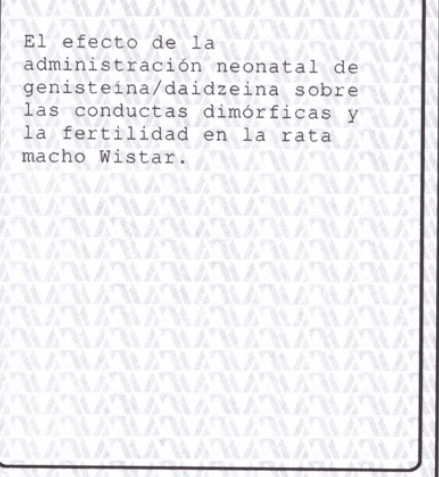

En la Ciudad de México, se presentaron a las 10:00 horas del día 24 del mes de enero del año 2020 en la Unidad Iztapalapa de la Universidad Autónoma Metropolitana, los suscritos miembros del jurado:

DR. PABLO GUSTAVO DAMIAN MATZUMURA DR. ARMANDO FERREIRA NUÑO

M. EN C. PEDRO CUAPIO PADILLA

PRA. REYNA CARMEN FIERRO PASTRANA

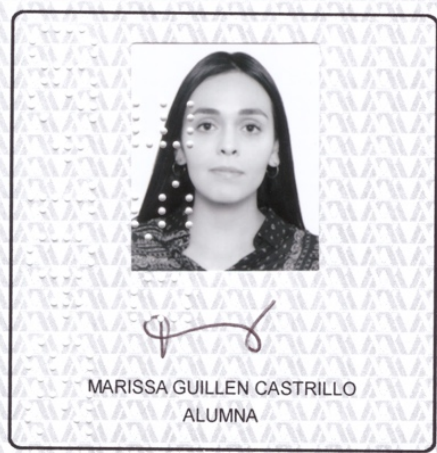

Bajo la Presidencia del primero y con carácter de Secretaria la última, se reunieron para proceder al Examen de Grado cuya denominacion aparece al proceder al Examen obtención del graction

MAESTRA EN BIOLOGIA DE LA REPRODUCCION ANIMAL

DE: MARISSA GUILLEN CASTRILLO

y de acuerdo con el articulo 78 fracción III del Reglamento de Estudios Superiores de la Universidad Autónoma Metropolitana, los miembros del jurado resolvieron:

\section{Aprobar}

Acto continuo, el presidente del jurado comunico a la interesada el resultado de la evaluacion $y$, en caso aprobatorio, le fue tomada la protesta.

MTRA ROSAIASERANO DE LAPAZ DIRECTORA DE SISTEMMS ESCOLARES

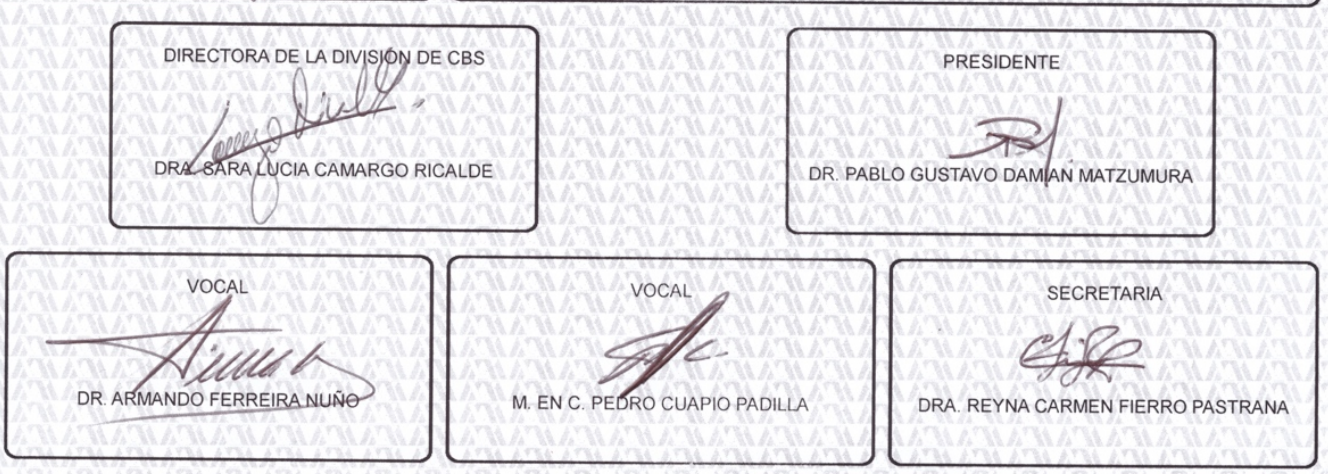

